\title{
The Second Promise
}

An Architect's Journey through the Shacklands of the North

\section{By}

\section{Joshua Armstrong}

A thesis submitted to the Faculty of Graduate and Postdoctoral Affairs in partial fulfillment of the requirements for the degree of

Master

in

Architecture

\section{Carleton University}

Ottawa, Ontario

(C) 2012

Joshua Armstrong 
Library and Archives

Canada

Published Heritage

Branch

395 Wellington Street

Ottawa ON K1A ON4

Canada
Bibliothèque et

Archives Canada

Direction du

Patrimoine de l'édition

395 , rue Wellington

Ottawa ON K1A ON4

Canada
Your file Votre référence

ISBN: 978-0-494-91511-0

Our file Notre référence

ISBN: 978-0-494-91511-0
NOTICE:

The author has granted a nonexclusive license allowing Library and Archives Canada to reproduce, publish, archive, preserve, conserve, communicate to the public by telecommunication or on the Internet, loan, distrbute and sell theses worldwide, for commercial or noncommercial purposes, in microform, paper, electronic and/or any other formats.

The author retains copyright ownership and moral rights in this thesis. Neither the thesis nor substantial extracts from it may be printed or otherwise reproduced without the author's permission.
AVIS:

L'auteur a accordé une licence non exclusive permettant à la Bibliothèque et Archives Canada de reproduire, publier, archiver, sauvegarder, conserver, transmettre au public par télécommunication ou par l'Internet, prêter, distribuer et vendre des thèses partout dans le monde, à des fins commerciales ou autres, sur support microforme, papier, électronique et/ou autres formats.

L'auteur conserve la propriété du droit d'auteur et des droits moraux qui protege cette thèse. $\mathrm{Ni}$ la thèse ni des extraits substantiels de celle-ci ne doivent être imprimés ou autrement reproduits sans son autorisation.
In compliance with the Canadian Privacy Act some supporting forms may have been removed from this thesis.

While these forms may be included in the document page count, their removal does not represent any loss of content from the thesis.
Conformément à la loi canadienne sur la protection de la vie privée, quelques formulaires secondaires ont été enlevés de cette thèse.

Bien que ces formulaires aient inclus dans la pagination, il n'y aura aucun contenu manquant. 
Blank pages were removed. This affects pagination but not content. 
$\begin{array}{lllllllll} & \mathbf{h} & \mathbf{e} & \boldsymbol{s} & \mathrm{e} & \mathbf{c} & \mathbf{o} & \mathbf{n} & \mathbf{d}\end{array}$

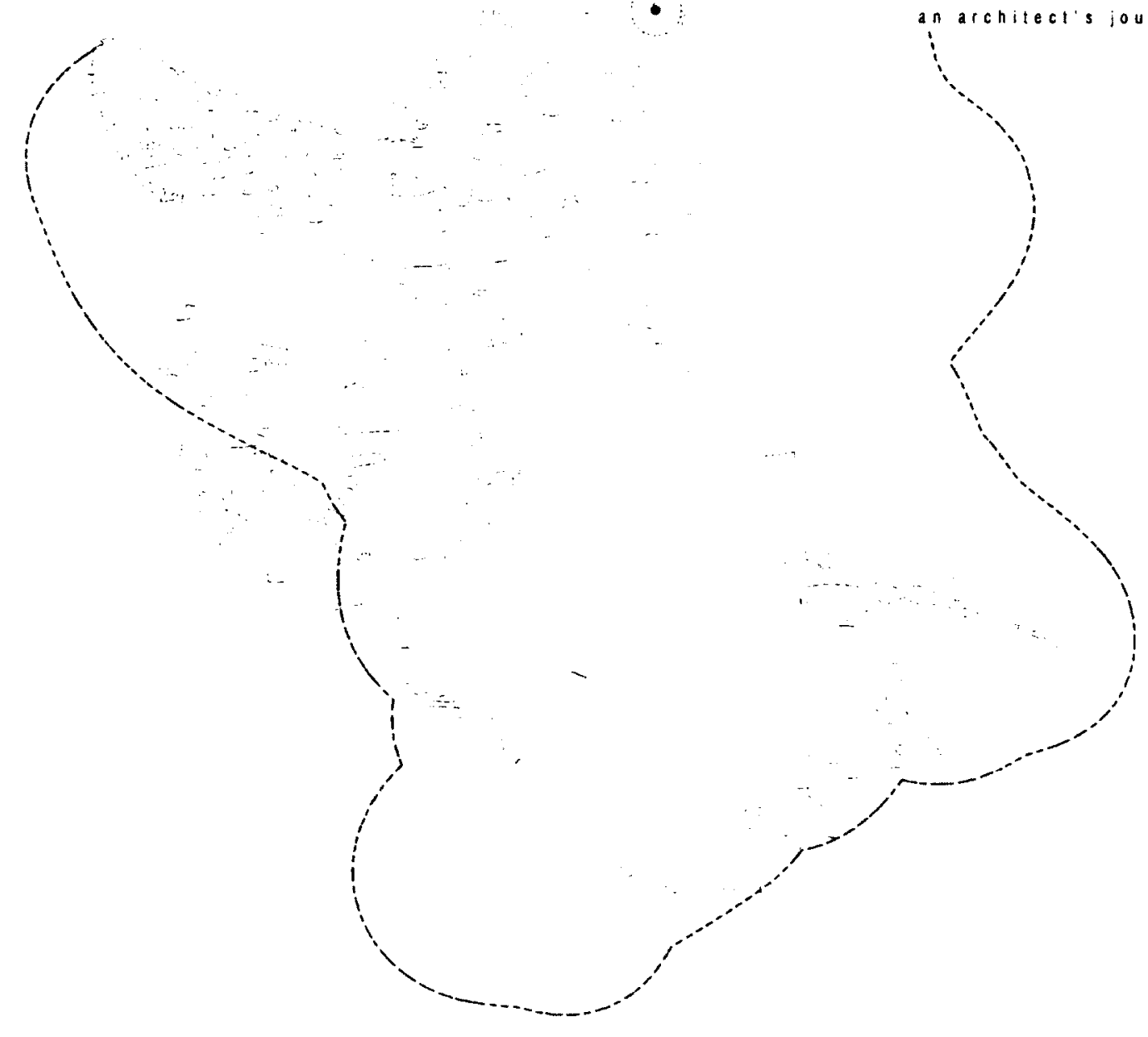

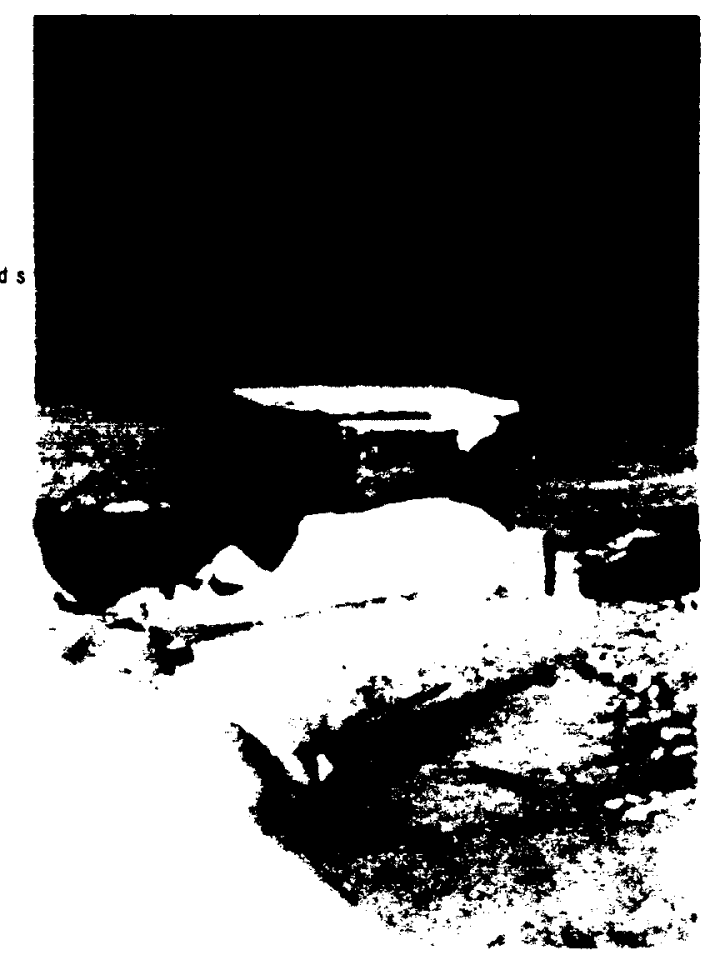




\section{abstract}

Architectural agency has been suggested as a means of extending practicability outside of the current boundaries of the profession, implying a capacity for operability within an informal milieu.

Anchored in Canada's Arctic through territories characterized by informal building practices, such agency is explored and rested against the empowerment of individual self-determination through the act of building.

In this investigation, these territories, which we will give the name Shacklands, provide a platform for reconsiderations of post-colonial space that are initiated by and focused on situated public concerns from the bottom-up, as referenced by the notion of the 'second promise'. Out of this we will attempt a new definition of a nascent urban north subject to an ongoing process of hybrid reversal. 
dedicated to

Wendy Margaret Ipirq Bens 


\section{contents}

foreword

a postcard from the saddest beach in the world

INTRODUCTION

1 chapter 1

architecture is not about shacks

LOGISTICS

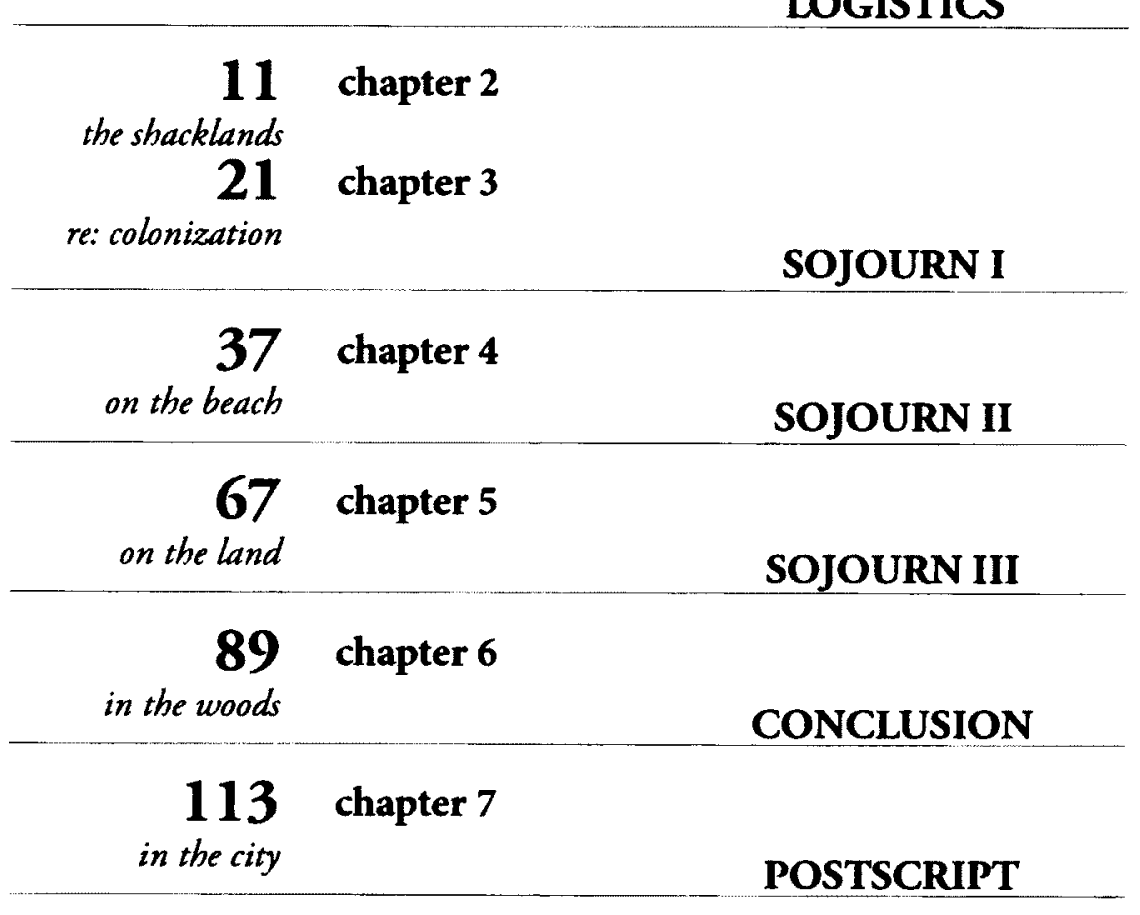

137 chapter 8

other detritus of the field

143 references

bibliography, plates, figures 
anaramio.com user rahn_matd is, like many travelers of this 'global' era, a sharer of journeys. He, or she, has eleven photos uploaded with ten indexed to Google Earth and two conversation-comments to date. The collection reads as a series of virtual postcards from a world tour perhaps; the Cathedral de Rouen, a boulevard in Bruxelles, the Chapelle at Innsbruck, seaside topographical villages in Vernazza and Riomaggiore, the elegant Pont D'Avignon, a sunset over the bridges of Firenze, the unspoilt majesty of the Vallee des Alpes. Last of the bunch, with ten times the number of views as the others, is an image simply labeled "the saddest beach in the world."

There is a slight post-apocalyptic sensibility to this dispatch from Canada's arctic; here seems to be a place that everyone left, perhaps to find those wonders of Western civilization from the rest of rahn_matd's collection. This is not the case.

Just beyond the cropping frame lies the shoreline facade of the capital city of the Nunavut Territory, Iqaluit, and a place that has been home to me for the better part of my lifetime. It is a remote and unforgiving place that is in the throes of reconciling a colonial heritage, an indigenous Inuit population, and global interest, all within an emergent urban spatial reality. This reconciliation has not been straightforward and there are many for whom the metaphor of the saddest beach in the world extends to Nunavut as a whole, given the 
current state of affairs. Indeed, there are deeply rooted systemic issues of social, economic, and cultural significance that plague the current generation of Nunavummiut; loss of language, homelessness, substance abuse, overt poverty, inadequate living environs, broken social bonds, dilution of culture, crime, increasing gulfs in class, reliance on welfare, and alarming suicide rates are felt by all. There is hope however. Nunavut, as a Land Claim Territory, provides Inuit with the capability to take on these issues through self-governance, but in merging an inherited Western model and an invented indigenous model much time will be required.

Many of these are not simply 'government issues', and nor should they be. They are issues for everyone to deal with at every level of society. As architects we might point to our buildings that promise and cost so much, to show our contribution. But architect designed buildings do nothing to directly address these issues, do they? Issues such as these have much more to do with building relationships, do they not?

An air of impermanence hangs over Iqaluit's urban character. It is not fenced in. Porosity has encouraged the traditional way-of-life of the Hunter, one intimately tied to the land, to develop with the city. Self-built and resisting authority, we might refer to such manifestations as 'Shacklands', but do how the informal buildings that exist on the beach and on the land redefine this urban centre? What might we find if we look to the past? And the future?

To approach these questions, we will survey some of the critical arguments that have come out of post-colonial discourse with regards to architecture, particularly those centered on notions of 'hybridity'. However, this thesis does not endeavor to engage in the deep 'linguisticbased' argument that post-colonialism provokes, since our main area of concern is the architect in the North. 
In this respect, it is worth mentioning two projects that have had great influence on this study, though they have not or only briefly been mentioned herein. Piqqusiliriviik, the Inuir Cultural Learning Facility in Clyde River, Nunavut, is a recently opened building that exists in a curious position, having been built by the government as a school that does not have a curriculum that is relevant to any other institution. It is contradictory; a truly hybrid building, program, and concept, that remains unresolved despite the building having been 'finished'. The St. Jude's Cathedral on the other hand is a key project in Iqaluit that speaks to a different kind of hybridity; its igloo form is both a direct literal reference to an overwritten Inuit past and ironically to a previous modernist model that burned down. These projects both look backwards to build forwards but do so in completely different ways, referencing different ideas about living in

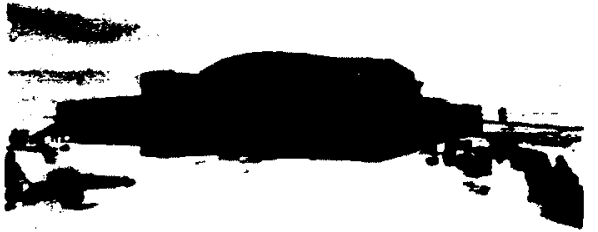

Inuit Cultural Learning Facility

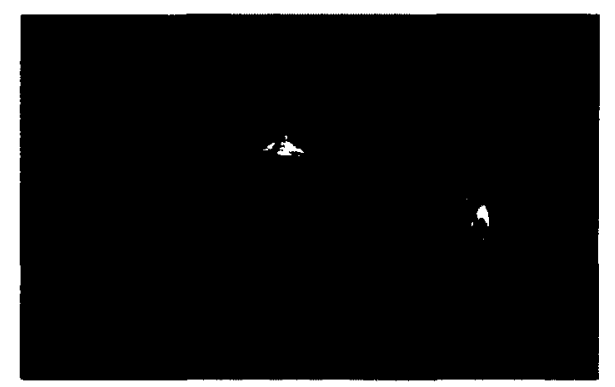

St. Jude's Cathedral the North that involve cultural translation.

When we look at the beach, and the buildings that are there, what references might we find? What translations might occur without the influence of an architect? As the example of rabn_matd so poignantly illustrates, the beach is not a 'tourist friendly' global landmark. Rather, many Iqaluimmiut view the beach as 'urban junkspace' to the extent that the Municipal authorities have been pressed into cleaning up 'the saddest beach in the world'. Do architects have any role in such a scenario? The Shacklands are not what one would typically call the architect's domain, but they represent spaces of potential in which to explore expanded notions of operability.

Shall we go outside and explore them? 


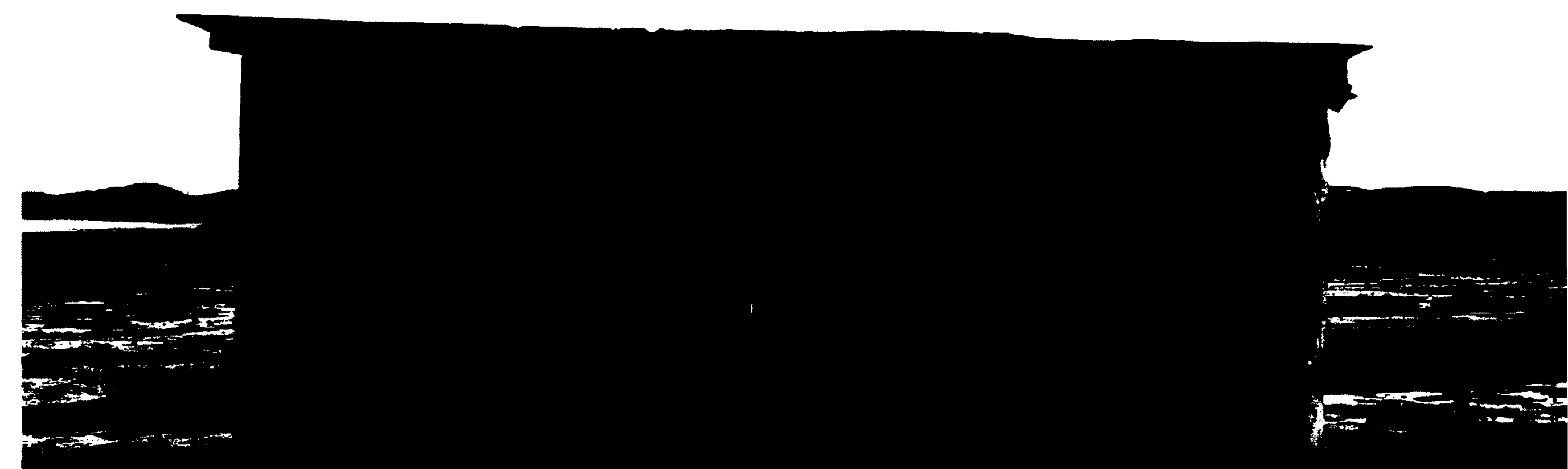




\section{CHAPTER 1}

The architect's role is under scrutiny. How so?

The Shacklands confront everyone involved with the process of planning and
place-making in Iqaluit. Formal procedures, those that do apply, have thus far
proved to be either ineffectual or inactive. Perhaps 'the powers that be' sense the weight in their hands. With a history so littered with social and spatial imposition as to be overtly 'post-colonial', have the authorities not interfered enough already in the business of the Inuit? Or perhaps this hesitancy is the unfounded "fear to act" that Mayor Madeleine Redfern believes it might be. ${ }^{1}$

Having found respite between these conditions of interference and neglect, the Shacklands speak to an indigenous informality of place. In a micro-urban centre that has squeezed its core for equitable land, this informality is read as under-planned, under-developed, and under-managed. Whether by design or its lack, this non-development of key urban growth areas serves as a tonic for the capitalist endeavor that has become entrenched in Western culture over the past century. Such gaps in the city fabric have the potential to be nurtured over the long term; they provide sires for the imagination of a culturally

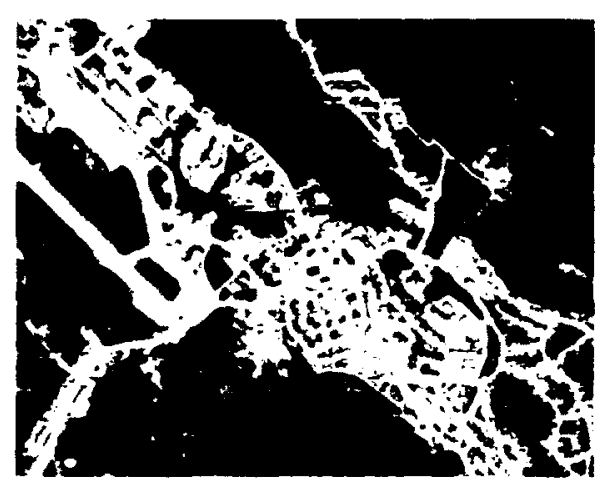

'Undeveloped' Inuit Owned Lands in Iqaluit considered built future. 
These gaps are not empty however. Some are native, some are barren but with history, and some have been appropriated but remain invisible. On the beach the refuse is gathering, the respect is waning, and the shacks are burning. On the land the traffic is increasing, the rights of ownership are tested, and the structures grow in number and temerity. ${ }^{2}$ The authorities can no longer afford to turn a blind eye. How can architects?

Why should architects care about what happens to some run-down shacks on a cold beach? What is at stake for us?

Certainly - conventionally - these shanties fall out of the architect's scope of interest and professional responsibility. Perhaps at some point in this region there will be a client who needs a building (something permanent), a brief will be written, and then architects can compete for a chance to take on a real architectural project. Is this where our responsibility lies, in formalizing a safe, efficient, and aesthetically pleasing building that meets the client's statements of area, program, budget, and schedule? If everything turns out well and the architect proves able to force through a contextual image that reflects well on the firm or practice, it could become a portfolio piece and a marketing move for the next job. Building anything in the complex and dynamic world that we live in is difficult and simply meeting technical requirements while earning a profit is an achievement unto itself; pragmatism is enough.

Where does this leave a Shackland-interested architect?

This variety of laissez-faire rhetoric is universal for much of the practice of architecture today and has proven to be the global capitalist methodology required to build the world
City of Iqaluit "Recreational Structures on Municipal Lands" Draft Meeting Minutes 2 Aug 2011.

\section{pragmatism is enough}

This reflection is drawn from my own experience working as an architectural designer in an office in Iqaluit. Scarcity, remoteness, and a largely public sector cliente ensured that this region is highly contigent on 'business first' principles. 
brand-making Anna Klingmann explores these collusions between architecture and capitalist systems in her book Brandscapes: Architecture in the Experience Economy.

current dominant practice This is a generalization and is not meant to disclude modernis and post-modernist architectura production which are very clearly still relevant and ongoing today.

Architecture is not about shacks. Under these conditions it can never be!

Architects, historically, have had little to do with the "low road" buildings, to quote

in which we live. One needs only to witness Vancouver's condominium boom and her Asian sisters. Blobs, parametrics, and diagram- icons, while less than pragmatic in their often gymnastic pursuit, appear to be neutered by complicity with brand-making in the guise of place-making (consider Bilbao Guggenheim, Beijing and London's new projects).

Current dominant practices, overtly anti-theoretical even post-critical in agenda, are often businesses-based models primarily concerned with the production of objects and contracts entrenched in an endless cycle of formalization.
"The Low Road" How Building Learn BBC London Jul 1997.

Indira McEwan's Vitruvius: Writing the Body of Architecture (Cambridge, Mass.: MIT Press 2003) XX

Stewart Brand, that categorize shacks and their ilk and constitute a significant proportion of the built environment across the world. ${ }^{3}$ This defection can be traced as far back as Vitruvius and his project of establishing the 'learned man over the craftsman': architecture as a purely 'high road' pursuit. "Beyond question and of highest authority", the Vitruvian architect was to situate the center of a self-referential universe of learning, city, and power. ${ }^{4}$ One might argue that this line of thinking has saturated the pedagogy and profession to this day, to the extent that our ability to be critical about the built environment beyond 'architecture for architects' has stagnated, as architect Jeremy Till has in his book Architecture Depends. Ironically, low road buildings, as informal entities, have inherent potential for social criticism, cultural development, and experimentation by virtue of not having architects involved in their authorship. 
The decadence of the aforementioned Vitruvian insularity is truly exposed through the timely, and timeless, question-cum-paradox, "what is architecture?" That architects have spent so much effort in defining the discipline's boundaries speaks volumes itself; architecture's borders are ambiguous at best, non-existent at worst. Harvard based academic-author Marrika Trotter's sentiment that 'anything can be defined as architectural so long as architects are talking about it' is both enlightening and scathing in its affirmation of the architects' perceived own role in the world.'

But shacks are architectural. Everything is architecture!

Here the schism of discipline and practice is played out in full, a conundrum of 'architecture' and 'architectural', formal and informal. The weight of market reality suppresses social, political and culturally driven space production despite our ability to think discursively outside of a capitalist model. The issue at hand, the Shacklands, is found to be practically inoperable for architecture despite the obvious architectural implications that it evokes.

Socially, politically, and culturally the Shacklands are critical spaces with a built heritage. If we evaluate them using any criteria other than their objective exchange value, they are found to be prized assets to the city and its inhabitants. Should not then architects be concerned about this lack of engagement in informal projects? Architect-activist Teddy Cruz touches on this divide when he laments:

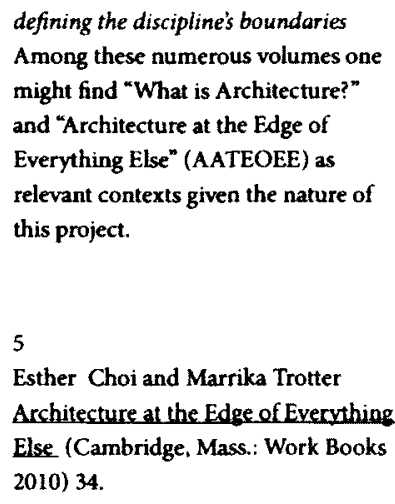
Else (Cambridge, Mass: Work Books 2010) 34.

\section{everything is architecture}

From among the various proponents of this idea, including notable

theorists as Superstudio (see Project Zeno) and Hans Hollein, perhaps architectural speculator-writer Geoff Manaugh makes this point most lucidly. His rant from "The Politics of Enthusiasm" went something like this:

:...everything in the $f^{* * * * * *}$ universe has something to do with architecture. Good moods, bad moods; enclosure, frustration, imprisonment. Freedom. The price of steel. Natural history. Military bases, oil derricks, mining camps. It's all architectural." 
empowering individuals Various explorations of "agency" are relevant to this discussion including those that look at 'spatial agency' 'architectural agency', and 'cultural agency', and while such differentiations are critical, at their core is the idea that architects have

a capacity to contribute to the empowerment of 'marginalized' groups and individuals.

Lisa Findlay Building Change rchitecture politics and cultura agency (London: Routledge 2005) XX.

"(I)t is disappointing to see how the institutions of architecture perpetuate the reductive separation between the formal and the informal, the large and the small, the social and the aesthetic, suggesting the inability to think politically in our profession."

Here Cruz describes a situation that has roots in the way that we define our world as a series of dialectical arguments. The tendency of architecture towards the 'black and white' is on one hand a simplification of the complexity that bogs contemporary life, but on the other a means for developing a platform for insular criticality. This is a kind of criticality that tends not to engage with 'real world' conditions that affect society at the level of agency. At a level of empowering individuals to act for themselves!

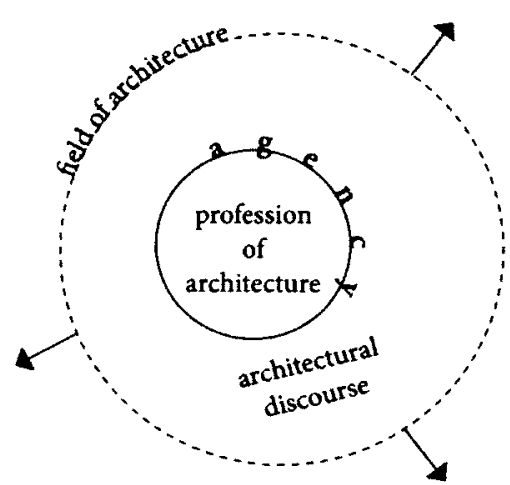

Locating Agency

How can we use this notion of 'agency'?

Agency, argue Florian Kossak et al. in the compilation Agency: Working with Uncertain Architectures, is for architects the acknowledgement that the field itself is part of and supports the "ideologies of the status quo" unless a critical stance is taken in hand with the acceptance of a responsibility to act on behalf of others. ${ }^{8}$ This notion of agency can help us ground an architectural discourse on the Shacklands through a base inquiry of how architects engage with the built environment and the people who exist in it. It offers us a space in which to test architecture's nuclear surface while navigating the discipline's architectural ether. 
Engaged criticality is at stake here; the ability to actively critique. Motive for such a critique in the Shacklands is provided by Brand's opening salvo from his How Buildings Learn episode 'The Low Road':

"There is a category of buildings that might as well be invisible... our eyes bounce off them as we were trained not to see them... architects don't even acknowledge these buildings, that's because architects had no hand in designing them... yet it's in buildings like these that you find the real creativity of a civilization...the main thing about low road buildings is that no one cares what you do in them... that's how low road buildings work, you spend less money and you get more freedom." ${ }^{\text {.10 }}$

"The Low Road"

Such celebration of the low road would hardly constitute the unanimous assessment of society at large. In fact, the most poignant statements therein are the most contentious; first, that authentic creativity is somehow anchored in informal space making and second, that liberation is not intrinsically tied to money. These two statements at once undermine the architect's authority and agency. The technical knowledge, expertise in synthesis, and responsibility to the production of space that architects pride themselves in, is rendered null by an inability to become situated informally.

How does one become situated between the formal and the informal?

We can now go on to investigate how these critiques coalesce within the context of the Shacklands through multiple readings of the notion of hybridity. A primary reading is scientific in nature, from the term hybrid, and is rooted in the concept of crossbreeding.

assessment of society at large While a general statement, this is drawn from my own ongoing discsussions with Iqaluimmiut. In particular, this was exposed during my participation in the Canadian Society of Landscape Architects' beachfront design charrette that will be discussed later.

\section{crossbreeding} definition

transitive verb : hybridize, cross; especially : to cross (two varieties or breeds) within the same species intransitive verb: to engage in or undergo hybridization http://www-merriam-webster.com/ dictionary/hybrid 
original hybrid

c. 1600 , from L. hybrida, varian

of ibrida "mongrel," specifically

"offspring of a tame sow and a wild

boar." of unknown origin but probably

from Greek and somehow related to hubris.

Drawing analogy from the original hybrid, we might question how the untamed lowroad (wild) and architecture (domesticated) might find new productive potentials in their blending. What, in this sense, is a hybrid architect, and what roles does he play?

In the context of the North, however, hybridity takes on an expanded interpretation that is pulled from the multi-faceted negotiations resulting out of colonialism. This interpretation, resting on concepts developed by post-colonial theorist Homi Bhabha, adds considerable complexity to these lines of questioning. How is hybridity at play in the scenarios presented by the Shacklands, who is the colonizer and who is the colonized? Can the interplay of these forces of authority and its subjects, deemed so culturally productive by Bhabha, be guided and leveraged by the architect? Or are we past the post-colonial, setting out on a new journey of city-making? 

Because it always exceeds what can be conventionally represented, dark writing is the discourse of the sublime. But of what use is that to planners, architects, and even journalists - all of whom, in the society of the spectacle, are employed to quantify phenomena in a way that dissociates them from the matrix of multiplicity where they belong and excel?

Paul Carter, Dark Writing

Marc Auge Non-Places: An Introduction to Supermodernity (France: Verso 2009) hut, a lean-to, a shanty, a shed, a shack; the ubiquitous image of the 'developing
world' is built on these, the lowly buildings. Cobbled together with minimal
rools, expertise, and with a budget in deficit, these buildings reek of poverty, need, and impermanence. Slums the world over from Mexico to China, Lagos to Mumbai, are populated by this building typology and the negative connotations that follow suit. Leaning close to refugee camp status, these are the sometimes transient 'Non-places' that French anthropologist Marc Auge alludes to in his book, that are without jurisdictional power or privilege, existing on borrowed time. 'Or perhaps they are places, of a locality, producing social culture, and operating with a different sense of authority.

These 'Shacklands' are simple yet complex entities of aggregation, existing typically on urban fringes and in marginal domains, taking advantage, like weeds, of cracks in the pavement of structured planning. Canada is not without its own Shacklands, indeed among many cities and communities of Nunavut and the Northwest Territories, at Canada's upper margins, they are ever-present. From the air they are plainly visible, sprawling across the waterfront; on the street, they are found adorning houses that do not harbour the same aesthetic accessorizing as their southern counterparts; and on the land they are a 


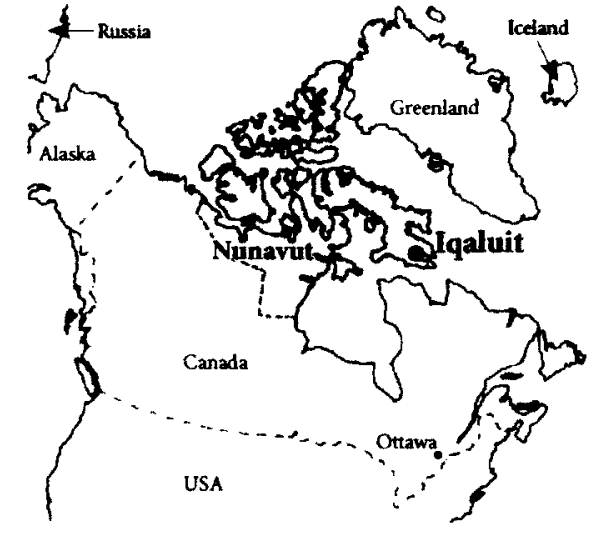

Iqaluit location map

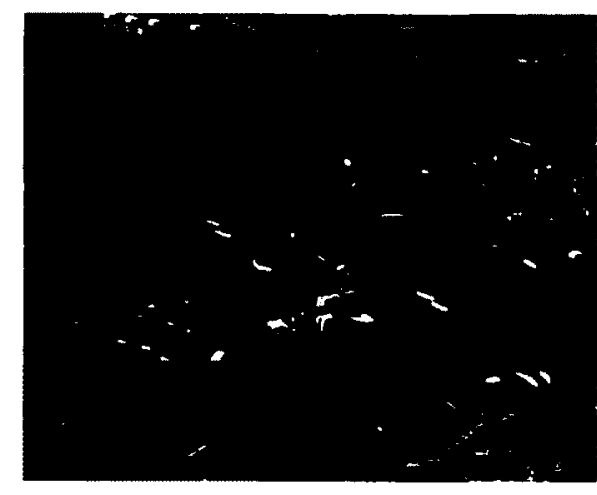

Iqaluit aerial photo

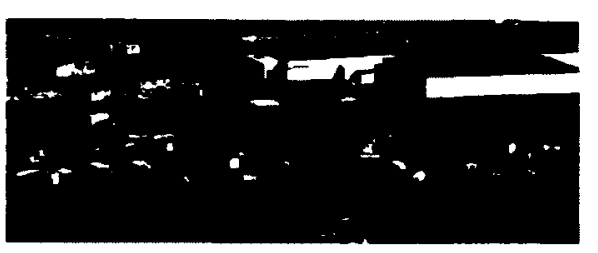

Beachfront aerial photo marker, shelter, and more. Unlike the slums in other regions, shacks in Canada's North seem to be of a different character, a character that reflects the nature of the place and more so the character of the people native to this place.

We should not make the mistake of claiming that the Shacklands of the North are all the same however, such would be akin to saying that all Inuit and northerners in Nunavut have shacks and that these shacks are all of a certain dimension and use. No, there may be some similarities, but such regional generalities dismiss the complexities of place that influence shack building by individuals. The scope of this enquiry is thus limited to those Shacklands in and around the micro-city of Iqaluit.

Iqaluit is a place of extremes and contradictions. It is a uniquely contemporary city, given its attributes as a supermodern gateway to the Canadian North, its status as a territorial centre of economicpolitical-administrative power, and as place that exists in the Canadian consciousness as exotic. Appropriately, architectural researcher Allesandra Ponte, in her essay Journey to the North of Quebec: Understanding (McLuhan's) Media captures this latter notion through her use of term 'frontier-town' to describe such remote northern settlements that now face rapid development. ${ }^{2}$ And while it is difficult to categorize Iqaluit as a 'city' in the urban sense of other Canadian capitals such as Ottawa, Halifax, or even Yellowknife, it 2

Allessandra Ponte Journey to the North of Ouebec: Understanding Mcluhan's Media Presented to Landscapes in Change Symposium (Tromso: January 2011). 
retains urban qualities in its complex demography, and layered history of development. Further to such interpretations of urbanity that apply to this place, an extended definition that looks at the city as part of larger network of traditional, local, national, and global infrastructures and networks is more appropriate given its wireless autonomy in the Canadian geo-political landscape.

How can we, as architects, read the Shacklands of this place? What do they say about Iqaluit as an urban entity, as an arctic ciry? Where do we start? If we claim that they are a kind of 'informal architecture', we might not say anything at all that is relevant to those who build them. If we claim that they are an authentic and critical regional architecture, we may have already missed the point. If we claim that the Shacklands are Iqaluit's shadow, do we already go too far?

Perhaps we might best begin by asking simply 'what is a shack'? The MacMillan Dictionary defines a shack as 'a small plain building, usually made of wood or metal. ${ }^{3}$ com/dictionary/british/shack Surely we could include cabins, cottages, shanties, huts, sheds, and an assortment of industrial and agricultural structures in this caregory. Pavilions and follies are not plain enough. Tents are usually not made of wood or metal. Houses are a bit too big as we will find out later.

The City of Iqaluit is more explicit with regards to such distinctions having established, through by-law, categories for shacks on lots, sea-cans, beach shacks, and cabins. Shacks on developed lots are considered accessory buildings and require development permits if over $10 \mathrm{~m} 2$ (can be up to $40 \mathrm{~m} 2$ and $4 \mathrm{~m}$ high) and have a use which is normally subordinate and incidental to the principal use of the main building or lot. These are not habitable. 


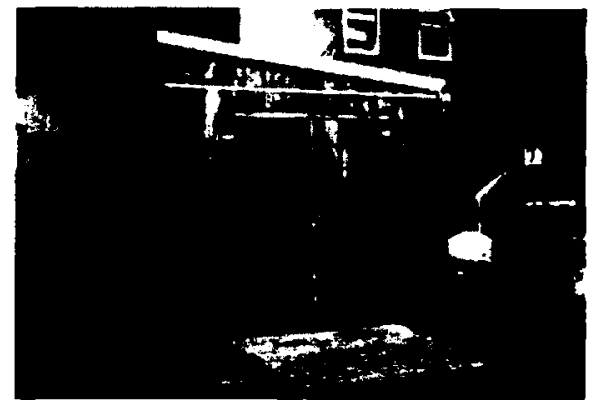

Accessory Shed

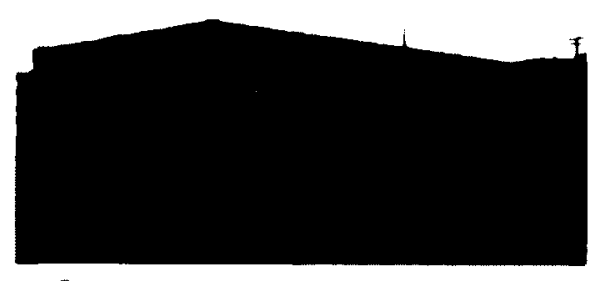

Sea Can

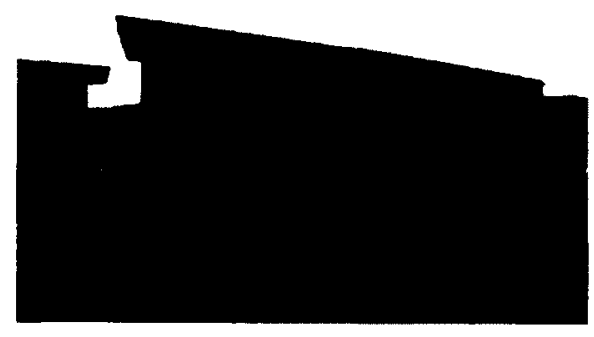

Beach Shack

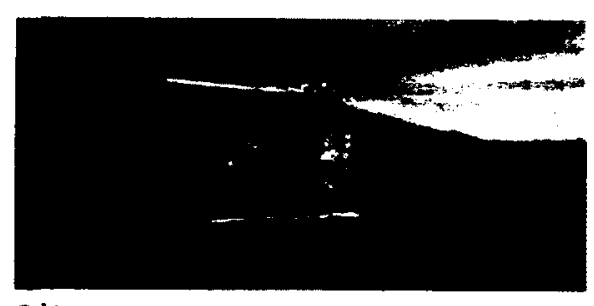

Cabin
Sea-cans are converted shipping containers considered accessories as per the former with one allowable per lot in designated areas for aesthetic reasons. Beach shacks are those that are in, or close to, a beach area used for harvesting purposes or other uses related to the owners' participation in the land-based economy. ${ }^{4}$ Cabins are not covered by the City By-laws at this time, though legislation is pending, however they are defined by City planning as habitable and are seen as permanent structures in the Municipal Reserve hinterlands that require $100 \mathrm{~m}$ setback from any other cabin. ${ }^{5}$

Of particular importance in these distinctions is the sense that accessory buildings, the first two categories, have prescriptive regulation mechanisms enforced by the city, whereas the latter, beach shacks and cabins should be managed in a more reflexive manner due to their relationship with the Nuna and consequently with a culturally based use of land by Inuit. Additionally, it is of note that despite having regulations in place to control the development of accessory buildings, the resources available to the City to enforce them are minimal; city planner Arif Sayani believes that only about half of all accessory buildings are documented formally and indicated that such illegal structures only become 'visible' when complaints are raised against them. ${ }^{6}$

It is clear then from these definitions that the informality of the shack is an essential attribute, given its general naming of building
City of Iqaluit "By-law 704" Zoning By-Law (Iqaluit: City of Iqaluit). Arif Sayani "Personal Interview" Aug 2011

Nuna

The Inuktitut word for 'land' has

been appropriated by the City in its

planning guidelines as a reference tool of culltural integration.

Sayani "Personal Interview" 
Paul Carter Dark Writing: Geography Performance. Design (US: University of Hawaii Press 2009) 4 types, and given the relative lack of their policing. More relevant however is the sense that there is an unwritten set of relationships between the city, in its formal authority, and the shack as a part of a culture of urban dwelling that is important but resistant. At the individual level this is a minor issue but en masse and in aggregation there are deeper implications for the city such as property ownership, safety, maintenance, regulation, aesthetic control, and administration. Such Shacklands are however, integral to the identity of the city, and have a history that is largely unwritten, partially due to their informal nature but more so, we will argue, due to colonialism and its big brother 'capitalism'.

With this notion in mind we might view Shacklands also as a conceptual construct, devised as a tool to question conventional notions of an urban north. Taking up the gauntlet thrown down by post-colonial theorist Paul Carter, it could be analogous to a loupe for reading 'dark writing'. Dark writing, as interpreted here, is that narration which is repressed in the normalized representations of our present realities. To find it is "to go both above and below the line of disembodied reasoning that currently mediates our designs on the world. It is to put the figure of the architect back in the picture." When we examine a map for example, dark writing is what is missing. It is the experiential mode of locality in representation that is found in place names, journeys, and, we posit, informal inhabitation practices that are situated by place. Just as dark writing is specific yet expansive, Shacklands might serve as a filter to allow us to probe a new conception of the urban north that Iqaluit presents. This we might achieve while also enriching an understanding of 'northness' by acknowledging complex and hybrid dynamics of culture and authority. 
Our thesis then takes on the form of a journey that travels between the lines of the unwritten but built and the unbuilt but written, between documentation and imagination, to probe the Shacklands and to find where there might be room, perchance, for an architect. The Shacklands might just be the place for architects, the place for them to go walk-about, to test their insurgency, to put themselves back in the picture.

This journey is arranged around an itinerary of sojourns, or stops, that provide for reflection and the testing of agency at multiple sites and scales. While a journey has direction it is not always carried out in a linear fashion, likewise these sojourns are arranged less by chronology than by the order in which they best relate to each orher and the issues that are explored to build a cohesive narrative.

Sojourn One takes us on the beach in Iqaluit, where, through historical and formal research, field investigation, interviews, and shack documentation, the patterns of hybrid reversal patterns are investigated. The role of the architect here is that of mediator, making sense of a complex politically charged public space. Who are the key players? What tactics are being used? Does something need to be done? 
An interlude on the land is the focus of Sojourn Two. Investigating the hybrid space between the land and map, patterns of building and use are exposed through drawing. By providing self-building practices with visibility, the architect questions the agency of freebuilding and its legitimization. What are people doing on the land, and how has it changed within a cultural context?

Taking a detour, Sojourn Three is a stop in the woods, where a Northerner is re-colonizing fifty acres of forest outside of Ottawa. Here the space between the informal shack and the formal house is investigated through a builder's self-determinacy, while the architect becomes a collaborator. Can one build a house in the same way that you build a cabin or a cottage? What is the difference?

The final layoff is in the city where our Conclusion considers agency at a community level through the imagining of scenarios of 'making' that probe the boundaries of formality, the role of the architect, and the Shacklands. Is this the second promise?

While this logistical outlay provides a structure for moving forward, it is an itinerary that is contingent upon an interpretative framework based on the notion of hybrid reversal. The following section Re: colonization, provides a context for this idea in its relationship to, and genesis from, colonial practices in theory and in practice in the Arctic as they relate to Iqaluit.
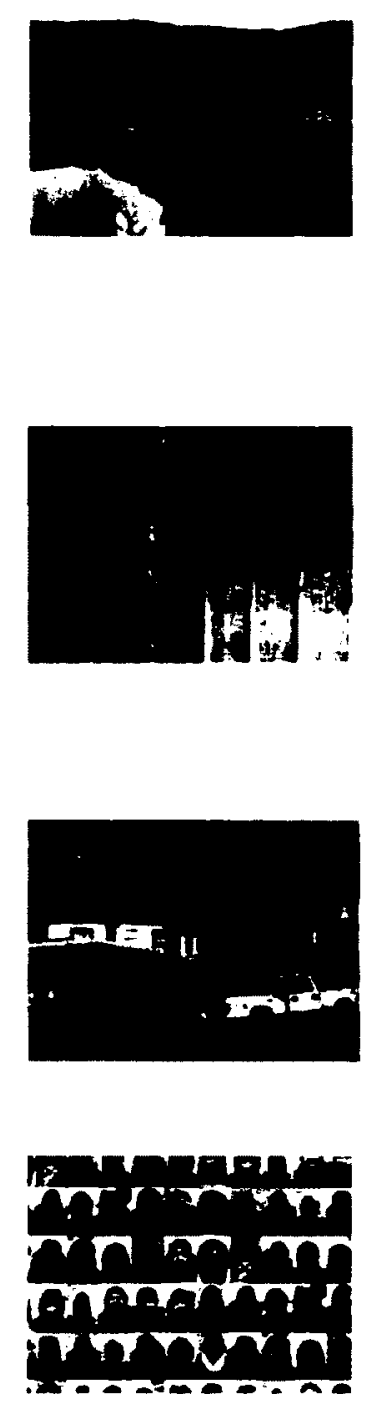


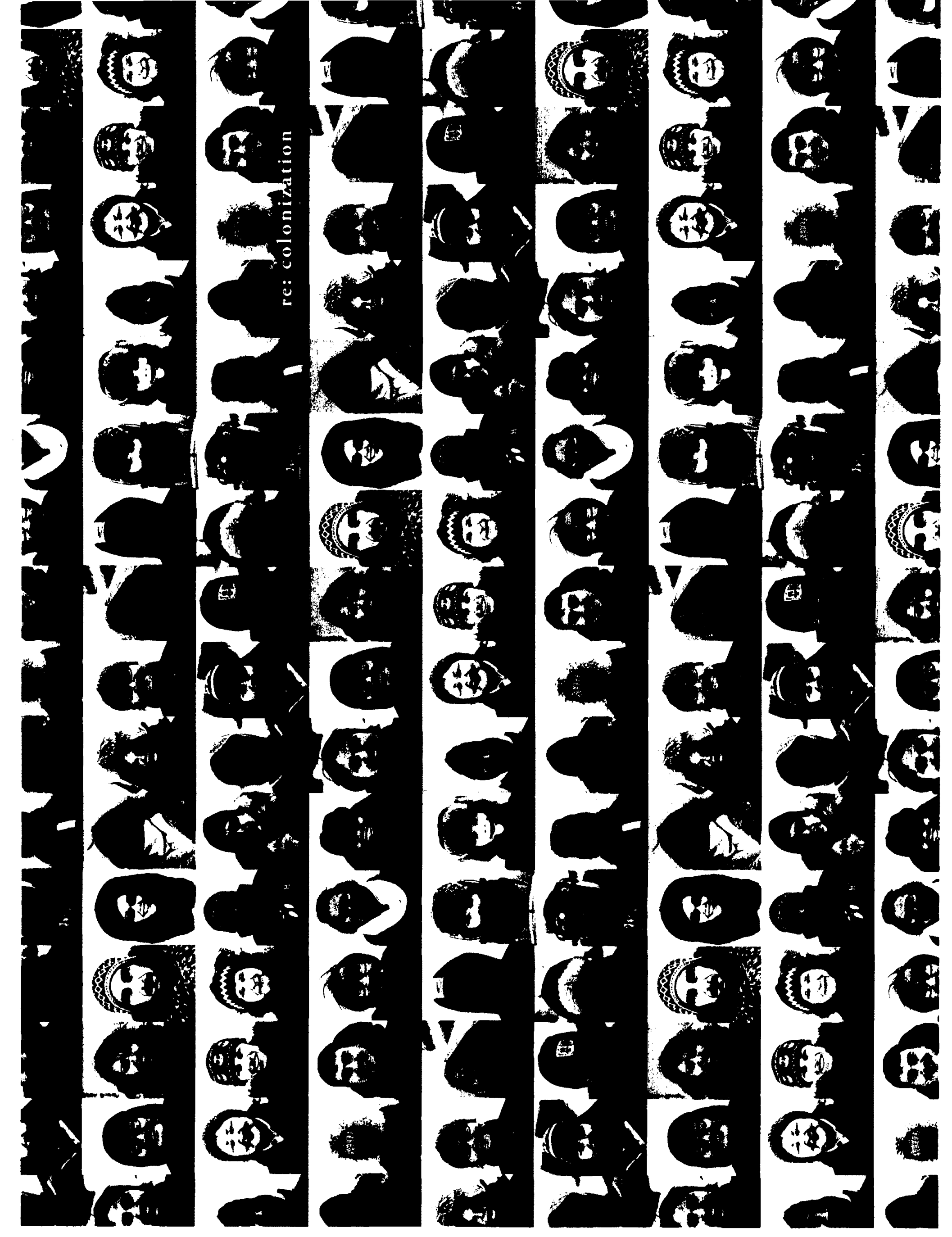


CHAPTER 3

\section{hunters and farmers}

Canada, Statistics Canada, 2006 Community Profiles, 23 Mar 2012 <http://wwwl2.statcan.ca/census recensement/2006>.

Hugh Brody The Other Side of Eden (Vancouver: Douglas \& McIntyre Ltd 2000) 6-7.
Taluit is unique in Northern Canada as the only city with a majority aboriginal population and is home to over 3500 Inuit. It is also home to a similar aggregate population of other southern Canadians and immigrants from other lands, with Newfoundlanders, Quebecers, and other aboriginals well represented.' Acknowledging the generality of the statement, we could say that this is a city split between two groups of people that have emerged out of essentially diametrical ideologies.

This divide is less between southerner and northerner than it is between what noted anthropologist Hugh Brody has framed as the hunter-gatherer and the farmer. At a basic level, he describes three critical differences between these groups. First, hunter gatherers inhabit zones that are considered marginal by the developed world. Secondly, and working from anthrolopological pioneer Franz Boas' critical argument of ethnocentrism; the difference between hunter-gatherers and famers has nothing to do with evolution or development. And third, "a crucial difference between these two groups is that one society is highly mobile with a tendency to both small- and large-scale nomadism, whereas the other is highly settled, tending to stay in one particular area or territory." 
This final claim seems straightforward until we realize that it is the farmer who, through generations of land appropriation, economic development, and high reproduction rates, is the nomad. The hunter-gatherer on the other hand forms an almost symbiotic relationship with a specific environment and is situated within it over long expanses of time with minimal lasting impact and no consideration of land ownership. Brody's argument is support by his considerable experience living among hunter-gatherer peoples, but moreover by extensive historical research of languages and their spread across time and geography over large generational spans. $^{3}$

The farmers, by virtue of the need to appropriate and develop land for capital are by default of a colonial agenda. While today the term 'farmer' may not describe the vocation of most of non-Inuit in Iqaluit, the colonial-capitalist ideologies with respect to language, time, valuation, property, and individual retain its relevance in relation to contemporary living. Douglas Cardinal, Canada's most recognizable indigenous architect, furthers these notions of disconnection between Western and indigenous world views by comparing social structures (hierarchical versus circular), beliefs (good/evil vs. following one's own self), attitude toward environment (man over nature versus man one with nature), creationism (technological imperative through competition versus ingenuity through balance) and interconnectedness (physical entity view versus life force view). ${ }^{4}$ To echo Cardinal's remarks, this is not to say that one is better than the other, rather that each has virtues and is different.

contemporary living

This is an intentionally general statement to speak to 'global culture' as it is experienced in the Canadian sense. School of Architecture, 13 Jan 2012. 


\section{colonialis m}

Experimental Eskimos dir Barry Greenwald, DVD, White Pin Pictures, 2009

6

Iohn Ralston Saul A Fair Counury Telling Truths About Canada (Canada Penguin Group 2008) 19
The reality is that Iqaluit and all of Northern Canada have gone through a colonial period wherein the farmers, via Federal Government departments and agencies, actively contributed to an assimilation of Inuit lands and values for outside motivations unrelated to those of the Inuit. ${ }^{5}$ Canadian political thinker John Ralston Saul elucidates that "[c] olonialism is the denial of the reality of self in favor of an imaginary special position inside the mythology of someone else's empire. That special position can never exist because empires have their own purpose." 6 This statement of 'mythology' is critical, as it denotes the overwriting of a belief system which, as noted, for hunter gatherers includes such integral values as interconnectedness with the environment, inclusivity, self belief, and balance.

There is no doubt that in present day Iqaluit many (if not most) Inuit are struggling to reconcile this clefr with the past, which is intimately tied to the land, and this is in no small part due to the totalitarian strategies employed by colonists, many of which are imparted by spatial transformation. Drawing from post-colonial writer Edward Said's theories, these spatial strategies of colonialism can be organized into a succession of four acts:

1. Appropriate the geographical domain through exploration, charting, and naming.

2. Imprint the culture of the colonist through building techniques and materials, and introduce new plant and animal species.

3. Radically transform the landscape to yield economic profit.

4. Ensure that the spatial transformation is no longer foreign in any appearance. ${ }^{7}$ 
Architecture as a colonial tool plays a key role in subjugating culture related values through various means, not all of which are so overt as to be immediately recognizable. Perhaps the clearest example of this is found in government housing typologies that were developed for

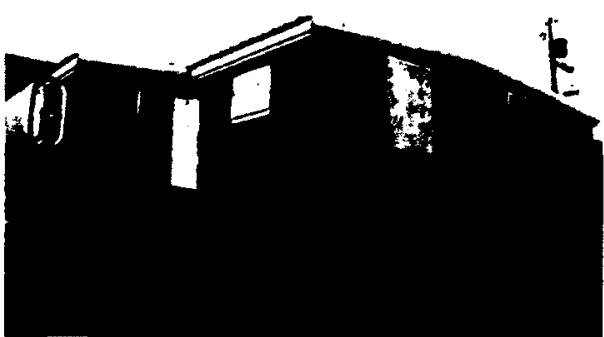

Single family government house unit from 1970http://

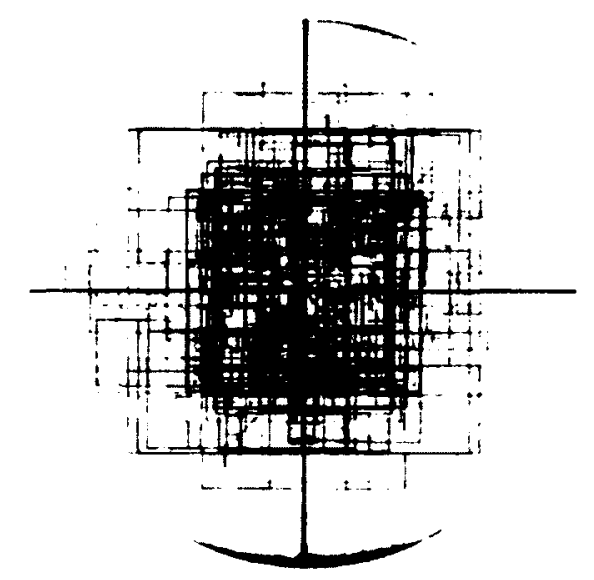

Tyranny of the 4' Square the Inuit and other indigenous groups across the Canadian North.

These structures, while of small and basic dimension would have been viewed as major improvements to the living conditions of their inhabitants by the Government 'benefactors' for reasons that are less related to service provision, i.e. heat, water, electricity, but rather from the standpoint of ideology in the general form of 'modernization.' Doug Wilkinson, a regional government administrator in Iqaluit during its early development, touched upon this link between housing and ideology in his letter to Southern-based superiors, stating: "proper housing is not only a roof over the head, but it is an important $\operatorname{cog}$ in the machinery for developing a new social existence for the wage earning Eskimo, his wife and family."

Seen as 'acculturation by design', the colonial act of building is discussed through a project by artist-academic Gavin Renwick of Dundee University called 'Tyranny of the 4' Square'. This project involved the study of all government house designs produced for Inuit and First Nations people beginning in 1950 with the 'matchbox' up until 1996 and refers to the process of manufacturing of plywood in 8 'x4' sheets and its resulting universal grid system. Of this work he cites:
"Letter to the Chief, Arctic Division. Department of Northern Affairs and National Resources" from Doug Wilkinson, N.S.O., 4 June 1956 
Gavin Renwick "Tyranny of the 4' Square" <http://gavinrenwick.org/ Tyranny_of the 4 Square/Tyranny of_the_4_Square.htm>1
The government house creates insulation from the land. In the communities one only has to look around the house exterior to see how a traditional lifestyle cannot be internally accommodated. Indeed, the separation of workplace and homeplace symbolizes an implicit cultural contradiction, the division of land from home... Through the Cartesian geometry implemented in the house a social order is taught. It can therefore be seen to be an 'apparatus [that] serves to suppress and hide ... Aboriginality'. The segregated and partitioned interior is in itself an ideological system, further qualified through the houses location within a standardized settlement plan that regulates and institutionalizes people's life. The provision emphasizes the dominance of the provider while largely disempowering the receiver. 9

Renwick's first assertion here is fundamental, a displacement from the land causing an 'implicit cultural contradiction.' This basically made irrelevant the skills and intuition of the Inuit cultural base in settled life while forcing an adaptation to a hierarchical system in spatial form at all scales. In addition, the inability to alter the living environment, due to non-ownership, reinforces this contradiction. Many Inuit in Iqaluit have and will continue to demonstrate this shift and the changes that it brought to other pre-colonial praxis, as well as how it has shaped systematic social dysfunction and government dependence that is evident today. A poignant and heartfelt reflection as such, to paraphrase Inuit student Pitseolak Pfeifer, draws on the fractured orally-based social ties and cultural-generational gap
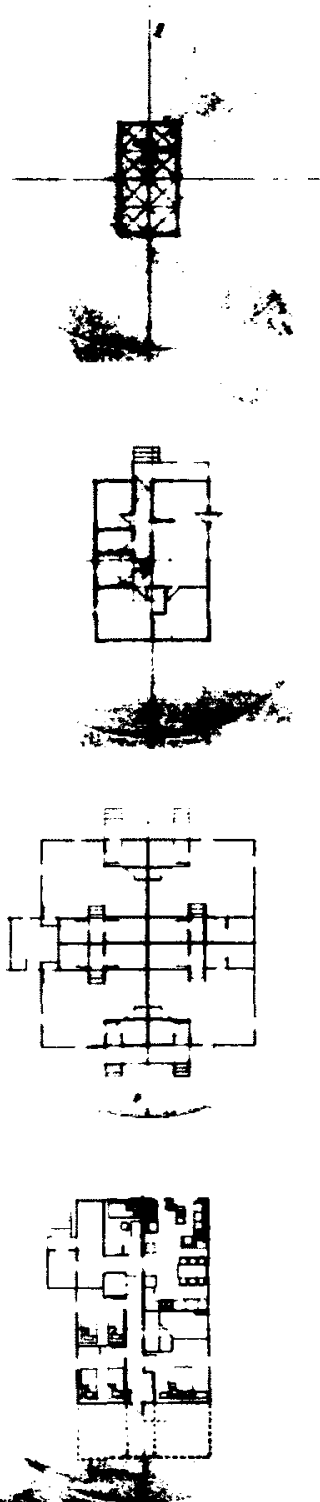

Tyranny of the 4' Square Plans 
between young and old Inuit in spite of co-inhabitation; "there is a barrier between us, quite literally... there are walls between us." ${ }^{10}$ Clearly the days of the igloo and its circle of inclusivity have been resigned to history.

This colonial relationship between the hunter gatherer and farmer typologies, while useful for drawing out a set of ideological value sets, particularly as related to space, as well as establishing the use of spatial design in the supplanting of these ideologies, is necessarily an essentialist understanding of the contemporary reality in Iqaluit. From an academic standpoint, one can look to Edward Said in Orientalisprom in which he begins to paint a picture of a less static colonizer that, through the study of 'natives', gives definition to a culture that is alien to Western societies, thereby simultaneously translating and de-alienating it through appropriation. Likewise, he also points to the significance of some colonizers 'going native' by taking up habits, customs, and ideologies of the colonized. ${ }^{1}$ Conversely, to step outside of academia momentarily and into Iqaluit as it is experienced, it is clear that the colonized do not simply deny the colonial ideology nor fully take it up. We could visit community celebrations and find what is known as "Inuktitut dancing", an offshoot jig dancing to Celt-tinged accordion music played by Inuit and danced by Inuit. Or perhaps play "Inuktitut baseball" all night long with Inuit children under the summer sun, using rules that are neither what you could rightly term baseball nor cricket. We could visit an Inuit family for dinner and probably sit at a table, unless "country food" is on the menu, then sitting on the floor to share raw meat from a flattened cardboard service would be in order. Iqaluit is a city in which the table and the flattened cardboard box co-exist. Statement" Visioning Session for the Carteton University Aboriginal Architecture and Urbanism, 13 Jan 2012 .

Paul Fry "Lecture 21: Post-colonial Criticism" Literary Theory Lecture Series. Yale University, Spring 2009. 
Frances Widdowson and A Howard Disrobing the Aboriginal Industry: The Deception Behind Indigenous Cultural Preservation (Canada: McGill-Queens University Press 2008) 264.
These scenarios allude to a more complex relationship, ${ }^{12}$ the impact of which is explored by Ralston Saul in his essay, A Fair Country: Telling Truths About Canada, through his consideration of those first Canadian immigrants and colonists who 'went native' as precursors for our national collective identity. Ralston Saul's principal assertion that Canada is a 'Métis Civilization' built on the three pillars of English, French, and Indigenous cultures. It is a notion borne of an unofficial pre-history to Canada's nationhood, when European explorer-settlers and indigenous peoples were living closely together, even intermarrying to the extent that the Métis people themselves were conceived. His critical argument is that underlying the colonial framework of the nation of Canada lays a subconscious crossbreed that guides the collective national identity. ${ }^{13}$ In a reduced form this can be understood as a common value set based generally around egalitarian ideals that promote cultural difference. Such an argument is provocative; a key claim for all Indigenous groups in Canada, as evidenced by the $8^{\text {th }}$ Fire series, is to be recognized as distinct, not only from 'settler' groups but also from other Indigenous groups, not simply as a part of a national equation. Further, if we look at Frances Widdowson and Albert Howard's Disrobing the Aboriginal Industry, such an idea as pressing forward based on a Métis Civilization is a waste of time. This becomes clear if we consider that while Ralston Saul advocates for the respect of kinship dynamics in their relationship to communal inclusivity, Widdowson and Howard state in their conclusion: "If we really want to achieve the aspirations of the Enlightenment, the answer does not lie in tribalism... There would be no such thing as the public sphere, where everyone is supposedly equal under the law, since kin would be favored over others in the distribution of goods and services." ${ }^{14}$ Despite such reactions that expose both the legacy and denial of colonialism, the thesis of a Métis Civilization is a poetic retort to the colonial hierarchy and a call to take aboriginal thinking seriously at the intellectual and bureaucratic level. 


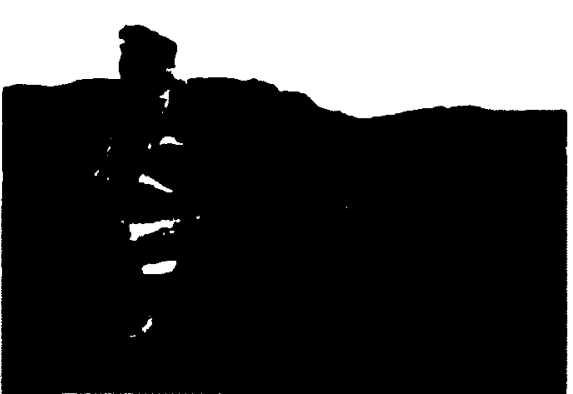

Inuk-Qablunaat in skin clothes and runners.

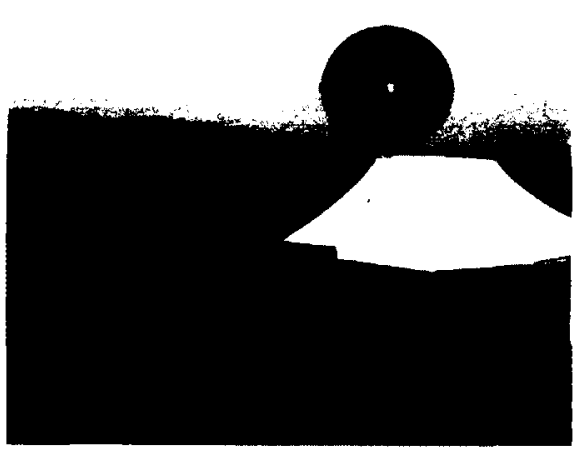

Qanurli? webshow broadcast studio.
Here it would be useful to revisit our demographically oriented point of departure; statistically there are an approximately equal number of Inuit and others living in Iqaluit, which were essentially hunter gatherers and farmers. Beyond these numbers and binary definitions is a group of people who do not fit so simple a set of distinctions and who float between both, either by blood or by nature. For lack of a better term we might call these people 'northerners' or like the Iqaluit based Aboriginal Peoples Television Network program Qanurli? protagonist, many might be understood as Inuk-Qablunaaq. This group gives image to a latent 'hybridity' that has emerged out of colonialism and more accurately describes the heterogeneity of the city as it is experienced; as more than simply the interplay of two static cultures.

While in common use, the term 'hybrid' might denote simply 'the mixture of two disparate entities in single form' (as in a hybrid car), the use here is a reference to post-colonial theorist Homi Bhabha's development of the concept in relation to cultural productivity that is born out of the contradictory nature of the colonizers act of assimilation. Bhabha explains this through definition from his essay 'Signs Taken for Wonders',
Qanurli?

Qanurli? What Now? is a new youth comedy series produced by the Inuit Broadcasting Corporation in Iqaluit and broadcast on APTN. "Think 30 Rock meets Rick Mercer when Inuk Qablunaaq attempts to broadcast his own TV show from a tent from the isolated Arctic tundra."

\section{Inuk-Qablunaag}

Slang term in Inukttitut translating to Inuk-whiteman. 
Hybridity is the sign of productivity of colonial power, its shifting forces and fixities; it is the name for the strategic reversal of the process of domination through disawovel (that is, the production of discriminatory identities that secure the 'pure' and original identity of authority). Hybridity is the reevaluation of the assumption of colonial identity through the repetition of discriminatory identity effects. It displays the necessary deformation and displacement of all sites of discrimination and domination. It unsettles the narcissistic demands of colonial power but reimplicates its identifications in strategies of subversion that turn the gaze of the discriminated back on the eye of power. ${ }^{15}$

This is a complex idea that can generally be understood for our purposes as a combination of two factors. First is the intent of the colonizers to make of the colonized a group who are in their image and of their ideals but not of their stature; a paradox of the superior making the inferior into a superior - if it is achieved there will no longer be a superior. Second, there is the ambivalence of the colonized towards the colonizer, an intentional non-acceptance of a whole assimilation; not only are the colonized editing the colonizing culture that is being pressed upon them in terms of what is accepted, but those parts that are accepted are translated. ${ }^{16}$

The result is a strategic undermining of the idea of purity for both parties, a process of negotiations and rearrangements of authority. Hybridity in this context is a concept that is relevant to current and evolving spatial practices in Iqaluit. While there are numerous examples to draw from in exploring this concept, perhaps the most relevant point of departure for our enquiry is to return to the 'Tyranny of the 4' Square' project. It is clear that Renwick's intention with the project is to draw upon the integrated and often neglected impacts on the colonized that would inhabit these spaces. He does not attempt 
to posit a reading of how the 'implicit cultural contradiction' of separating land/home, read also as work/home, might be manifested in a hybrid translation and subversion of authority. While the interior of the house itself is beyond major transformation, due to non-ownership, it is precisely the house exterior where an interpretation can begin.
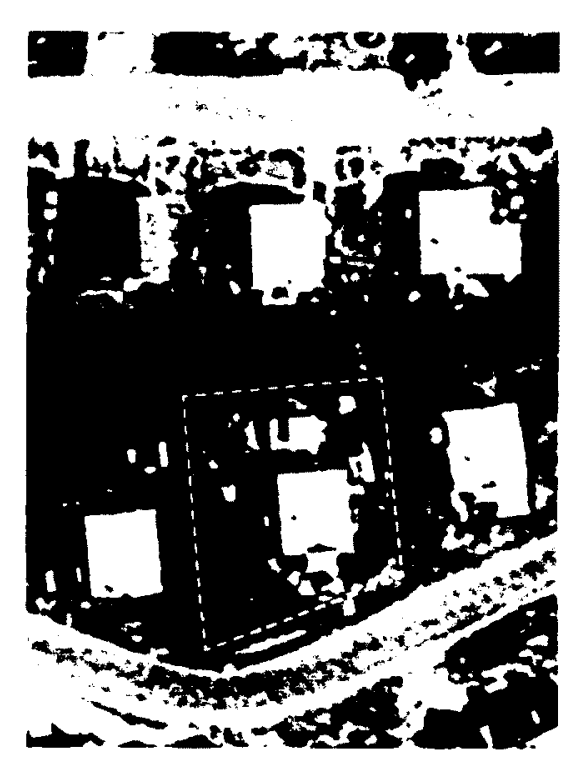

Typical Hunter's house and outbuildings
If we look at a typical single-family government housing unit in Iqaluit, of the breed discussed in Renwick's project, it is clear that a traditional lifestyle does not fit internally because of the proliferation of specialized equipment, supplies, and outbuildings that are found directly adjacent. These exterior accumulations of structure and program can be read as an overt spatial translation of traditional hunting camp needs onto a modern lot-based arrangement. Whereas the government house is uniform and neutral in all aspects, outbuildings in particular provide a means of breaking down the internal structure of the lot to suit the inhabitant as well as providing a platform for individuality through self-design and construction. Unlike the static construction of the house, these outbuildings are readily transported if a family moves houses. This spatial arrangement can be read as the strategic disavowal of the rational and internalistic ideologies of the colonizer while facilitating the translation of the purely traditional methods of seasonal, temporal construction, as referenced by igloos, qammaat, and tents to semi-mobile all-season structures. 
These strategies are amplified into the urban scale if we consider that many government unit inhabitants throughout the history of the city have constructed and sited outbuildings and beach shacks at the waterfront in large number. And if we consider the proliferation of similar structures in the lands around the city, both within its formal boundaries and far beyond them, the scope of Iqaluit's spatial hybridity begins to take on deeper significance; an interconnected multi-scalar system of 'hybrid reversal'.

Vitally, it must be noted that this interpretation is not what has been termed in post-

http://www.macmillandictionary. com/dictionary/british/decolonization colonial politics as a process of 'de-colonization', which denotes the political process by which colonies become independent. ${ }^{17}$ To make this distinction it is once again fruitful to return our gaze upon the colonizer and in specific to the actions of the Canadian Government.

\section{de-colonization}

Beginning with the period of Federal Government administration in Iqaluit, there was a clear mandate to first segregate the Inuit from the settlement and subsequently to implement 'integration' of the Inuit with the modern culture of southern Canada. Both of these tactics involved a process that implicated spatiality but were based foremost on a process of policy and social experimentation. The residential school program is the best known of these large scale cultural policies, given that it so brutally exposed the

Leslie Moody and Isabel Cordua von Specht " Stones: Social Capital in Canadian Aboriginal Communities" Drnamic Balance: Social Capital and Sustainable Community Developmen (Canada: UBC Press 2005) 134 colonial spirit and resulted in a massive bankrupting of social capital, as described by such studies as Stones: Social Capital in Canadian Aboriginal Communities by Lesley Moody and Isabel Cordua-von Specht. ${ }^{18}$ But in this case we might look at the story of the three 'Experimental Eskimos', Peter Ittinuar, Zeebeedee Nungak, and Eric Tagoona, who were uprooted from their communities as children, without their families, and immersed in 
the public education and urban culture of Ottawa to assess the capabilities of Inuit to adapt to modern life. All went on to become politicians at the forefront of the movement for aboriginal land claims in the North, becoming the first Inuit Member of Parliament, leading the Inuit in the signing of the James Bay Agreement in Northern Quebec, and contributing to the introduction the concept of Nunavut respectively.19 These are all milestone contributions to Nation making, Inuit representation, and self-governance, and they are all part of a process of decolonization.

The concept of Nunavut, a land-claim territory governed and administered by the Inuit, eventually grew into the Nunavut Land Claims Agreement (NLCA) which is administered by the Government of Nunavut (GN) and implemented to a large degree by the federally funded Inuit Organizations such as the Inuit Tapirisat of Kanata, regional Inuit Associations, and Nunavut Tunngavik Incorporated. There are numerous differences between the Territory of Nunavut (the political body) and Canada's other provinces and Territories, three of which stand out. First, there is a mandate to have $80 \%$ Inuit representation within its administration. Second, working capability in the language of Inuktitut is to be required for GN workers in $2020 .^{20}$ Third, the GN has an agreed upon set of principles drawn from traditional life called Inuit Qaujimajatuqangit (IQ) that constitute an ideological platform. ${ }^{21}$ Each of these objectives aims to break down the hegemonic power structures of the previous colonial governing system through policy and legislation. However, these objectives are far from being achieved as John Ralston Saul claims:

"Because in 1999, when Nunavut was set up, they had little choice but to borrow a model of public government from the Northwest Territories" - a Southern model put in place by Southerners who had worked in Yellowknife. Even with the best will in the world, IQ often ended up as a series of ad hoc initiatives pinned onto this borrowed model."22

Experimental Eskimos
Inuit Qaujimajatuqangit (!Q) IQ is traditional Inuit Knowledge. Inuit as a people have a long-standing code of behaviour based on timehonored values and practices. These values were communicated to younger Inuit at a very early age through stories, songs, direct modeling of behaviour and legends that spoke of the success associated with remembering them. $<$ http: $/ /$ www.gov nu.ca/hr/site/beliefsystem.htm>

Sarah Rogers "GN workers ca now speak Inuktitut at work:

language protection" acthttp:/ www.nunatsiaqonline.ca/stories/ article/65674gn_workers_can_now_ speak_inuktitut_at_work_language_ protection_act/

See NLCA

Ralston Saul 290 
This is not to suggest that Nunavut is a failure rather that it is having difficulty putring a 'round peg (indigenous circle of inclusivity) into a square hole (colonial rational grid) and in the present operates as a top-down bureaucratic hierarchy in for the most part. In Iqaluit, the administrative center of the territory, this contradictory situation of reality and objective is almost tangible. Local social entrepreneur William Hyndman, who operates a non-profit country food exchange program to bring hunters and consumers together, summarizes the dilemma that de-colonization poses in remarking that "there are two promises of Nunavut, one of those is to get Inuit into cubicles... and the other is to

get them out." ${ }^{23}$ For the purposes of our study this comment provides an opportunity to draw a focus to our area of interest. While the concept of 'de-colonization' comes out of and is entrenched in the top-down mechanisms of the colonial legacy, the concept of 'hybrid reversal', as used here, comes out of colonialism but is located with the individual and associated socio-cultural webs from the bottom-up. Spatially the 'first promise' can be referenced by the plethora of new office buildings and accommodating structures (hotels, apartments, restaurants, etc.) occupying Iqaluit's 'Core Area' that seem to be trying to invent a relevant architectural language for a new government. What is the spatial language of this 'second promise' that the notion of hybrid reversal makes reference to?

The Shacklands are assumed to be sites that have emerged in the shadow of colonialism and provide us with a point of departure for such research, but in the attempt to bring light to this space of the 'second promise' it is also evident that the architect is an actor. What role does he play? Is he an agent? Designer? What is his contribution? Perhaps we will find out on the beach.

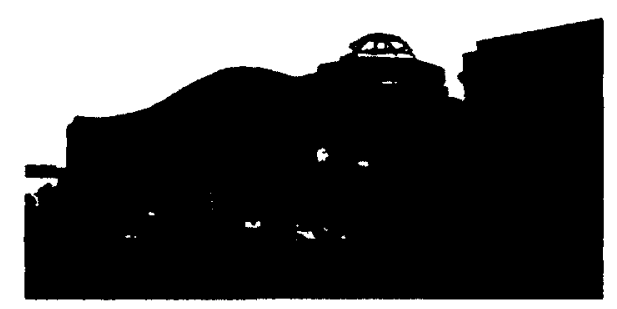

The language of de-colonization? 


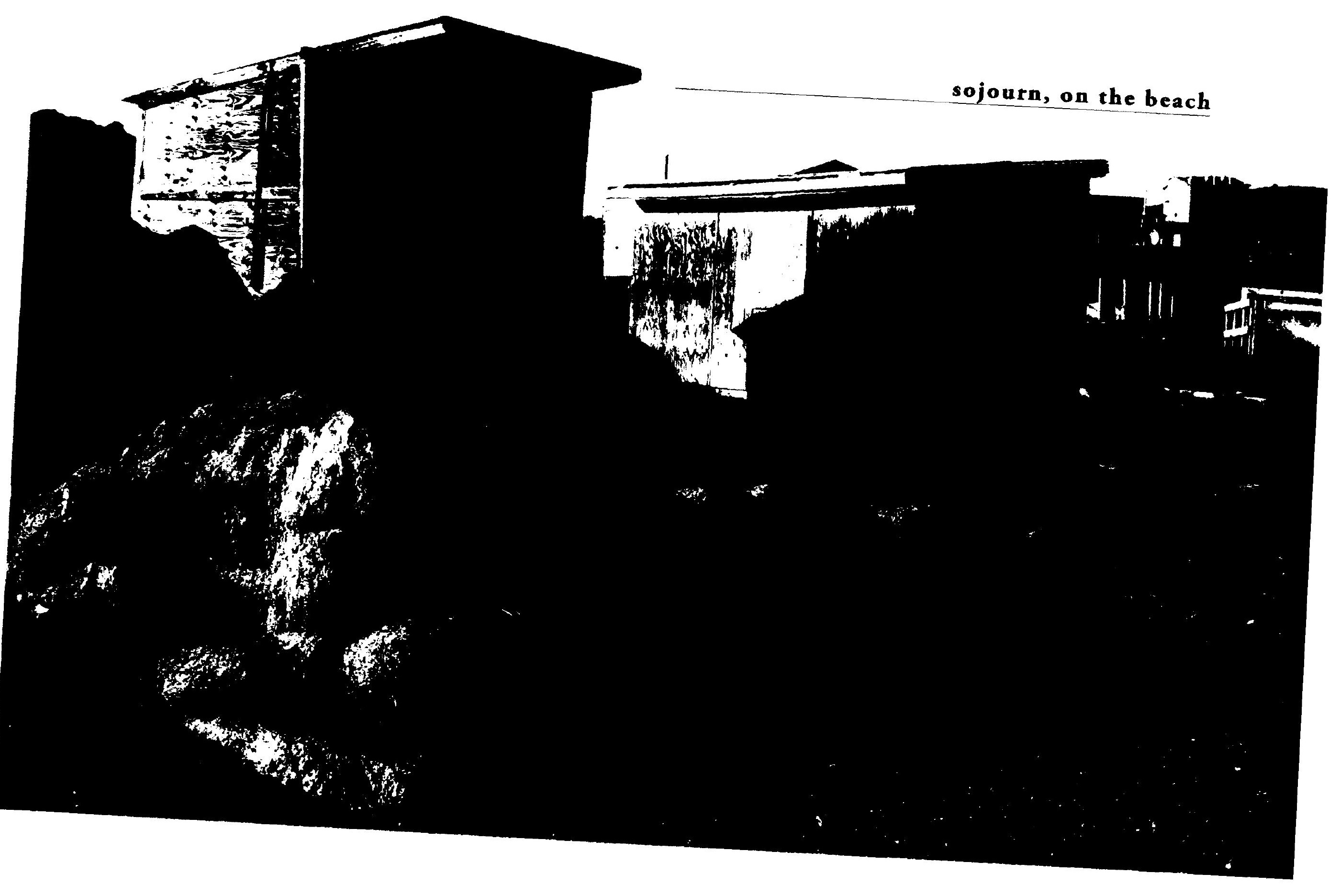




\section{CHAPTER 4}

Every trip in the Arctic begins with the same question; 'What is it like outside?' This of course is in reference to the weather and by extension to climate and geography. But to the architect a deeper metaphor is referenced; outside is contingent, inconvenient, and in the North, it is sovereign. To go outside means leaving the safety of the office, and the rules and guidebooks that tell us what the answers are. Experience and intuition trump such abstract notions in the wild. Winds, tides, snows, and storms require survival-mode decision-making for one's survival. We'd better be prepared to bring some common sense and adaptability. Sila qannuipa?!

\section{going outside}

he southern end of Baffin Island is a dynamic extreme environment and the understanding of it has since time immemorial been a question of utmost concern to its inhabitants. For the Inuit, the reading of the environment was experiential in every respect and taught from a very young age. It is built on a language of sights, smells, sounds, and textures, intimated orally through story, metaphor, and song. Volumes such as Uqalurait: An Oral History of Nunavut by John Bennett and Susan Rowley, have initiated the documentation of these cultural praxis through the compilation of Inuit elder recollections that illustrate the gap between traditional environmental understanding and contemporary science-based readings. The former requires on-theground situating, generational knowledge passing, and 'ecosystem-

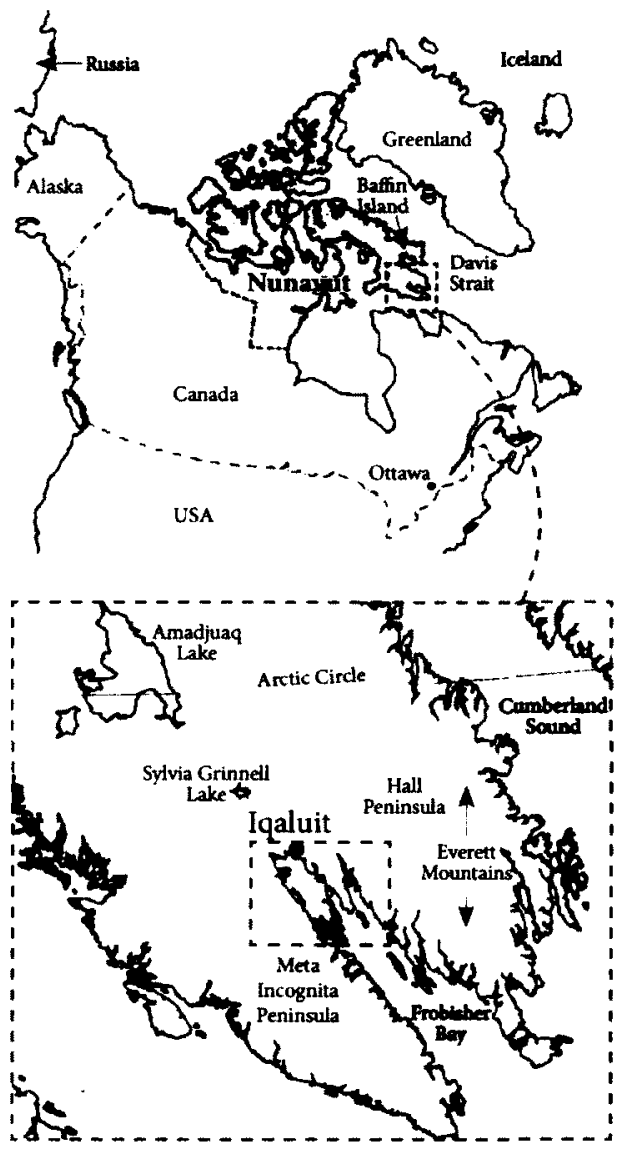

Geographical context of South Baffin Region 


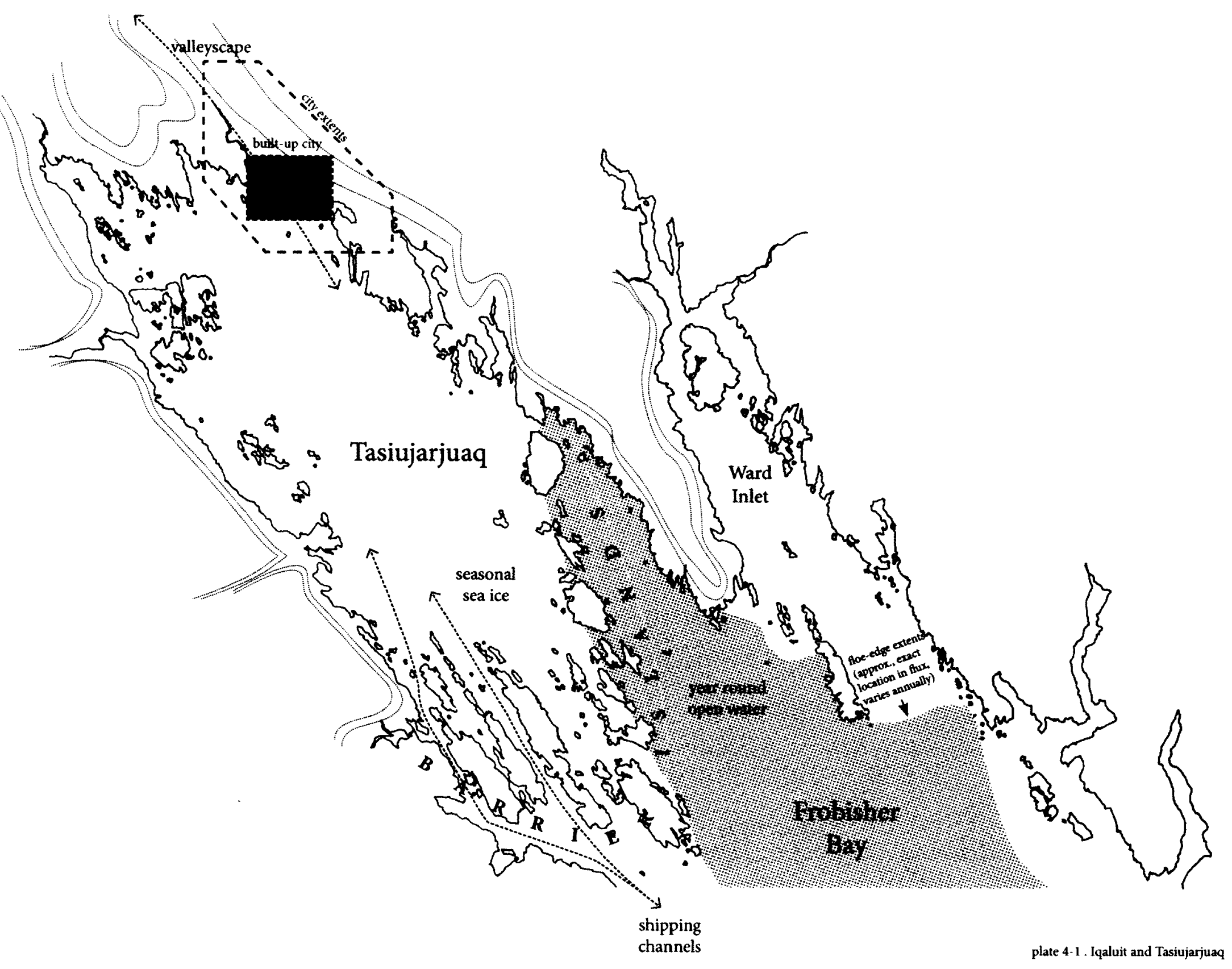



1

John Bennett and Susan Rowley. Ugalurait: an oral history of Nunavut (Montreal: MoGill-Queen's University Press, 2004) 113-125.

Natural Resources Canada, "Terre trial Ecozones." The Allas of Canada 04 Mar. 2009 <http://atlas.nrcan.gc.ca/ auth/english/maps/environment/ forest/forestcanada/terrestrialecozones/ $1>$.

Scott Hatcher, et al. C-Change Work ing Paper: Coastal Hazard Assessment

for Adaptation Planning in an Ex. panding Arctic Municipality (Canada C-Change Secretariat, 2011) 6

culture integration' that most of us will never know.' So naturally, we turn to science for the moment.

Our location, near the $63^{\text {rd }}$ parallel, occupies a subarctic ecozone south of the Arctic Circle (near the $66^{\text {th }}$ parallel) and north of the tree line (around the $58^{\text {th }}$ parallel in its closest proximity). Characterized by its prevalent permafrost sub-grade, tundra ground cover, numerous lakes and ponds, and cold, dry weather, there are no trees larger than willow shrubs. ${ }^{2}$ The region is also affected by its proximity to the open seas of Davis Strait and the Everett Mountains along its eastern coast, which combine to produce consistent and high wind events. In addition, sun angles are affected by latitude such that January darkness can last $18 \mathrm{hrs}$ per day while in early summer, sun light is visible for days and nights on end. Located at the head of Frobisher Bay, Iqaluit is subject to a number of additional integrated climactic phenomena that are relevant to understanding its local environment.

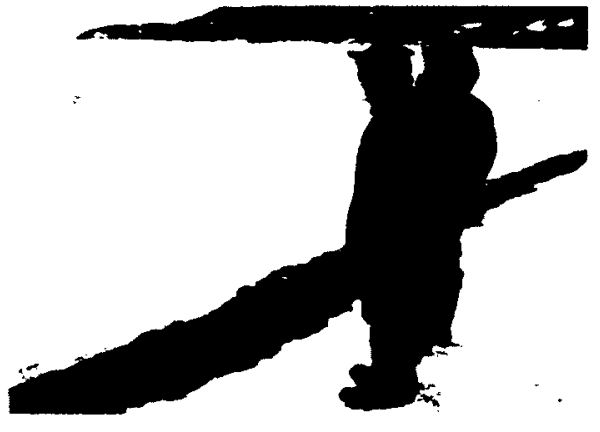

Hunters gauging an ice crack

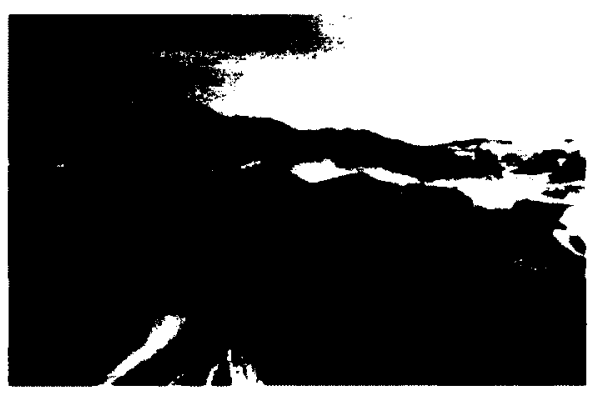

Ice, wind, and snow

Within a global context, this is also a sensitive environment that is highly vulnerable to climate change and as a result is attracting interest from researchers such as the C-Change group who are studying the potential impacts on Iqaluit. Potential hazards to the city that have been highlighted by ongoing investigations by $\mathrm{C}$-Change include increased cyclonic activity, resulting in storms, and changing ice conditions, resulting in flooding and altered hydrodynamics. ${ }^{3}$ Their detailed working papers also provide a platform for introducing the complexities that arise from the intersection of the city and the environment in such a region. 


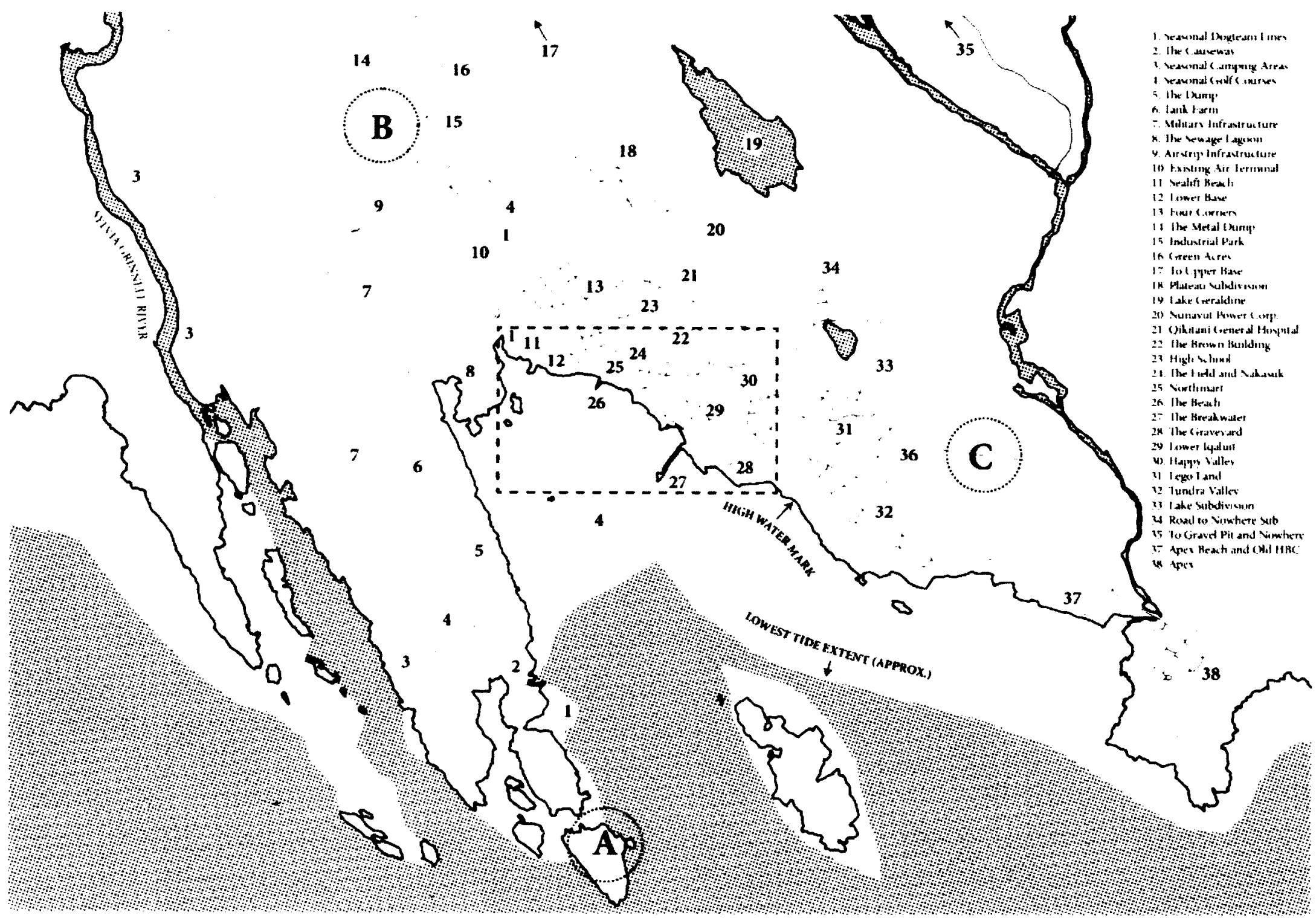

plate 4-2. Common places in Iqaluit 
Topographically, three critical features have been affective in the development of the city. First, the city's founding site sits at the base of a valley, noted for considerable flats that provided an excellent location for a long runway and adjacent base infrastructure. This valley funnels wind such that the airport is relatively free of crosswinds, but the city is affected by consistent to high prominent winds in the SE-NE axis. The city has since developed to encompass the hillsides of the valley to the north, leading to considerable sloping elevation change and resultant challenges to infrastructure provision, including expensive water pump stations and high maintenance winter roads. Second, the city sits on the edge of Koojesse Inlet and is exposed to SE storm events that are funneled up Frobisher Bay from Davis Strait. These storm events from the open sea can produce large and damaging waves which are buffered to a large extent in Iqaluit by a set of offshore barrier islands. The area bounded by the islands and the head of Koojesse Inlet is known as Tasiujarjuaq. Third, the coastal area in Tasiujarjuaq is frequently characterized as macro-tidal with an elevation range of $11 \mathrm{~m}$, the largest in Canada outside of the Bay of Fundy. This is particularly evident in the long shore zone at the Iqaluit waterfront where tidal flats extend beyond $500 \mathrm{~m}$. Since access is high-tide dependent the implications on boat travel are Hatcher 9 significant while there are instances whereby flooding along the city shoreline and over roads has occurred. ${ }^{4}$

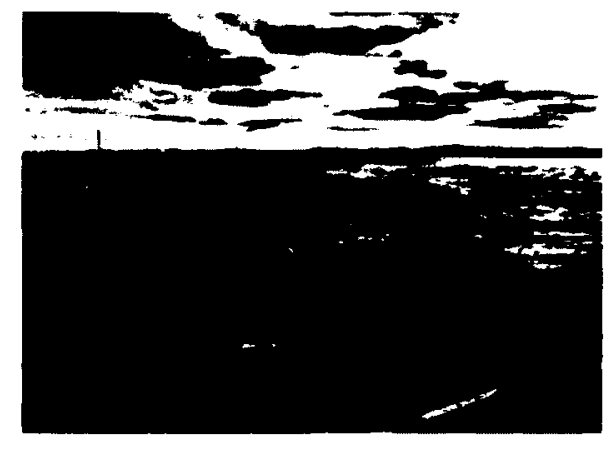

Waterfront at low-tide

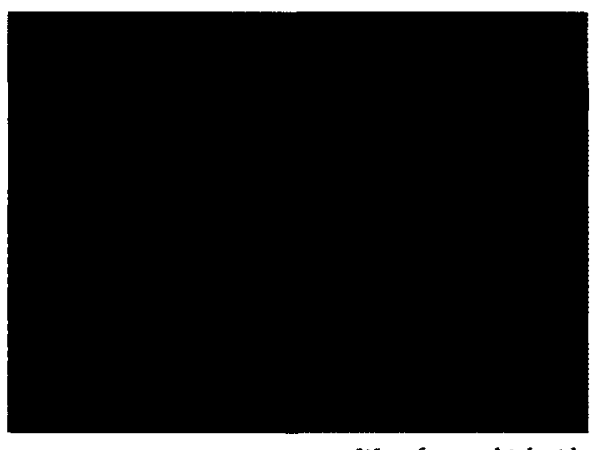

Waterfront at high-tide
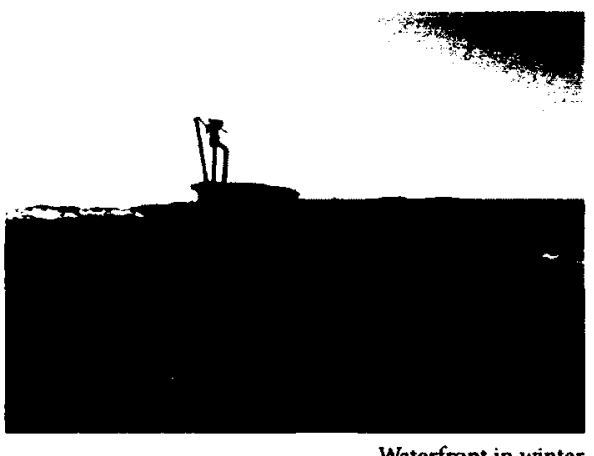

Waterfront in winter 


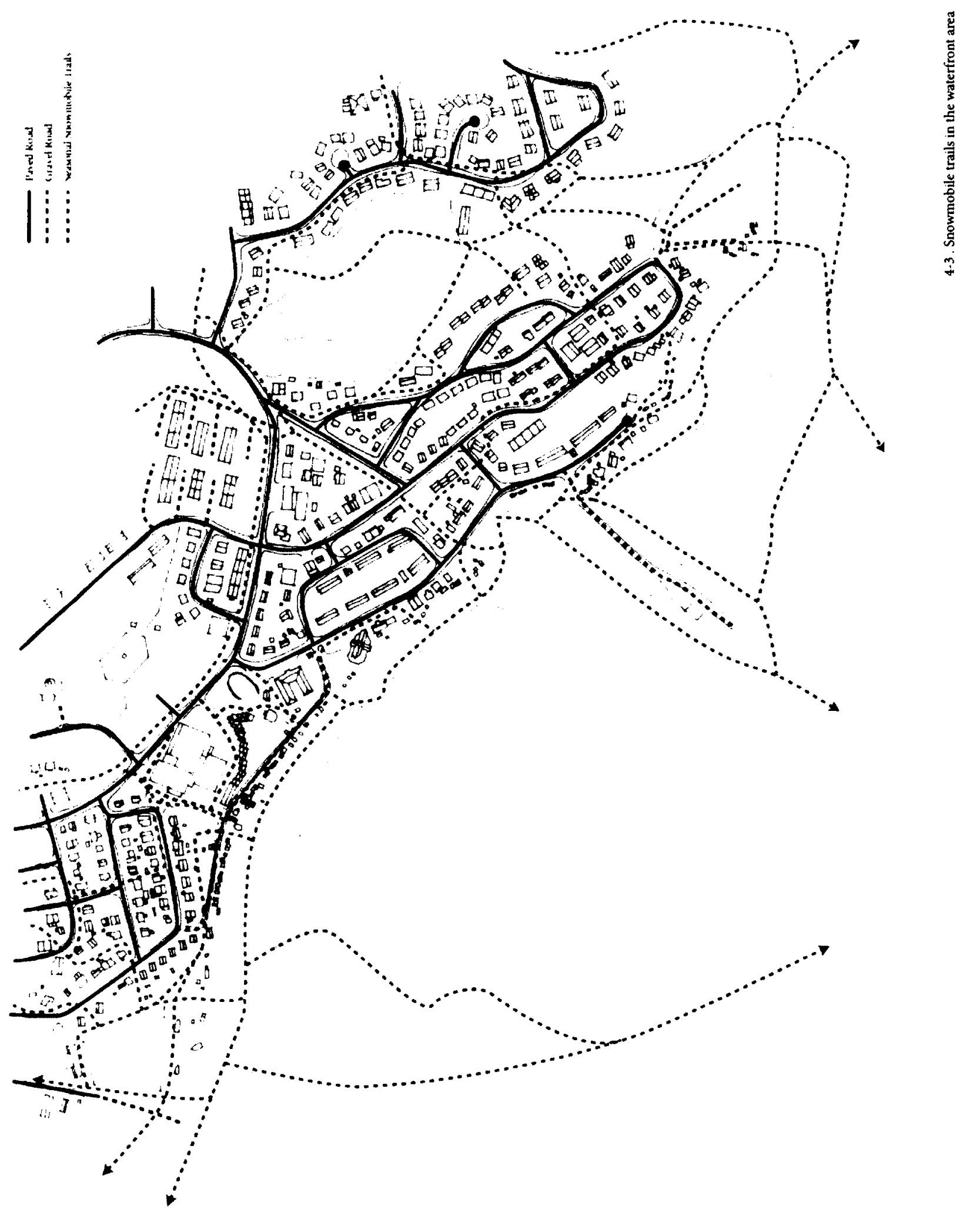


An area of open water surrounde by sea ice. A polynya can be formed by the presence of a heat source that keeps the area from freezing. A more complex process involves wind or ocean currents that carry ice away from the polynya, constantly exposing more ocean water to ice formation and resulting in the release of very salty, dense water that sinks to become part of a halocline. <http://www. thefreedictionary.com/polynya>

pack/pressure ice

Floating sea, river, or lake ice that has been deformed, altered, or forced upward in pressure ridges by the lateral stresses of any combination of wind. water currents, tides, waves, and surf. $<$ http://www.expertglossary.com/ weather/definition/pressure-ice\#>
Compounding these three topographical features is that of seasonal change. Summer is short (July-August), winter is long (NovemberApril), and snow-cover is prevalent in various capacities (on the lee of hills and on the ice) for most of the year. Snow, in its accumulation and drifting patterns, as affected by all of the phenomena noted, in addition to locally built structures, literally changes the groundplane. This is perhaps best understood by reconsidering the valley landscape. Whereas the fixed infrastructure of roads, and cars that can travel only on them, must consistently resist snow-drifting, snowmobiles are relatively free to travel on almost any snow covered

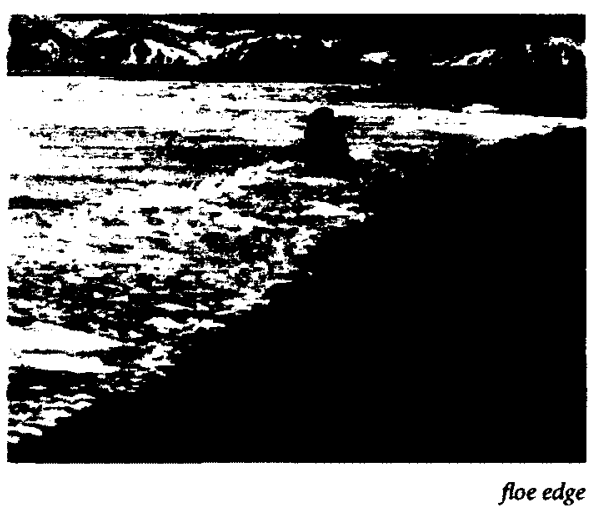
condition regardless of slope.

Ice further alters the landscape through its appropriation of water bodies. Rivers and lakes become flatlands and connective corridors for higher speed transportation; the seaice becomes a new horizon plane. In the larger context this horizon breaks and reforms where underwater and wind born currents are strong, to form hazy edges of solid and hazardous thin ice at floe edges and polynyas that border year round open waters which are as a result high in nutrients and game. For Tasiujarjuaq and its macro-tidal topography this is a horizon that shifts vertically, breaking and reforming into rough pack-ice or pressure ice where the ice comes to rest on the uneven ground below at low tide. These are violent tectonic zones that constitute significant barriers to travel and illustrate the highly integrated interplay of climate, season, and topography. At the shore edge however, is typically found an interfacial zone of land-fast ice called the ice-foot that is a relatively stable level plane and extends the land in many cases for much of the year. ${ }^{5}$ In Iqaluit, the Hatcher 6 shore front has a considerable ice-foot due to the low slope of its beach that literally rescripts the boundary of the city in a regular, yet uncontrolled, pattern. 


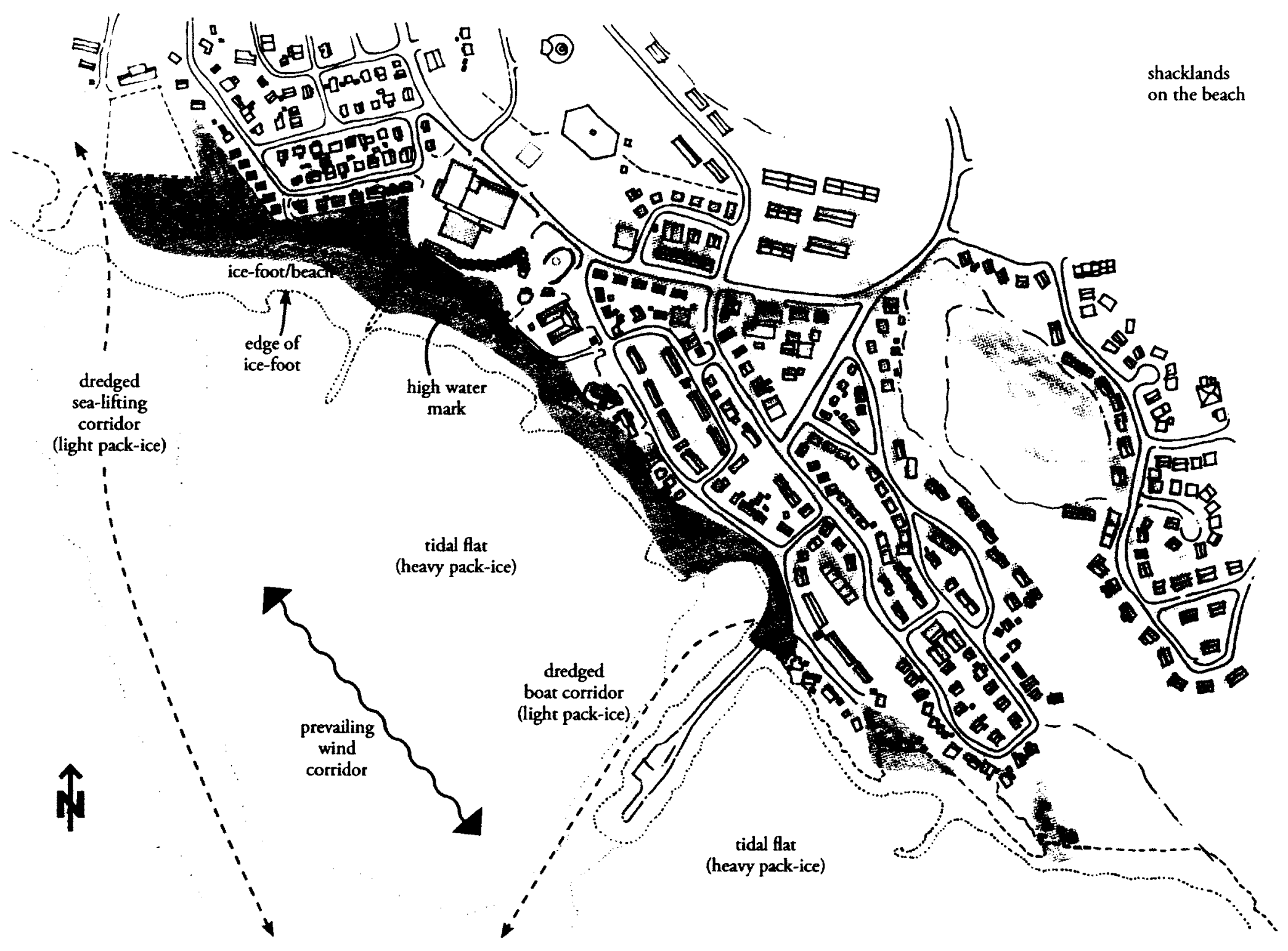


the field In their Summer 2011 publication, the editors of San Rocco Islands conceptualize a realm that exists not between the dialectic of city and nature, but of the inherent interplay it creates as the 'natural domain of the city'. This is a zone that is attributed much of the expansive fringe spaces of the urban realm in less developing countries, the rural-urban interface, wherein they posit a resistant capability of tradition and new condition for architecture and geography. This zone, the field, is a non-architecture, non-architect zone that shares many characteristics with the beach, albeit, in miniature. Architects, "Beach Design Charrette Panels." CSLA Annual General Meeting Aug. 2011.
It is here that my journey begins, on a beach that is also an ice-foot at the edge of the city, in a zone that is in constant negotiation with the environments of nature and of man, realms of contest in their own right. This is not a no-man's land however; for hunters and others of the city who use it, the space has developed into a critical zone that gives form to a hybrid reality. It is a shackland, the dominion of the beach shack, but also of other detritus of the field; boats, sea-cans, oil drums, building supplies, qamutiit, snowmobiles, trailers, and the carcasses of many things both biological and synthetic. In this place you might find the remains of seal, innards out on a piece of plywood, next to a decomposing boat and a shiny new one, while a plastic bag tumbles by in the breeze. You might see children running across the roofline, skipping ice pans; playing with fire. It is a place that seems to be haphazard, unplanned, and crying out for management and design!

At least this is what the members of the Canadian Society of Landscape Architects were faced with during a short design charrette conducted there in the summer of 2011 . Having been a partial participant, I curiously witnessed the immediate response to the task at hand, which was to envision an enhancement of the waterfront; replace the buildings with fire-safe and standardized designed sea-cans, install tourist meeting points, ensure it is authentic (not Disney), install a walking path/boardwalk with lookout, focus on management (trash, density, shack succession, and permitting). The most poignant entry was minimal, just a few arrows and notes that attempted to understand the site and a concessional Statement of Intent: "Any long term changes must be based on long term benefits and incentives for the residents. Ideally, some of the changes would be initiated by the residents. They should come from within and not imposed from without." 


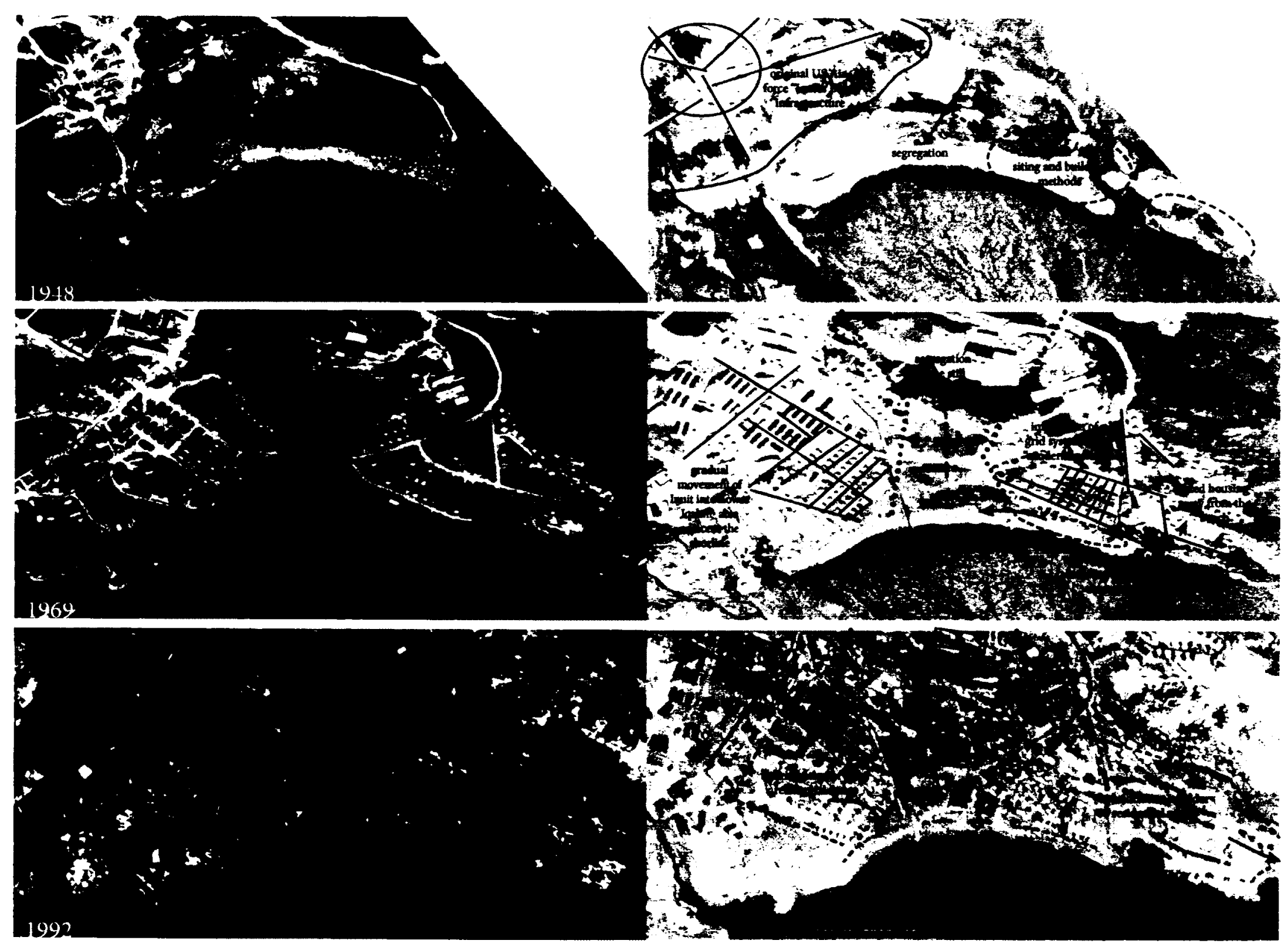


Mellanie Gagnon, et al., Inuit ioaumanirijangit unaliksaiait igaluneniinniri laugtanginni Inuit recollection on the military presence in lqalui (Iqaluit: Nunavut Arctic College Language and Culture Program, 2002) 179.
Is this just a relinquishment of authority? Indeed, most other architects consulted note its potential for a 'unique design project' and are most eager to describe their own formal responses to what is viewed as something that doesn't work. But how can we say that it doesn't work if we do not understand it in all contexts? On the beach, this is the architect's project, making sense of a complex system of space and use with multiple stakeholders and structures of authority and influence.

Historically, the beach exists as a place within Inuit territorial practices, perhaps given additional attention due to its proximity to a prominent summer fishing location at Sylvia Grinnell River as illustrated by the remnants of qammat (sod houses) at nearby the Qaummarviit historical site. The establishment of the US airbase in Iqaluit (then Frobisher Bay) in the 1940's, as consequence of World War II strategic flight patterns, prompted an increase of seasonal settlement on the beach by Inuit near the present-day breakwater, as a response to accessibilities of new material goods in exchange for labor services. ${ }^{7}$ This led to more permanent settlement, despite continued seasonal movement, and the establishment of an Inuit village that incorporated the building of houses from discarded wooden crates and other materials. Concurrently the military had established its own settlement at Lower Base that reached over one hundred buildings by 1957, but maintained strict non-contact segregations with the Inuit village. This relationship is tainted with colonial imperative (as noted in various Inuit recollections) despite generally amicable interactions, however, as the enlisting of men

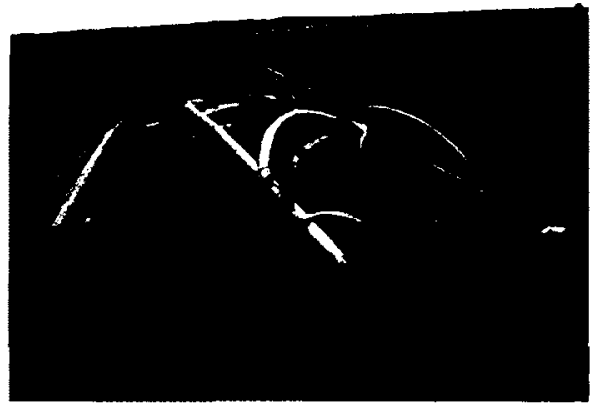

Whale bone qammaq

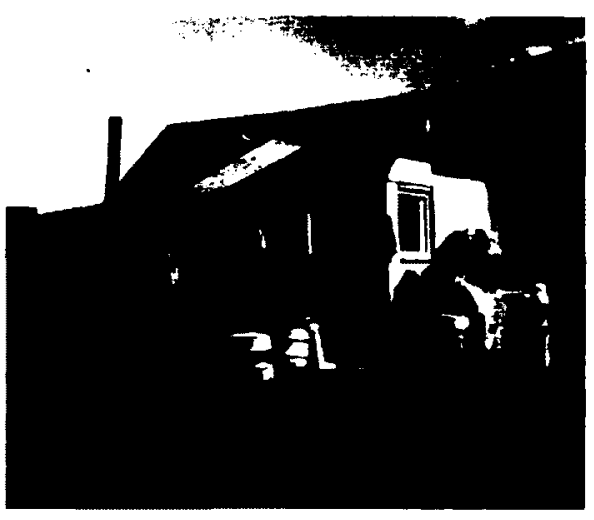

Early house of the Inuit Village circa 1950 


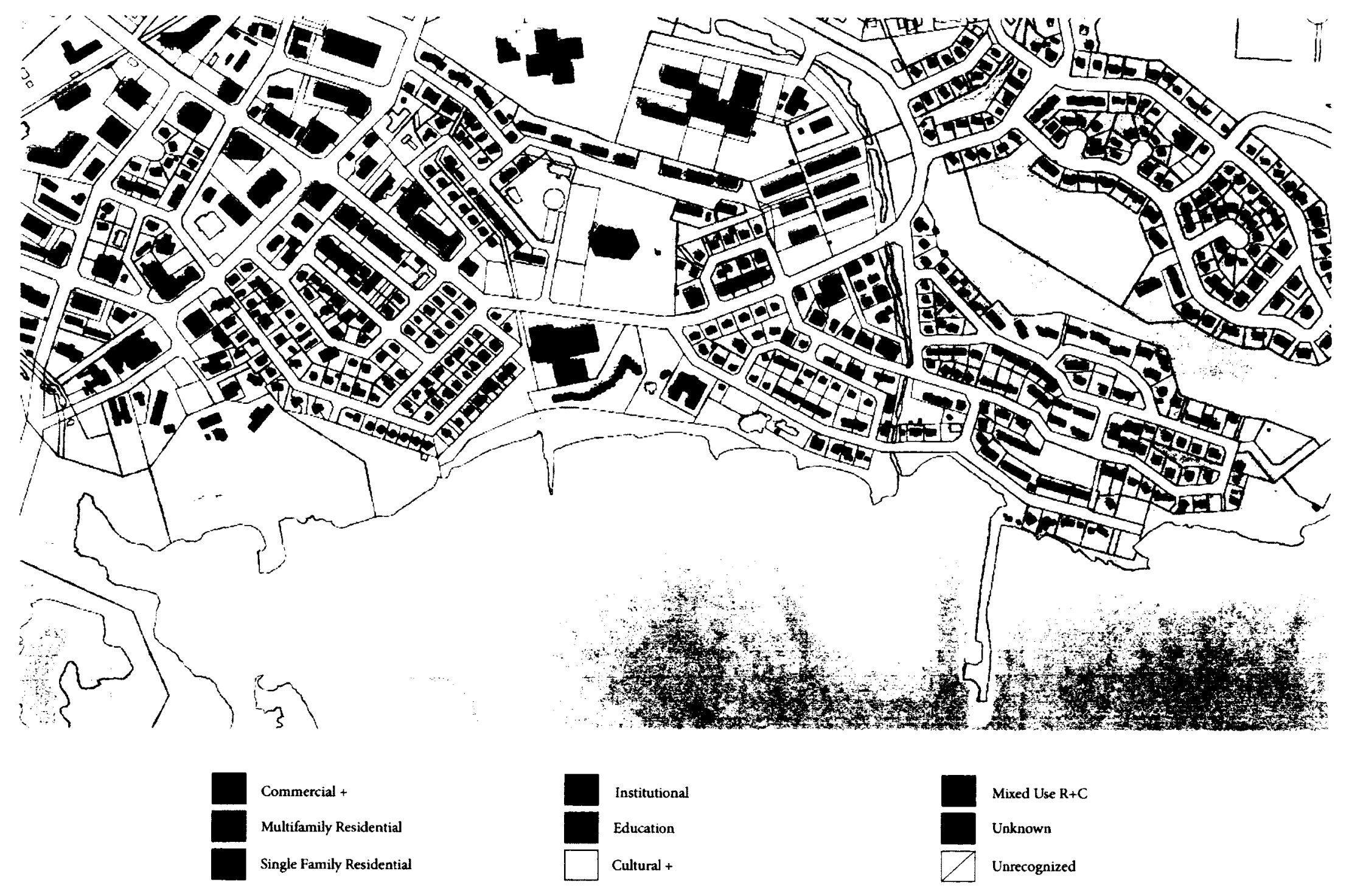



Gagnon 181

Eskimo Suburb Originally established in 1955 by the federal government and was intended to be a separate administrative unit physically distinct from Qallunaat at the base area. The growth of Iqaluit led to neglect and deterioration of the suburb, absorbing most service except for the school. However, new construction, increased levels of car truck ownership, and the acquisition of lots in the area by individuals seeking to take advantage of the community's natural beauty are contributing

to a visible renewal of the area. http://www.qtcommission.com/ac tions $/$ GetPage.php?pageld=118comm unityld =4\# Overview

9

Aerial Photos courtesy, Natural Resources Canada, National Aerial Photo Library, Ottawa.

traditional economy Iqaluit (and Nunavut's) traditional economy is based on harvestin animals, plants and fish. Traditional

harvesting is based on the use of knowledge (IQ) for productive purposes. This knowledge of the land can be applied to new economic opportu-

nities - eco-tourism, environmental monitoring, resource management, security, prospecting for minerals even film making. Harvesting can help

build the foundation for economic growth in other sectors.

http://www.lookupnunavut.ca/tradi tional.htm changed social relationships and established hierarchical authority including the movement of Inuit into army-built houses. ${ }^{8}$

The takeover of the town by the Government of Canada in 1953 led to increased numbers of Inuit from the surrounding area and Qallunaat from the south. Despite efforts at continued segregation, including the establishment of an Eskimo Suburb in Apex, the Inuit village on the beach continued to intensify and was subject to planning and government housing schemes that pushed dwelling away from the water edge. These schemes were not totalizing however, recounting the hybrid reading of Renwick's project and shack development outside of government units; informal settlement and construction in relation to a Hunter lifestyle continued Inuit representation on the beach, which is clearly evident from historical aerial photos. ${ }^{9}$ With the relocation of Inuit into houses further and further from the beach, as formal development occurred, the shacks and equipment on the waterfront grew into an excluded space of cultural production; a new space in the city from an old space. Why?

The shacks represent a programmatic shift from dwelling places (for the most part) to storage and production places that are spatially related to the beach rather than to the requirements of Western infrastructure and planning. As well, they are in essence a continuation of nascent construction practices borne by the availability of materials, typically in re-use capacities. And finally, perhaps most ironically, they represent a relatively fixed countenance of a hunter's identity (and that of his family) as part of what is now being dubbed the traditional economy. We might then read these shacks as fixed spatial moments of authority in an otherwise unstable arrangement of housing shortage, socioeconomic change, and minimal property ownership. 


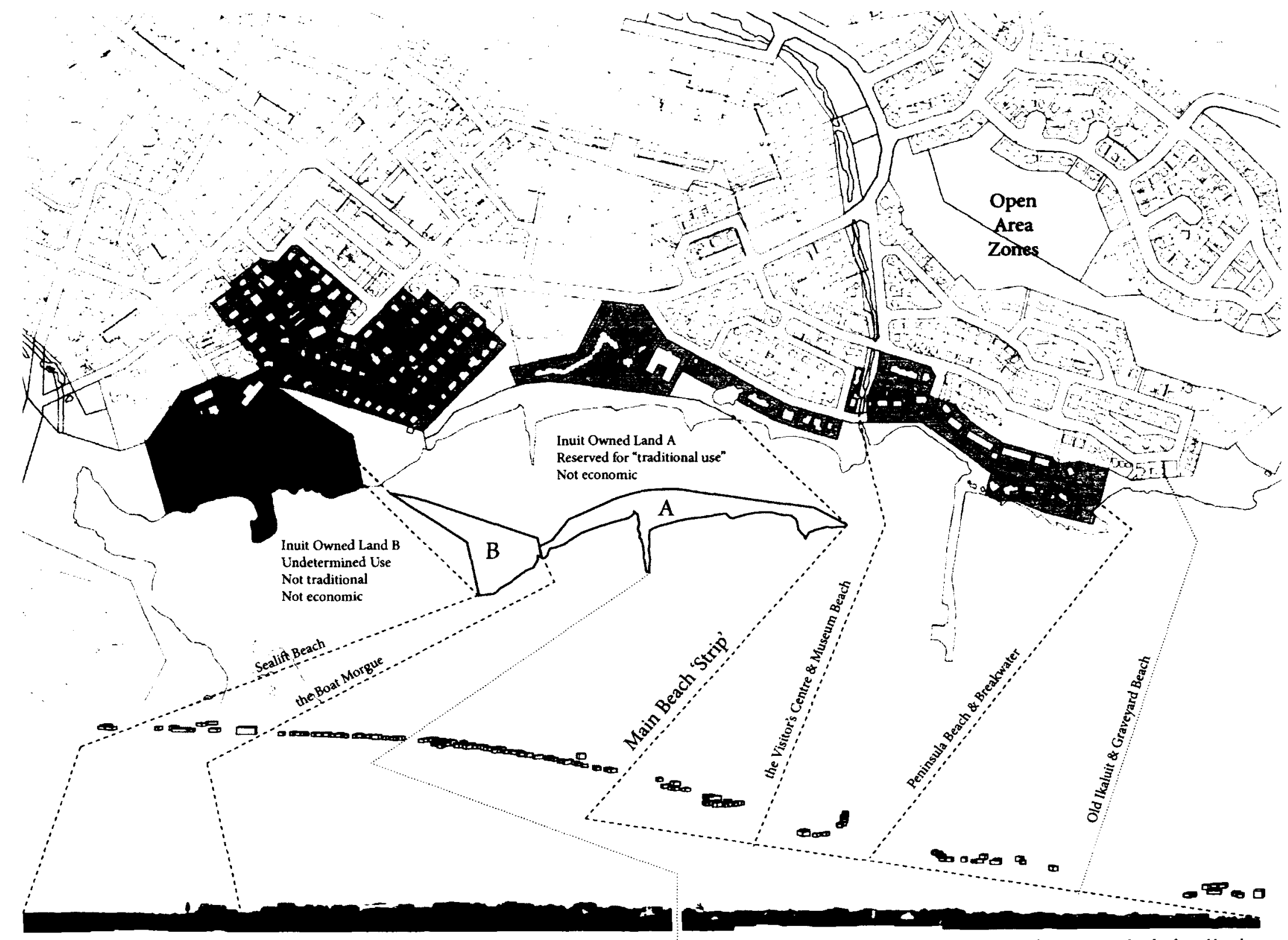

plate 4-7. Formal and informal beach zones 

lonialism and the City (New York. Routledge 1996) 28.

Open Area Zones Allowable uses in this zone include cultural interpretation centre, dog

area, park, beach shack, camping structures, temporary utility installation and firing range.

City of Iqaluit "By-law 704" Zoning By-Law (Iqaluit: City of Iqaluit) 81 .

Canada "Section 14.5.1" 12 Between the Inuit of the Nunavut Settlement Area and Her Majesty the Queen in the Right of Canada 130
Let us now return to agency. This 'fixed spatial moment of authority' is also a moment of agency for the builder-owner in a political capacity that illustrates urban theorist Jane Jacobs key issue with Homi Bhabha's concept of hybridity. In Edge of Empire: Postcolonialism and the City, Jacobs criticizes Bhabha for not doing "justice to the politics of contestation, expressed, at the very least, as tactics of subversion but at their most collective as collective insurgencies." 10 This may seem to be strong language with regards to the issue at hand but it is evident that today these beach shacks go beyond simply subverting a latent suburbanism. In this sense it is worth identifying the beach development as an indication of hybrid reversal, that is to say, a process of space making that has evolved out of a specific locality, was borne of hybridity, and is oriented towards politically charged cultural production. What then are the contemporary conditions of this place?

Today, the waterfront can be segregated into five distinct sections, from West to East; the Sealift Beach, the Boat Morgue, the Main Beach 'Strip', the Visitor's Centre/Museum Beach, the Peninsula Beach/Breakwater, and the Graveyard Beach. While each of these areas is home to shack development, there are varying by-laws and policies that affect them. The City of Iqaluit has an overarching concern in all of these areas and has delineated them as Open Area Zones with the exception of the sealift beach which is a Transportation Zone. However, the latter is also subject to Federal transportation guidelines that take precedence over Municipal authority, while two zones in the former are on Inuit Owned Land (IOL) administered by the Qikiqtani Inuit Association (QIA)." Furthermore, the beach is subject to the " 100 foor strip" rule in the Nunavut Land Claims Agreement (NLCA) that extends inland from the ordinary high-water mark to delineate a zone of crown land that shall be administered and controlled by the Commissioner for the use and benefit of the municipality. ${ }^{2}$ One result of these intertwined and layered planning geo- 


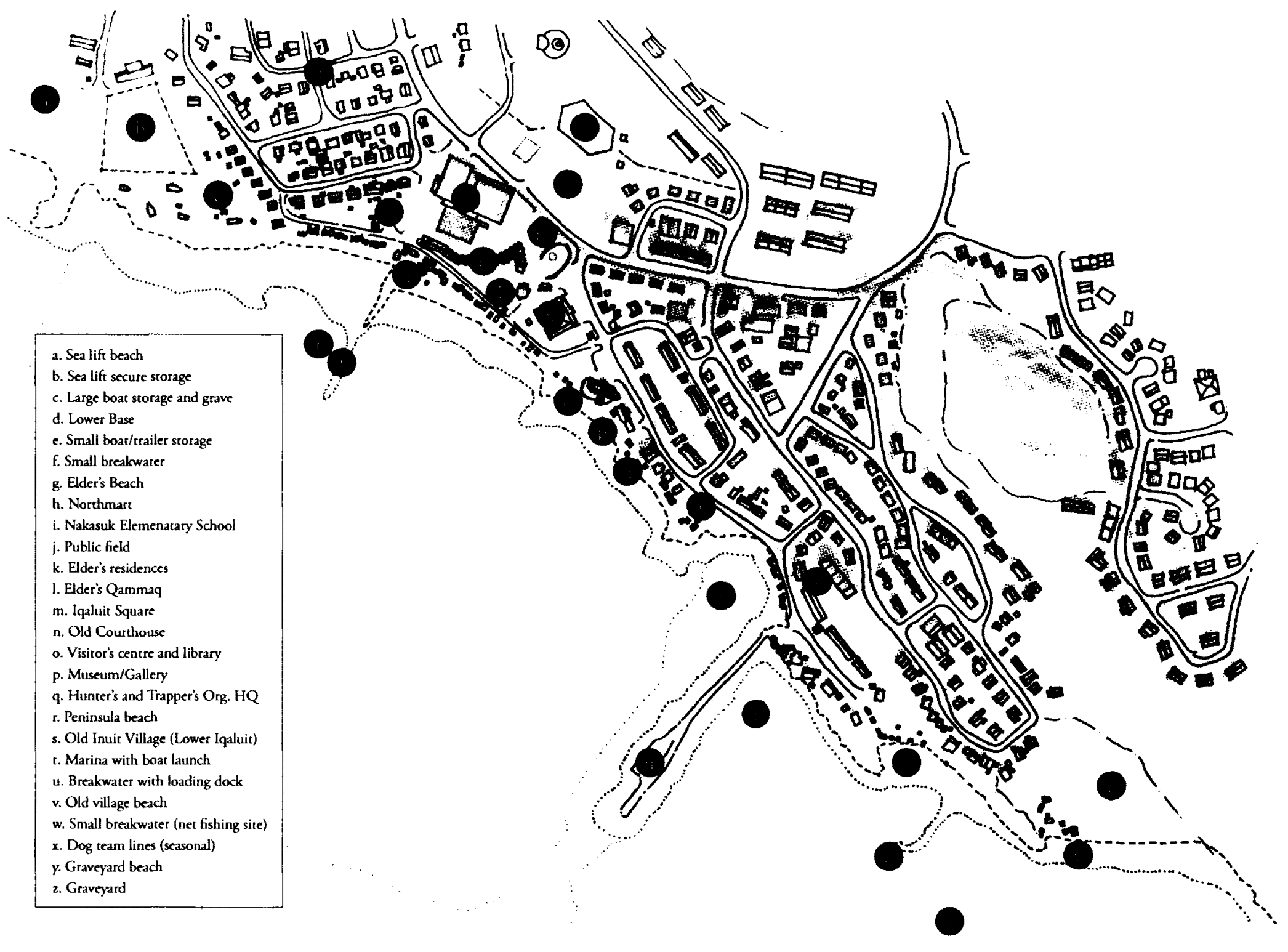

plate 4-8. Places relevant to the beach 
free-space theorist Lebbeus Wood's concept of architectural reinhabitantion of ruined buildings and spaces in post-war cities. Of this he notes "I had hypothesized that " $90 \%$ of the

damaged buildings would be restored to their normal pre-war forms and uses, as most people want to return to their old ways of living .... but $10 \%$

should be freespaces, for those who did not want to go back, but forward.

The freespaces would be the crucibles for the creation of new thinking and

social-political forms, small and large. http://lebbeuswoods.wordpress. com/2008/02/06/the-reality-of-

theory/ William Hyndman, Tom Critelli, Qayaq Ellsworth, Matty McNair Lucassic Peter "Personal Interviews" Aug 2011-Feb 2012. policies is the lack of a visible and active authority for the waterfront as a whole. Indeed, the City has only in the last year begun to take an active leadership role with regards to the management of the beach through the instigation of a series of bureaucratic and public meetings that focused less on the issues of land ownership than on shack management as a function of public safety and waste control.

The crucial difficulty of developing policies across this zone is the understanding of the shack users and their attitude towards policies that govern traditional use of space as embodied by the beach shacks. Both the Hunters and Trappers Organization (HTO) and the QIA have noted that the planning rules in Iqaluit are much more stringent and numerous than in other Nunavut communities but that they are not communicated, nor enforced. Anecdotal evidence gathered from discussion and interview with various shack and cabin owners tends to support the lack of communication, or rather the lack of consistent communication, with respect to leasing, permission, proximity, and other issues. ${ }^{13}$ Enforcement is particularly difficult as the definitions with regards to the temporal and programmatic use of the structures is open to interpretation. For example, determining whether or not a beach shack is used as part of the traditional economy rather than simply for household storage or intermittent dwelling is a marginal exercise; the differences are blurred because the traditional economy is based on an informal lifestyle. QIA Lands Administrator Salamonie Shoo whose department is responsible for the IOL parcels at the Strip and the Boat Morgue has indicated that the owner/user group is highly diverse in age and background (though most are Inuit), but that it has been extremely difficult put together 'a list' and register owners to a tax-free lease to facilitate management responsibility. ${ }^{14}$ These difficulties point back to the beginnings of the beach shack as a hybrid development; a tactical subversion in a strictly hierarchical system; a free-space. 


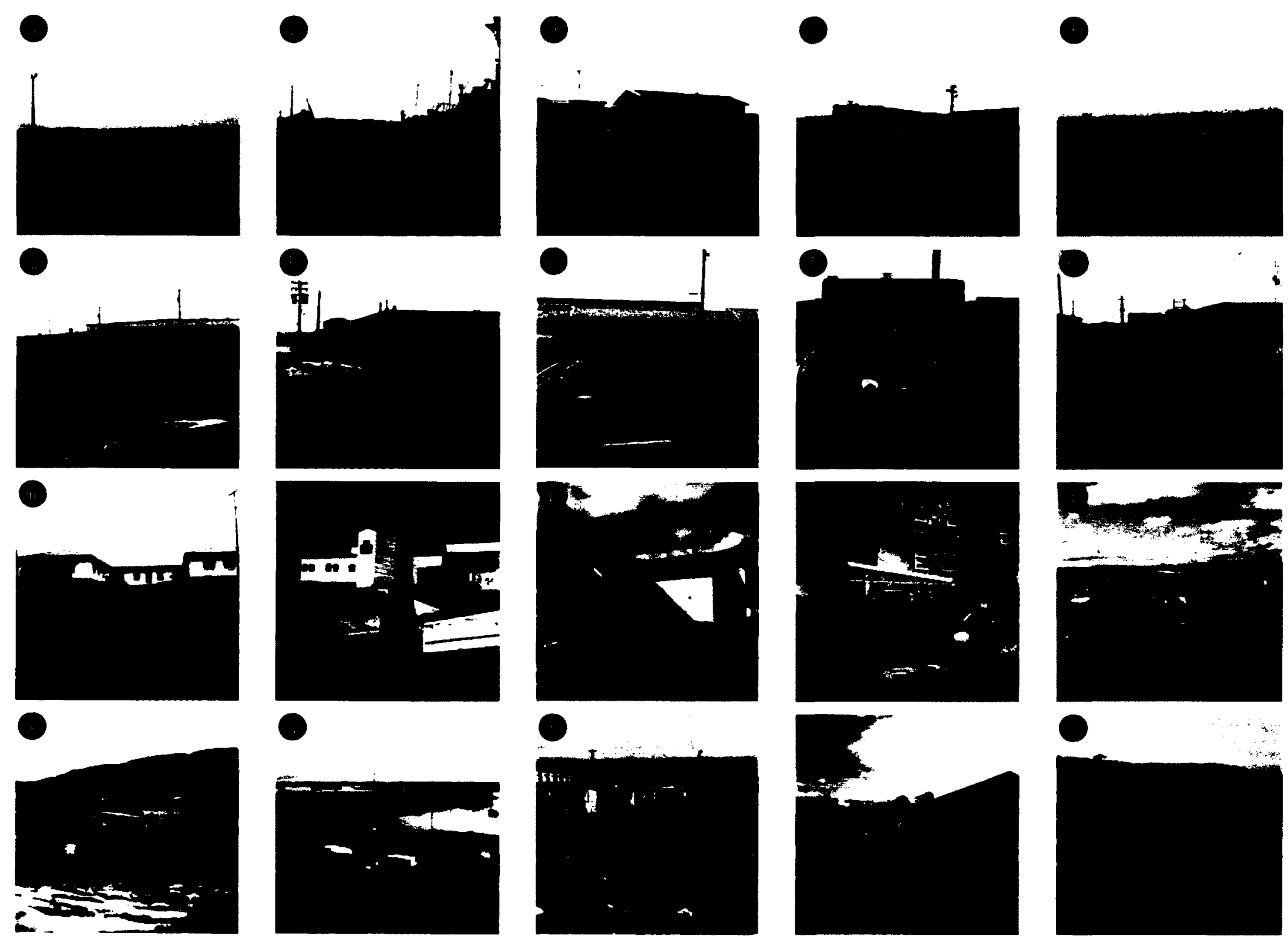


This free-space is far from utopian however; one need only to peruse the local broadsheets (Nunatsiaq News and News North) for an ongoing account of vandalism, theft, arson, and overt substance abuse on the beach. Without formal management, shacks are densely arranged and sometimes crudely built, often using salvaged materials, while fuel storage is often readily accessible to anyone with a lighter and a motive. Despite these issues there is one confirmed permanent family (Joe Timmotee and his wife) living on the beach according to Mayor Redfern, though anecdotal evidence suggests there are at least two more currently and possibly five to ten more seasonally. In a city and territory rife with homelessness the beach is an overflow zone. When pressed on the subject during a personal interview, Salamonie Shoo (also a shack owner) indicated that rather than view these squatters as perpetrators, they might be better thought of as 'eyes and ears' that help to discourage crime as they seek respite from couch surfing their way through the city; his only fear is for their safety. ${ }^{15}$

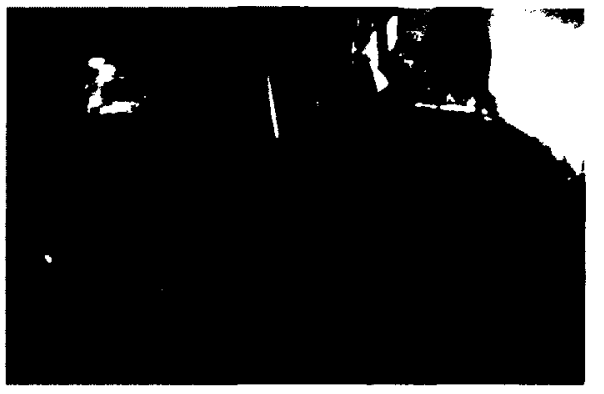

Inside joe Timmotee's shack

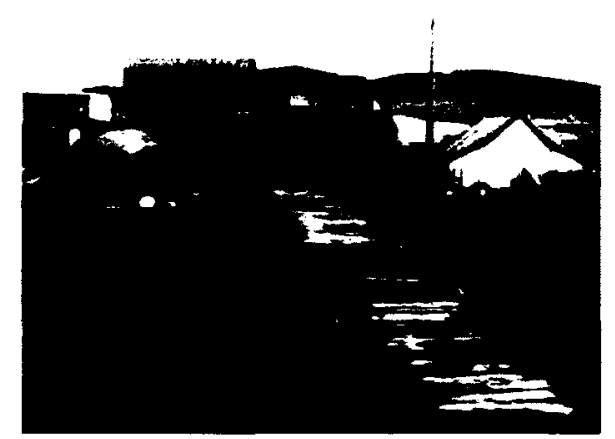

Homelessness and seasonal dwelling

Perhaps we should interpret the waterfront in simple terms as the result of a series of individuals acting separately yet similarly, and as such the beach shacks represent over one hundred itinerant points for Iqaluit's hunting community. Of course, this assumes that the intended use of said structures is reflective of a basic and implied interpretation of the Municipal By-Law, in that they are used to support the individual's participation in the 'traditional economy'. Notwithstanding the inherent contradictions of the term, this means a place to store hunting supplies. In this capacity it cannot be understated how much accumulated value these shacks represent. They are often built by their owners, or 
A Taste of Beach Activity (as shown from left to right top down)

sealift cargo marshalling and loading

boat repair

hunting preparation

snowmobile travel

ice-pan hopping

kite skiing

maintenance of equipment (fishing nets) seal skinning and storage
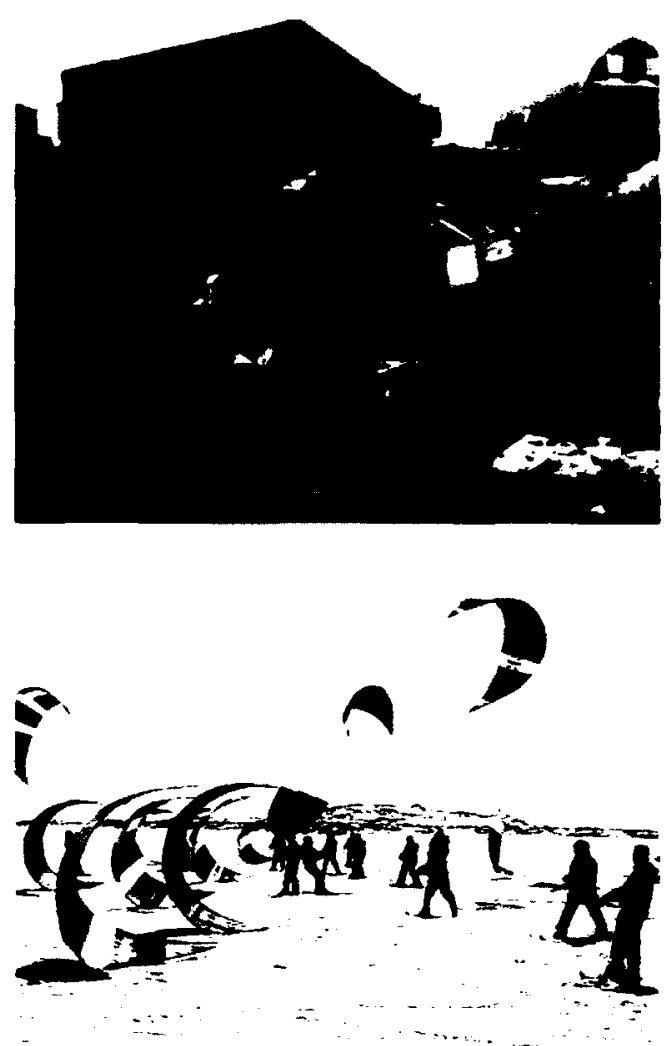

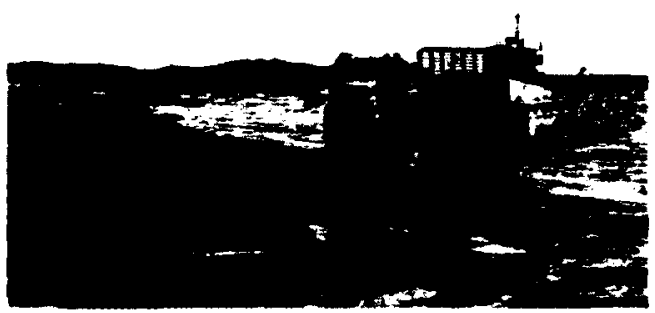

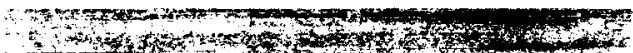
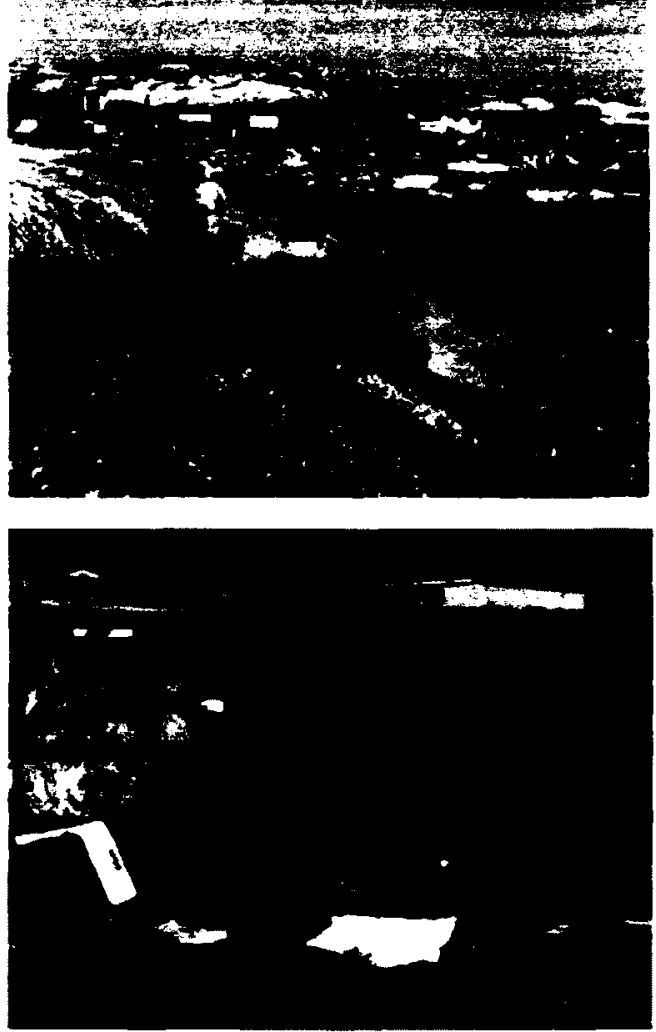
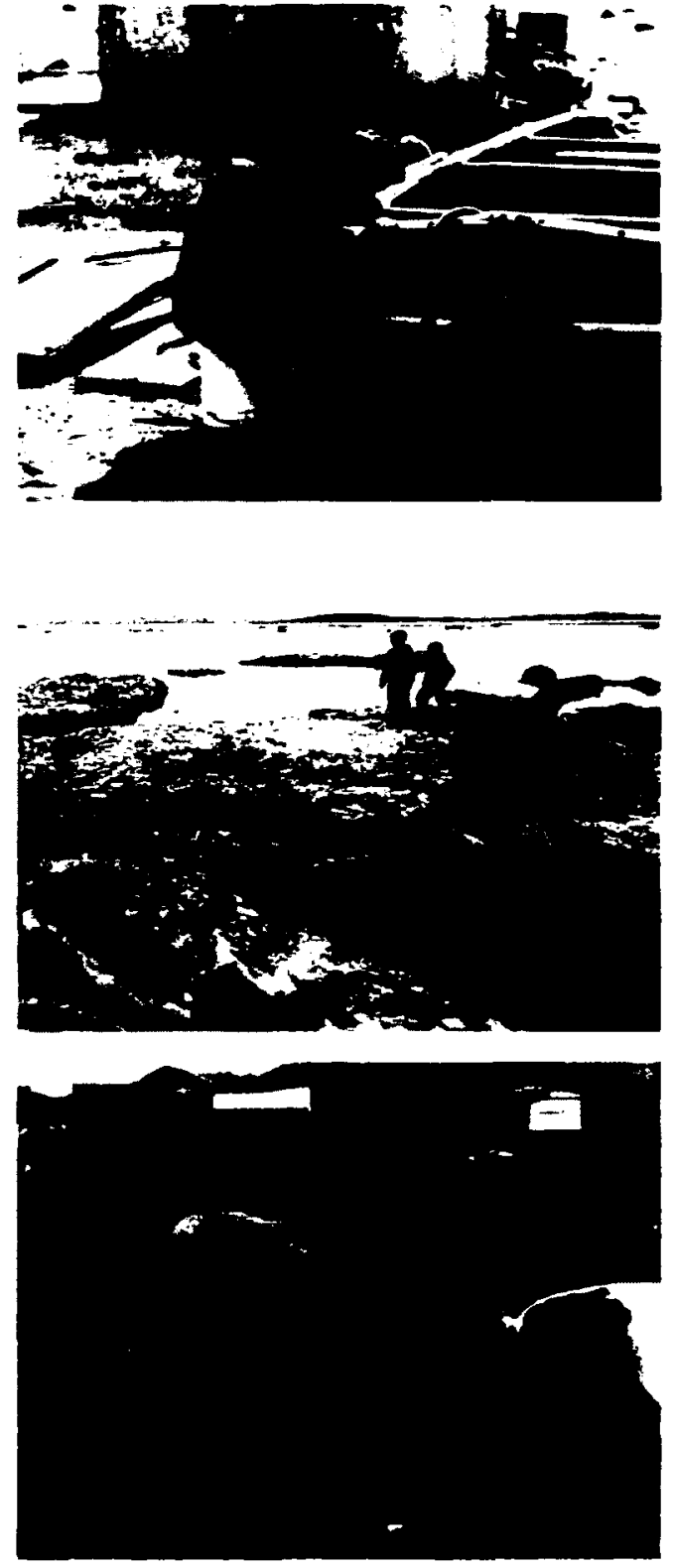

plate 4-10. Photo narrative of beach activity 
John Ralston-Saul A Fair Countron Telling Truths About Canada (Toronto: Penguin Group 2008) 295 . David Monteith "Personal Interview"
Aug 2011 . handed down from parents or family and are sites for the building and storage of hunting tools and other material living on the land. Further to this, when Ralston-Saul laments about the lack of investment in arctic specific snowmobiles, he illustrates the need for hunters to modify almost every piece of equipment to the demands of arctic climate and thus the motivation towards environmental ingenuity. ${ }^{16}$ While of a typically small size (roughly $8^{\prime}$ to $12^{\prime} \times 12^{\prime}$ to 20 ' dimensions) the beach shack may contain tens of thousands of dollars in accumulated equipment while the materials and artifacts that are crafted, handed down, and gathered over generations of hunting of equal or greater value in cultural, social, and intellectual

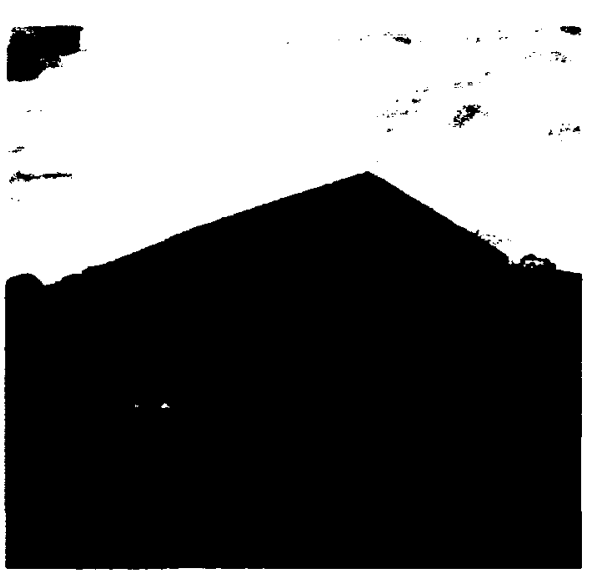
capital.

But is this too simple and pure a rendition however to be representative of the body of the beach as a whole? How can we define what the parts of the hunter lifestyle are with the complex and culturally differentiated reality of contemporary Iqaluit? Indeed, many of the accessible and dilapidated shacks that were witnessed had relics of this blended world; spare tires, fishing nets, kid's toys, construction materials, etc. It is in this sense that the Government of Nunavut Director of Parks, Trade, and Tourism, David Monteith has expressed serious concerns that the waterfront is turning into a 'warehousing zone'. ${ }^{17}$ Without policy and enforcement capabilities from authority, the only mechanism that can regulate the programming of the area is the users themselves. While there are formal examples of this, usually through the exposure of offenders to authorities via complaint (as noted during an interview with City Planner Arif Sayani in August 2011) it remains unclear how much communal planning actually occurs. It is clear however, that beach shack 


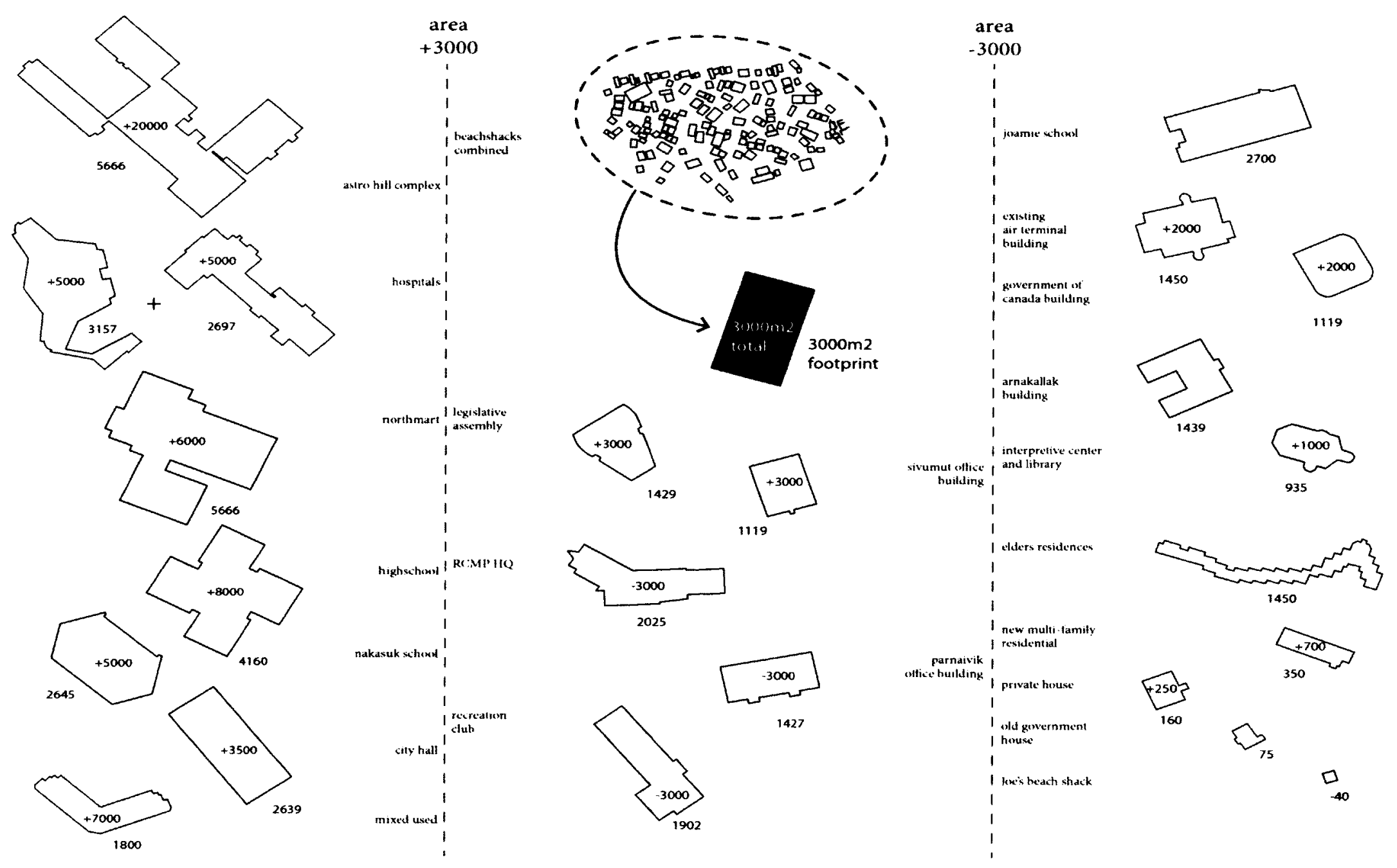

plate 4-11. Area analysis of beach shacks in context of Iqaluit's architecture 
owners identify with the shacks in a deeply rooted way that belies their humble stature, and that they continue to use them. Is this because they represent a built and manifested connection to an ancient and endangered culture? Partly to be sure, but perhaps it has something to do with self-determination, with building for one's self just as one hunts for one's self.

Present issues in the beach zone, vandalism et al., together with increased home ownership, access to higher income jobs, technological improvements to transportation, and the development of communal facilities over the past twenty years have seen an evolution in the dynamics of beach use. More often shacks are built near houses. Some beach users can afford trucks and trailers to facilitate the movement of large and numerous equipments. Just as dog teams are no longer a primary mode of on the land transportation, old snowmobiles and freighter canoes of earlier eras are being phased out to some degree in favor of larger, faster, newer, and significantly more expensive models. These changes are not insignificant to patterns of beach use; freighter canoes for example were maneuverable by hand and were often beached directly shore side of the owner's beach shack strengthening the connection of place. Infrastructural improvements such as the road along the shorefront and, most significantly, the development of a breakwater, have changed the direct nature of many of these relationships as now large boats can be launched and loaded more efficiently, left in safe harbor, and accessed during earlier tide swells. In combination with owners moving away from the community or deaths to previous owners this has resulted in an obvious number of unused shacks that are falling into decay. Monteith illustrates this evolving use of shacks through his recounting of the events surrounding the building of the Visitor's Centre and Museum in the 1980's during which some 40 beach shacks were removed with little fuss from the community. ${ }^{18}$ This is not to suggest that the use of beach shacks is dying 


\section{The Costs of Hunting}

The following cost estimates are drawn from Clyde

River 200446. This is a basic "all-season" outfit and some

harvesters have boat \& motor combinations that can cost more than $\$ 30,000$

Typical Outfit (rounded to the nearest $\$ 100$; no GST)

\section{$22^{\prime}$ freighter canoe $=\$ 8,100$}

Snowmobile (Bombardier Scandic model) $=\$ \mathbf{\$ 8}, 700$

55hp Johnson outboard motor $=8,200$

90hp Honda outboard $=12,300$

Canvas tent $\left(10^{\prime} \times 12^{\prime}\right)=550.00$

Coleman stove $=130.00$

$.22-250 \mathrm{cal}$ Remington rifle (w/out scope) $=1,100$

$.22-250 \mathrm{cal}$ ammo $=50.00$ (box of 20 rounds)

Honda 4-Trax ATV $=9,200$

Woods 3-Star sleeping bag $=\mathbf{4 0 0 . 0 0}$

Socket set (for engine $\& /$ or suspension repairs) $=100.00$
Typical 2-Day Snowmobile Hunt ( $n=4$, mid-June): Ave. Cost $=\$ 200.00$

\section{Gas $=20 \mathrm{gal} / 578.00(19.50 / 5 \mathrm{gals})$}

Motor oil $=38.96(9.99 / \mathrm{L})$

Coleman fuel $=33.00(5.50 / \mathrm{L})$

Misc. food (biscuits, tea, soup, canned meat)

$$
=\$ 30.00
$$

Ammo expended (avg. 3 hunts) $=@ 20.00$

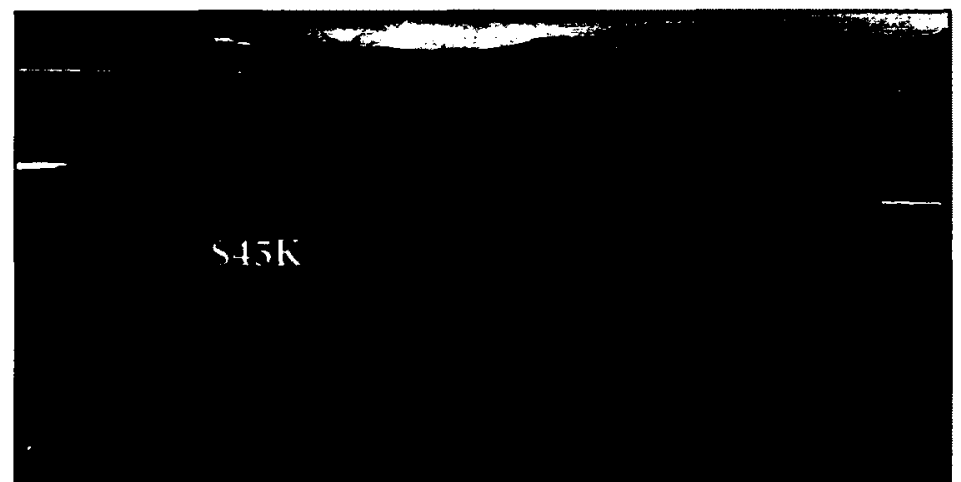

Replacing a Shack

While it is difficult to accurately estimate the value of a shack and its contents there are some reference points as noted below and left. However, in terms of the shack itself, we might better look to those that the Municpality supplied as part of a program to support hunters in the early 2000 's. These units (form shown above) cost $\$ 45,000$ each

\section{Things that might be found}

\section{in a hunters shack}

Hunting implements including, tuuruq Garments including, skin outerweart, (ice chisel)*, nitsiq (gaff)*, harpoon*, qamiks (skin boots)*, skin mitts* pardetachable harpoon heads*, bulles, seal nets, buckets, tubs, bullets, seal nets, buckets, tubs, tarpolines, canvas, steel traps, binoculars, scopes,
seal blind", decoys, burlap for goose blinds* ${ }^{*}$ goose calling devices, knives" snow-knives, handheld GPS, Spot de-
vice, satellite phone, rifle scopes, qamutiq (sled) and or parts*... thets, sheets, sleeping skins", foam matnets", rods, lures, hooks, lines, ice jig- tresses, old cushions, pillows.. gers*, augers, kakivak (fishing spear)* bouys, floats, buckets, knives. dles, electric lamps, pressurized fuel spray skirts kayak paddles, ayas, lanterns, head lamps, flashlights, local flares, depth finders, lifejackets, small lamps with extension cord.
Fuel including, gasoline, naptha (white Tools including, wrenches, sockets, Miscellany including, 2-way CB radio gas), propane, butane kerosene, bat- handsaws, chisels, planers, files, nuls/ and antenna, household extraneous bolts, nails, hammers, pry-bars, rope materials, paint, wood, stcel, teflon (lo varing) vises, some powertools (re- various devices/machines/appliances/ floating),vises, some powertools (re- various devices/machines/appliances/
ciprocating saws/jigsaws/beltsanders/ vehicles, plexiglass, windows, insuciprocating saws/jigsaws/beltsanders/ vehicles, plexiglass, windows, insu-
dremmels), carving tools, welding lation (rigid and fiberglass), booze, outboard motors, old snowmobile en- dremmels), carving tools, welding lation (rigid and fiberglass), booze,
gines, generators, replacement parts, torches and equipment...
snowmobile camouflage*, fuses, sparkoutboard motors, old snowmobile en- dremmels), carving tools, welding lation (rigid and fiberglass), booze,
gines, generators, replacement parts, torches and equipment...
snowmobile camouflage*, fuses, sparkplugs, snowmobile belts (old and new), Dogteam equipment including, dry cutlery, coolers", dry and canned food, old snowmobile tracks, electrical wire dog food in large quantities, old meat frozen meat and fish*, drying skins* and equipment, snowmobiles, ATVs, (usually seal or walrus)*, whips*, har- skin racks* first-aid kits, spare naput spare tires, windshields, hitches... nesses*, lines, chains, line anchors*, (sled parts)*, water containers, fabrics of various kinds, sheet metal, spare hitches for sleds*, bones and antlers. freezers, toys for children, mosquito spray and coils, drying seaweed, dam buckets, clam spades. 
but rather that it is changing dynamically as a response numerous factors relative to the city; the most densely developed and most obviously used section of the beach is directly adjacent to the Elder's Residences along the shorefront road where owners can run power lines from government subsidized buildings.

If we look at present long term planning projections by the City, four key development projects are seen as drivers for the next phase of urban evolution; a new residential subdivision on the road to Apex adjacent to a new Commercial-Institutional Core Zone anchored by a new legislative assembly; a new Transportation Core Zone anchored by an international air terminal building to the west; and a new Port Zone anchored by a seasonal deep water port on the opposite shore to the beach. While all of these will change the city drastically, the beach will be most significantly impacted by the last project, a Port,

This is an allusion to Homi Bhabh exploration of the paranoia of the colonist that arises from conflicted attempts at authority over the other, of which he notes;

"If these symbols are always the same their ambivalent repetition makes

them the signs of a much deeper crisis of authority that emerges in the

lawless writing of the colonial sense. There, the hybrid tongues of the colonial space make even the repetition of the name of God uncanny.." Homi Bhabha The Location of Culture (London: Routledge 1997) 93-101. that represents a further move away from the individual-oriented to city-oriented. There is no doubt that all boat users would see a port as benefitial infrastructure, but will such a development undermine the beach to the extent that it is no longer used? Could this signal a programmatic shift for the beach?

a residential expansion

b proposed commercial-institutional core c existing core area

d new transportation core

new port zone

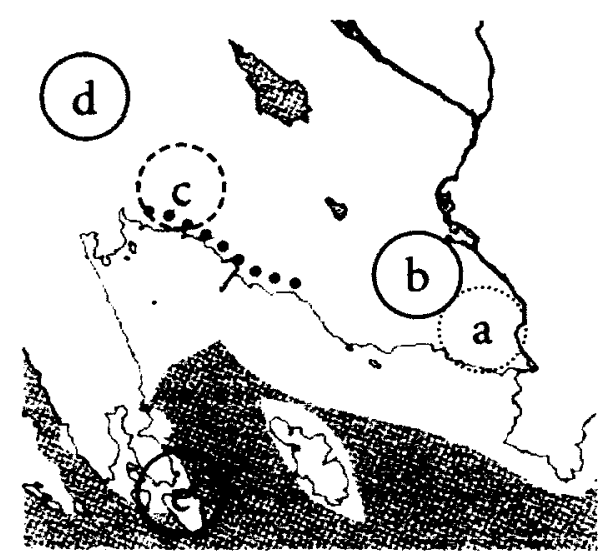

Long-term City Plan

Perhaps, on departing the beach, it is best to reflect on what it might become by reconsidering the tactics that have made it what it is today; an urban entity characterized by its sly civility. Authorities, negotiating the internal difficulties associated with formal policy (a colonial construct) have thus far enabled the beach to evolve by disengaging but allowing it to occur through vague definitions, minimal enforcement, intervention on 

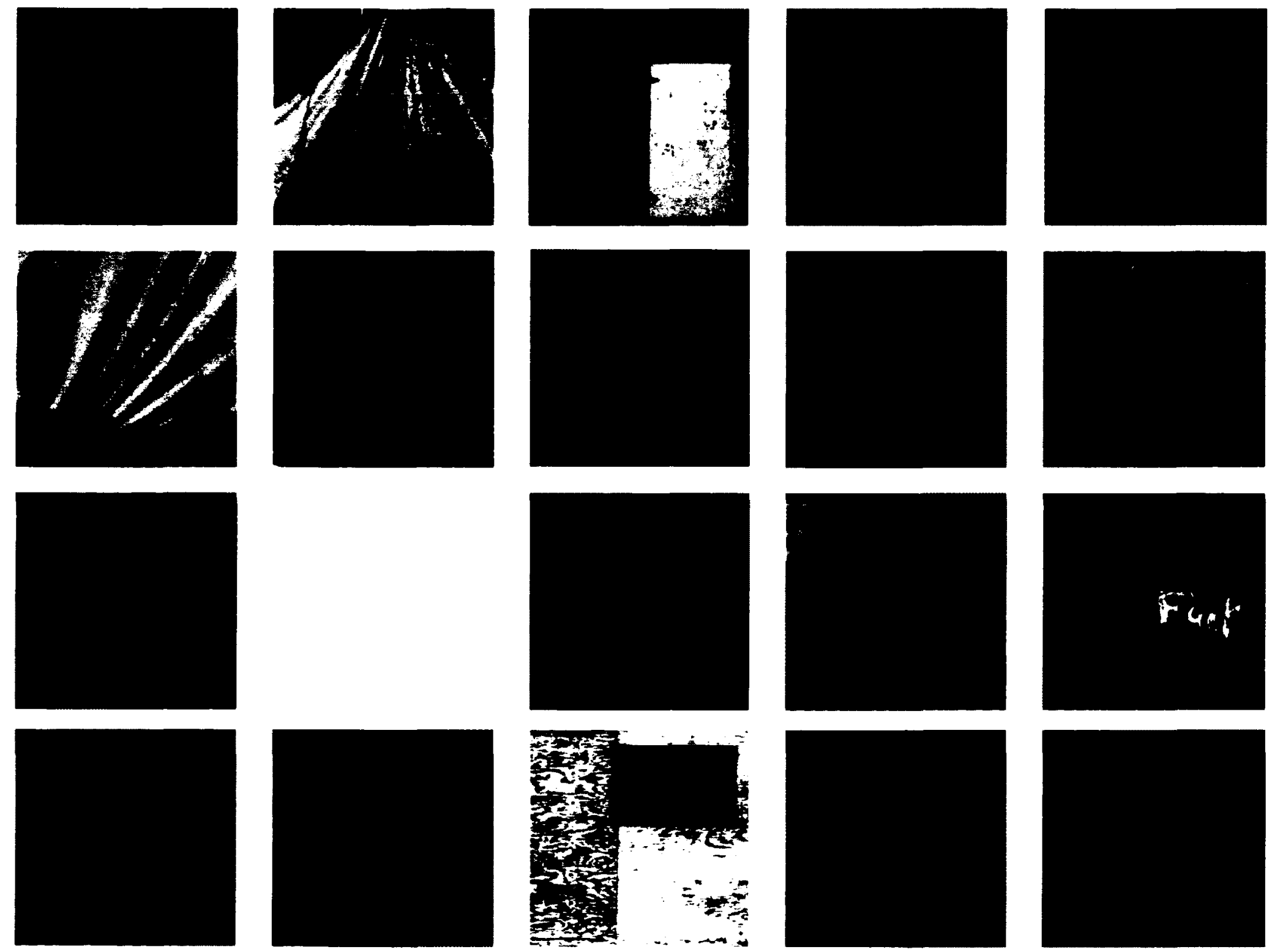

plate 4-13. Texture and difference 
an individual basis only, and up until the City's recent efforts at taking a leadership role, the deferral of responsibility. Beach users, for their part have subverted formal authority through action (building without permission), squatting (inhabiting without permission), avoidance (making oneself invisible to authority), ignorance (intentional or nonintentional not-knowing of policies), complaint (using the policies as tactical devices), and resistance (refusal to accept policy enforcement). These tactics, assembled both through the research of published documents, and through informal 'interviews' (many of which were discussions, chats, and stories told during various visits) speak to the respect of view" Mar 2012. and struggle for self-determination that has shaped this place. Such maneuverings have provided the people who use the beach with the agency of building a culturally interpreted zone in the city, but is it a place "for everyone" as the Mayor believes it should be?" Can it be a place for everyone and retain its essential and contested freedoms? To consider the agency of the hunters who have established their stake in the beach, one might be concerned that the City is changing strategies by taking an active lead. It is now, in this moment of increased instability and possibility, that an architect might have a role to play. How can we contribute to projecting the beach forward? Certainly architecture will not suffice on its own, after all this is a self-made place, but perhaps architectural thinking will be of value to both the City and the Hunter and everyone else. 
sojourn, on the land

sojourn, on the land

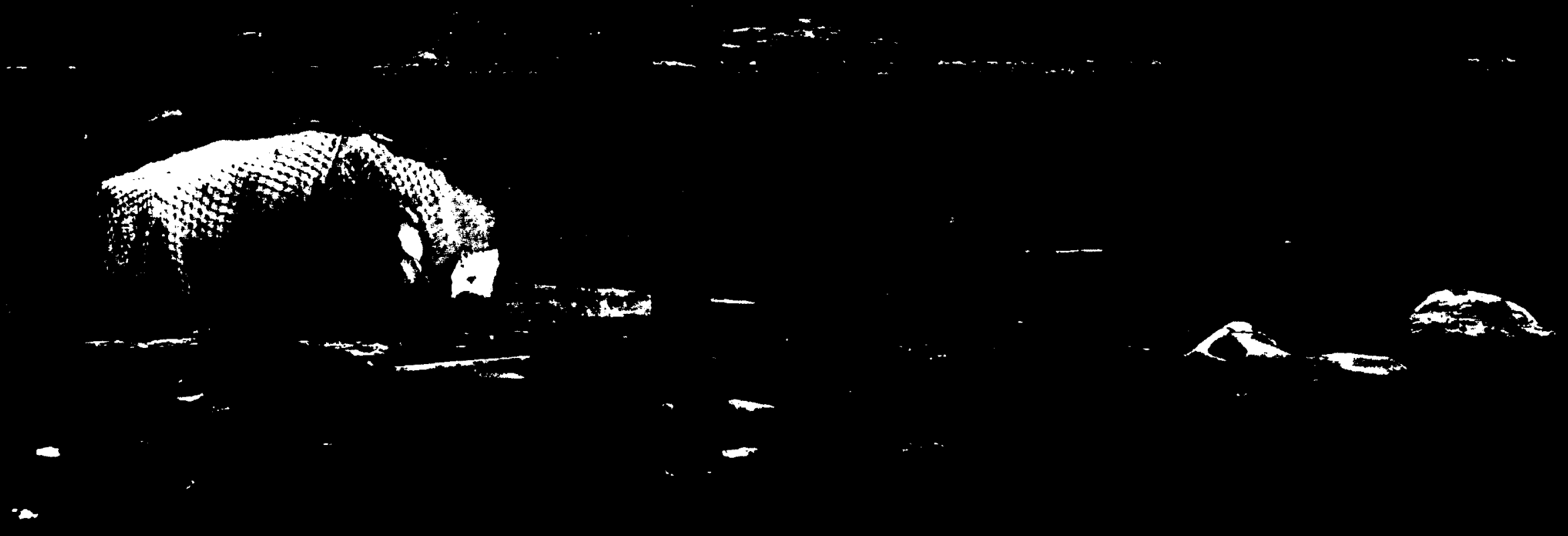


It is odd to consider, but if one was to walk for thirty minutes in any direction away from beart of the city, they would be alone. Really alone. In nature. With the wolves and winds. An hour more in the right direction and they'd find "the Bend" and a different shackland than on the beach. To discover such civilization in the vast unknown has prompted many to chorus "I was here" on the plywood walls and tables. And yet, they haven't even left the city. We should go a little further. What signs of life will we find on the land?

"Whose Land Is It Anyway?" The Fire. CBC. CBC-TV, Ottawa. 12 lan.

2012.

2

Claudio Aporta "The Trail as Home: Inuit and Their Pan-Arctic Network of Routes," Human Ecology April 2009; Volume 37: 131-146.
I

f nothing else, the processes in play at the beach allude to changing relationships with 'the land' as a result of city-making. Such relationships between indigenous people, the land, and 'settler' development, were the focus of the Canadian Broadcasting Company's recent series The $8^{\text {th }}$ Fire, particularly Episode 3, wherein it was expressed that for all indigenous people in Canada 'the land' is integral to identity; it is home; it is everything.' This is most certainly the story for the Inuit of the South Baffin. The land may be known as barren ground, but it is not empty, and it is not unknown despite its 'wildness'. Like the beach, it is an itinerant realm. For the Hunter, argues Carleton University professor Claudio Aporta, the land of the arctic is punctuated by named places, geographical signposts, and invisible temporal highways, all connected by the interwoven stories of life-times of travelling through it. ${ }^{2}$ But for the settling Farmer it is an untapped resource ripe for 'development'; the transformation of game into industry, the harnessing of waterways for electricity, the scouring of the land for mineral resources. These are the coexistent realities of all Iqaluimmuit, who must negotiate the contradictions that these 


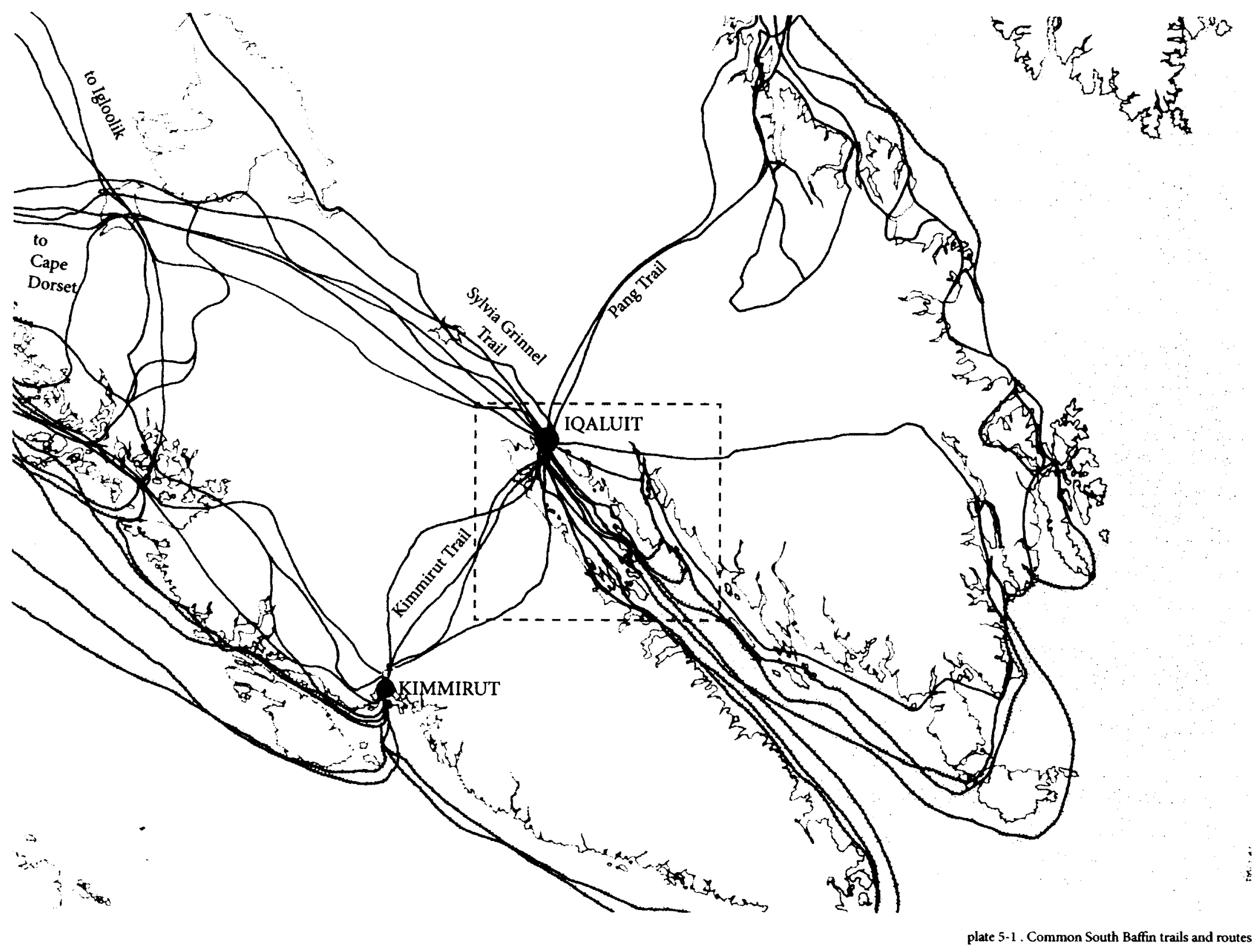


caricatures present for themselves and, as The $8^{\text {th }}$ Fire proposes, learn to build a new relationship together. Some in Iqaluit are choosing to build a new relationship with the land through the construction of cabins. This, the second stop on the journey is 'on the land', by boat and snowmobile, to seek out emergent patterns of re-colonization that such building practices elicit, and to probe the geographical limits of the city.

Cabins on the land are a relatively new phenomenon in their current manifestation, having exploded from seemingly nothing in the last ten to fifteen years. This emergence represents a sudden and dramatic shift to traditional living patterns. How can we read this shift that cabins present within the context of Iqaluit's history?

Inuit have traditionally lived on the land in igloos, skin tents, and at their most permanent in qammat, literally wrapping themselves in the environment and moving with the seasons, as recollections from oral history such as those documented in Uqalurait detail vividly. Across the arctic this way of life was increasingly influenced by contact with explorers, missionaries, and eventually government agents (beginning with Royal Canadian Mounted Police outpostings), but for the area immediately affecting present-day Iqaluit, according to the Qikiqtani Truth Commission community history, early fur traders were the most significant. Indeed, the establishment of a Hudson Bay Company post in Frobisher Bay could be read as the

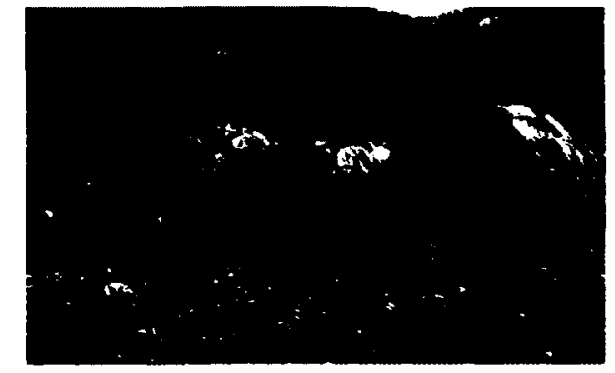

Traditional Igloos

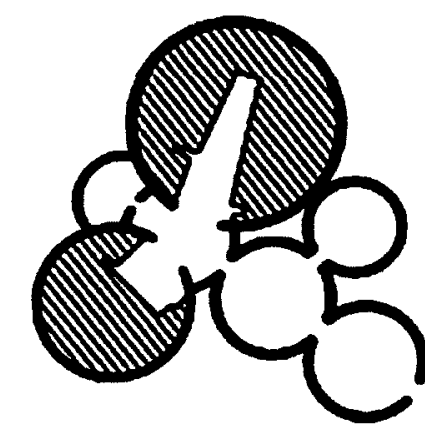

Four family igloo plan as depicted in Knud Rassumussens's Fifth Thule Expeditiom

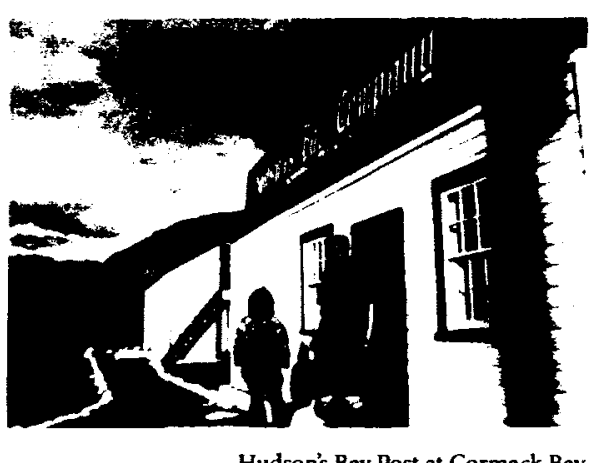

Hudson's Bay Post at Cormack Bay 


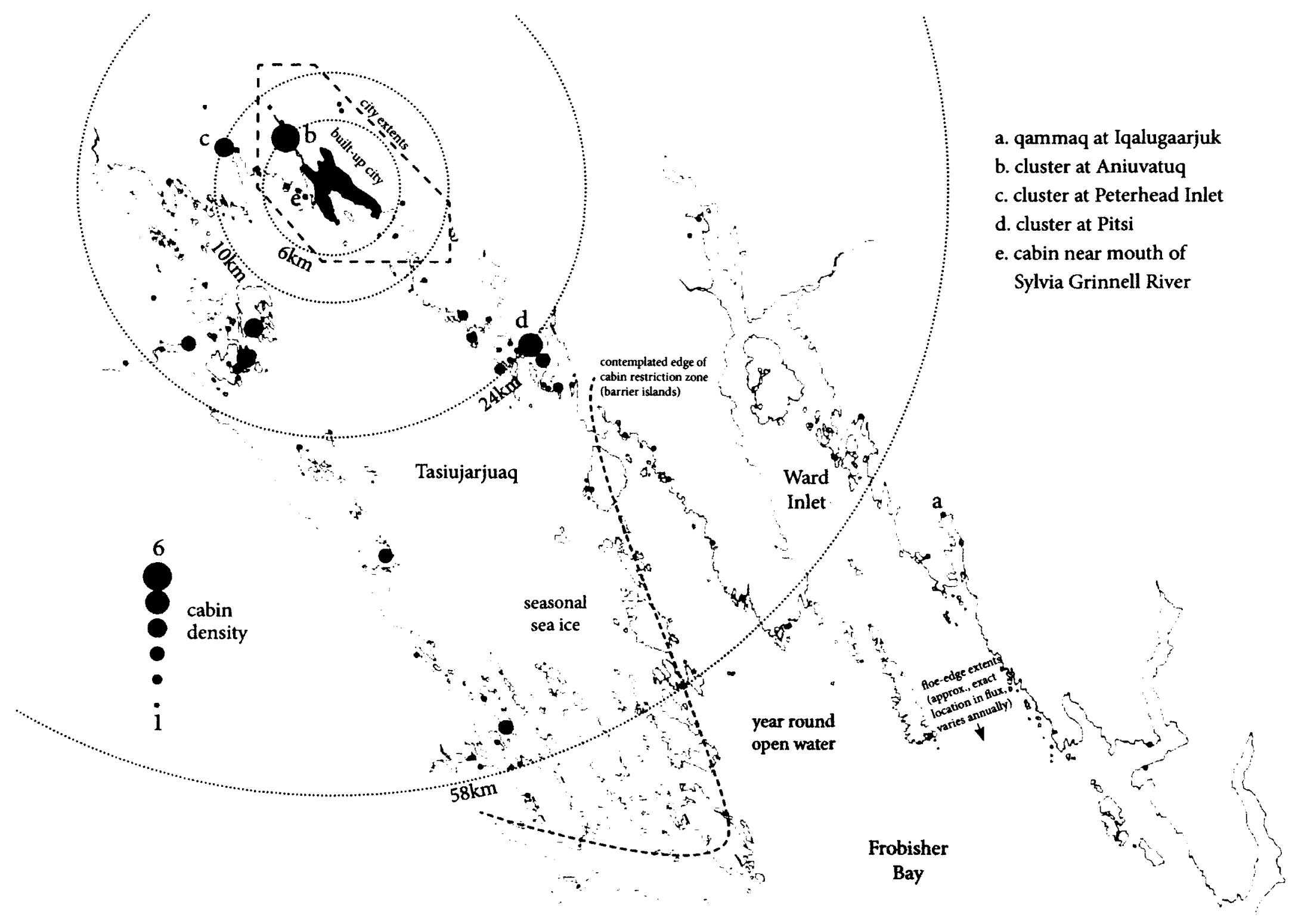


first settlement using Western based ideologies in this area, though "Igaliut Community History" The Qikigtani Truth Commission <http:// www.qtcommission.com/actions/G tPage.p?pageld $=11$ \& communityld $=4>$

it is not insignificant that it was moved on numerous occasions to refine its siting in relation to its client base, the Inuit. ${ }^{3}$ However, it was not until the establishment of the US airbase at Iqaluit that Inuit in the region began to significantly alter their living patterns towards settlement. It is important to note that American activity in Frobisher Bay precedes the setrlement of Iqaluit and was not only limited to the area of the today's city, having had an earlier airstrip and camp at Crowell Island and a recreational fishing camp known Gagnon 183 as Chartic Lodge at the Bay of Rivers. ${ }^{4}$ All of these activities have since been subsumed by the city; moved for commercial purposes, to be houses, or as part of the airbase, and many are still in use today. As a result Iqaluit, up until the influx of cabin building, appropriated all significant foreign structures in the region. Similarly Iqaluit since its inception has been a magnet for Inuit families from other nearby regions and communities to access trade, work, and services.
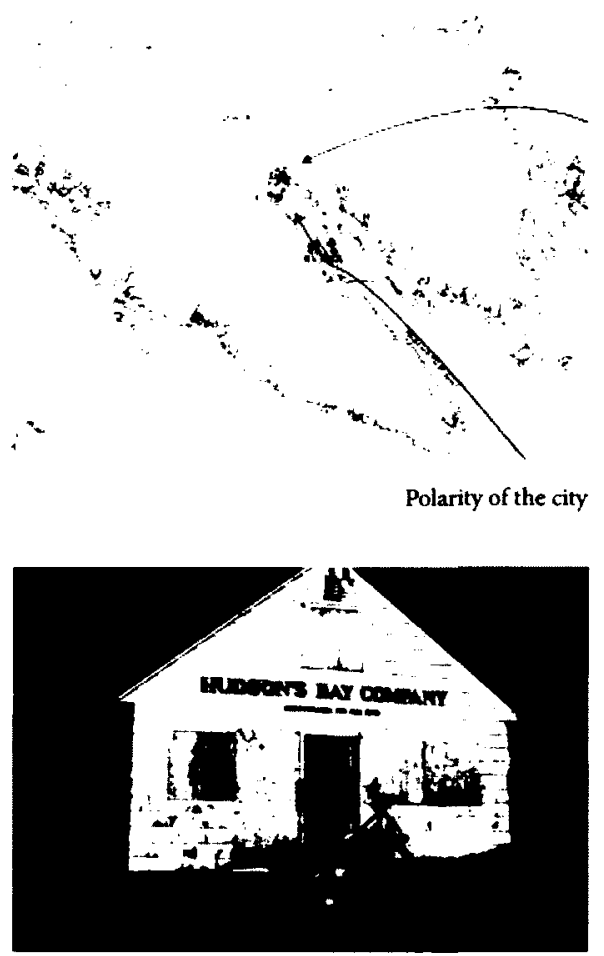

Tranplanted $\mathrm{HBC}$ post building

Despite the concentrating effect of settlement in the city, Inuit land use of the area has continued; hunters continue to harvest and people continue to move freely throughout the area as in previous eras, though much translation has occurred in both material and practice. Movement has been expedited through technology, with snowmobiles and outboard motors making "ten day trips into ten hour trips" according to local elder Jimmy 'Flash' Kilabuk. Such an exponential reduction in travel time, coupled with high speeds of moving across the land have changed the dynamics of hunting and experiencing the land as hunters can travel far and in short amounts of time return 


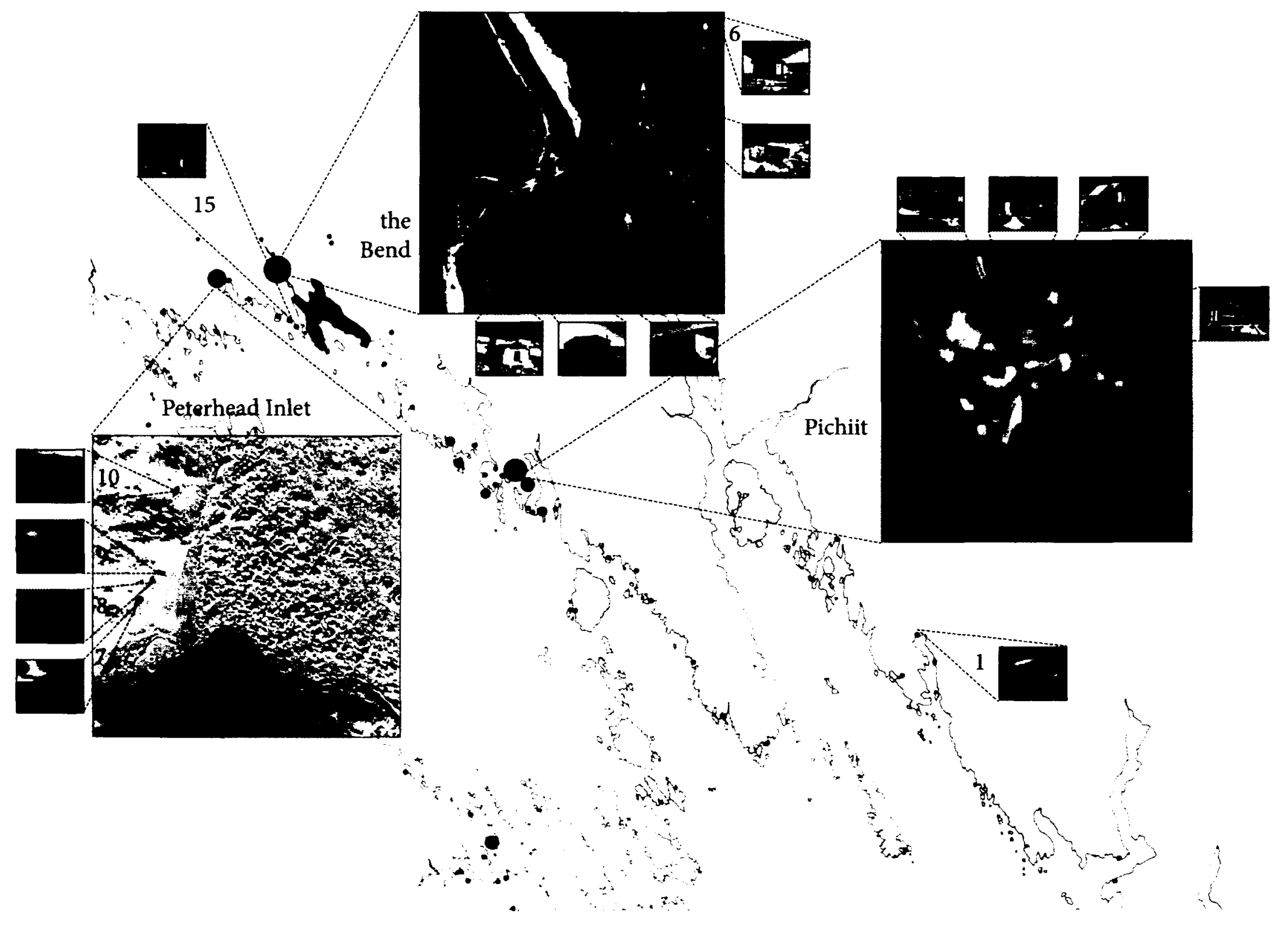


to the city, often eliminating or drastically reducing the length of stays on the land. In materiality the now ubiquitous canvas tent has replaced those temporary structures drawn from nature while retaining their qualities of scale, form, and temporality in a translation of traditional use of animal skin. Such tents are used extensively both by hunters travelling in all seasons and by families in more extended stays during the warmer months. Qammat, in their previous role as 'placed' itinerant seasonal dwellings in encampments have incurred similar translation to include wood, canvas, tarpaulins, cardboard, and other accessible material and are now often recognized in conjunction with the concept of 'outpost camps' as defined in the NLCA. The actual use, related to the historical derivation of seasonal and year round inhabitation, of such outpost camps in the Iqaluit region are in decline notes Inuit hunter David Veevee: only one camp, at Iqaluarjuguluk, is in regular use in the region currently and this use has diminished since the passing of the family patriarch. ${ }^{6}$ But can we not read these new cabins as outpost camps; are they not simply another translation? It makes some sense to draw such a conclusion as even legal definitions are hazy in this regard. However if we examine the cabin and outpost camp in relation to the city, they are diametrically opposed; the former is a hybrid affect of the city (the owner lives in the city) and the latter is of a Hunter-gatherer ideology (the owner lives on the land).

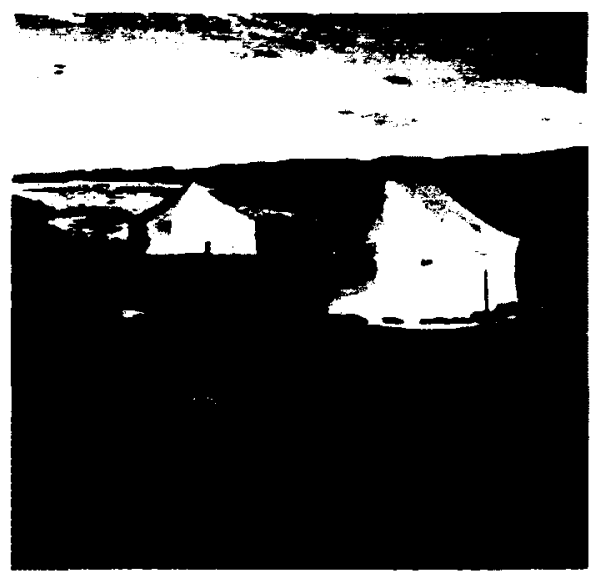

Seasonal round canvas tents on land

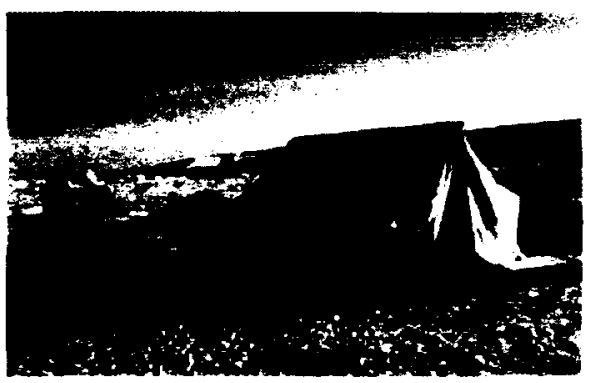

Temporary canvas tenting by hunters

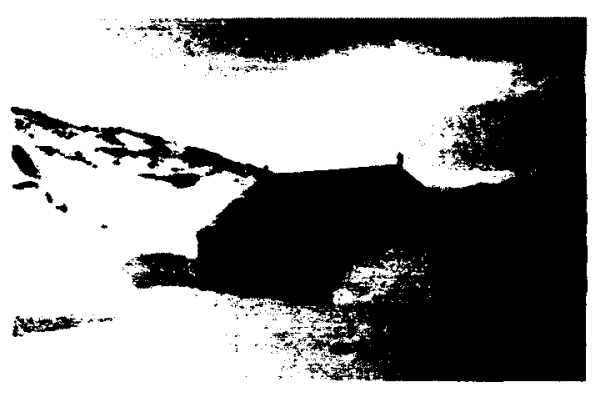

All season canvas "frame tent" on the land 


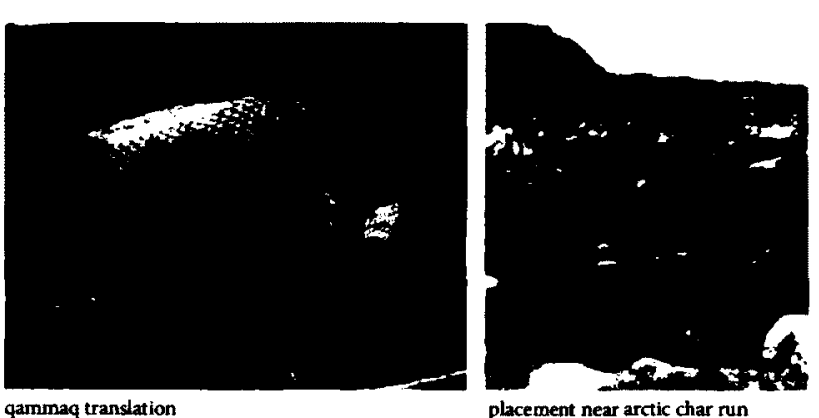

qammaq translation placement near arctic char run

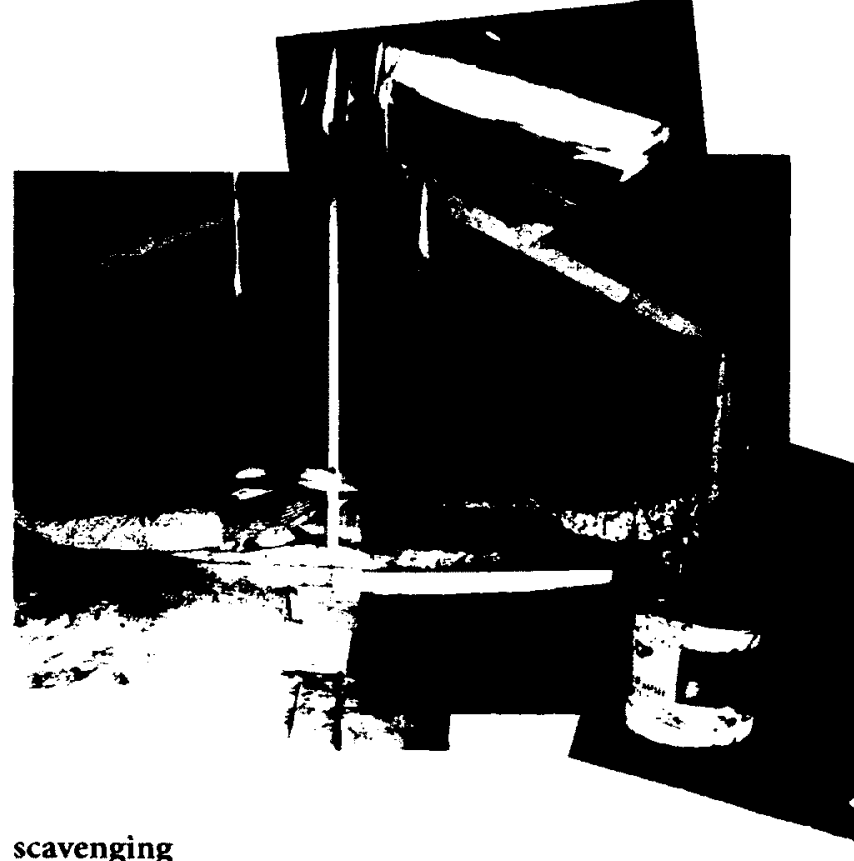

\section{cavenging}

The Qammaq at Ikalugarjuk, here called Cabin 1, is a very basic and light structure that is built using found material in an almost impermanent and completely functional way utilizing minimal alteration to the material. Likewise Cabin 15 is constructed from material found at the local dump but in more playful, expressive, and permanent way that required significant modification to make found materials suitable.

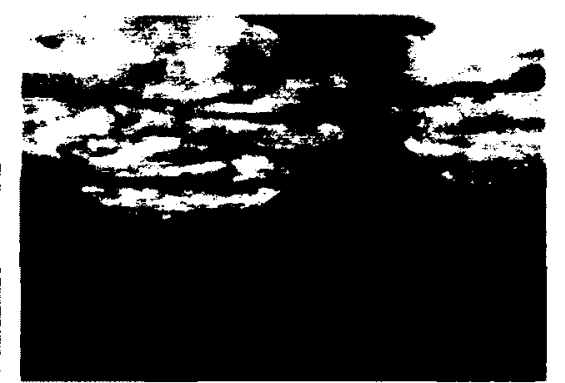

remote historic siting at old Hudson's Bay Post

at the extremes

The cabins of outside of Iqaluit have various uses, forms, histories, strategies of siting, and roles in the lives of city denizens who spend time on the land. At the extremes of some of these criteria lie an old "traditional stylen qammaq (Cabin 1) and an experimental model (Cabin 15) that is in many ways far removed from a traditional Inuit perspective but at the same time projective in its approach to the environment and the city. Cabin 1 is a remote and temporal structure, part of the last working outpost camp in the region, and is placed to take advantage of annual arctic char spawning runs. Cabin 2 is the closest cabin to lqaluit, but has been sited such that it is both nordic ski accessible and difficult to reach by snowmobile and both has tremendous views of the bay but is difficult to sees from it. Cabin 1 is a direct translation of Inuit structures in relation to a hunting culture while Cabin 15 is a recreational and political waystation. Most cabins are neither one nor the other, they sit in a gradient of difference, of hybridity.
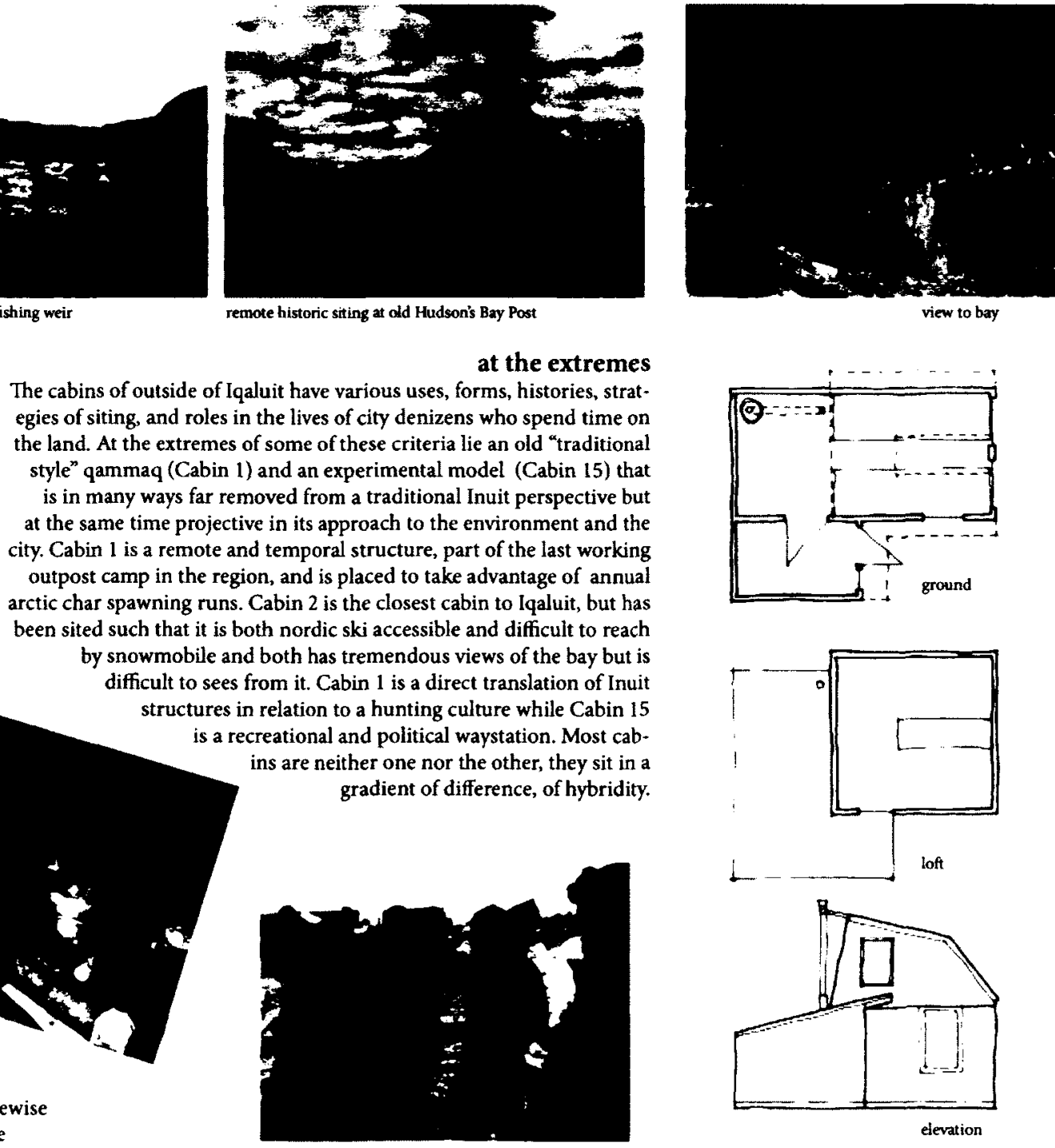

view to bay
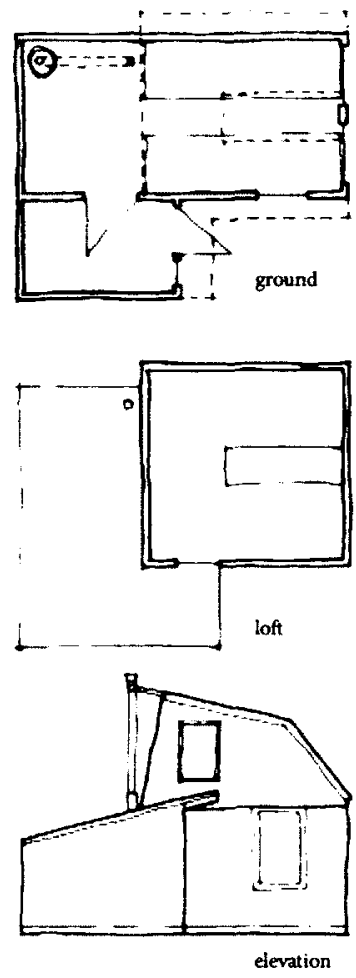

plate 5-4 . Traditional and contemporary 
Rhoda Ungalaq and fohn Maurice "Personal Interview" Feb 2012

Robert Mellin Tiling: launching, slide hauling potate trenching, and other tales from Newfoundland fishing village (New York: Princeton Architectural Press 2003) 136-138
This differentiation is clearer if we concede that many of the first cabins in the area were erected by various community groups, societies and organizations for communal use, such as the Outward Bound, Air Cadet, and Boy Scout cabins, or for emergency shelter, such as those erected by the HTO and Government of Nunavut Parks. While formally undocumented, it is clear in my experience that these cabins quickly adopted itinerant status as either stops or destinations for a variety of land users, Inuit and nonInuit, hunter and recreationalist. Perhaps, it has been mentioned by local cabin owner Rhoda Ungalaq, the emergence of personal cabins is an adopted trend, introduced to the area from the Kivalliq region of Nunavut where cabin use is even more prolific by way of the late Inuit leader Jose Kusugak. ${ }^{7}$ Better yet, one need only look to the 'cottage countries' and hunt camps of Southern Canada for some aspects of precedence. Or is it a movement coincident with the influx of Newfoundlanders that have migrated to Nunavut in the last twenty years? Architect Robert Mellin's documentation of the fishing outpost in Titling, Newfoundland saw a similar trend of cabin development and increased usage during in the 1980's. These recreational buildings he remarked are "perhaps less an outbuilding than a small second home". ${ }^{8}$ Iqaluit's cosmopolitan nature is such that these are all likely influences, drawn from within and without, from the past and the future, but perhaps the last statement is most relevant to an understanding of these cabins in relation to the land and the city. They are another aspect of 'home'. Just as shacks on the beach redefine the pattern of house to city, cabins redefine the pattern of city to land as an extension of home.

The bulk of the cabins in the Iqaluit area are located coastally around Tassiurjuaq, though inland cabins can be found along the shores of the Sylvia Grinnell River and in high traffic locations such as along the Pang Trail, Kimmirut Trail, and Ward Inlet Trail. The latter 'trail cabins' are largely consistent of emergency shelters for use by hunters during travels. 

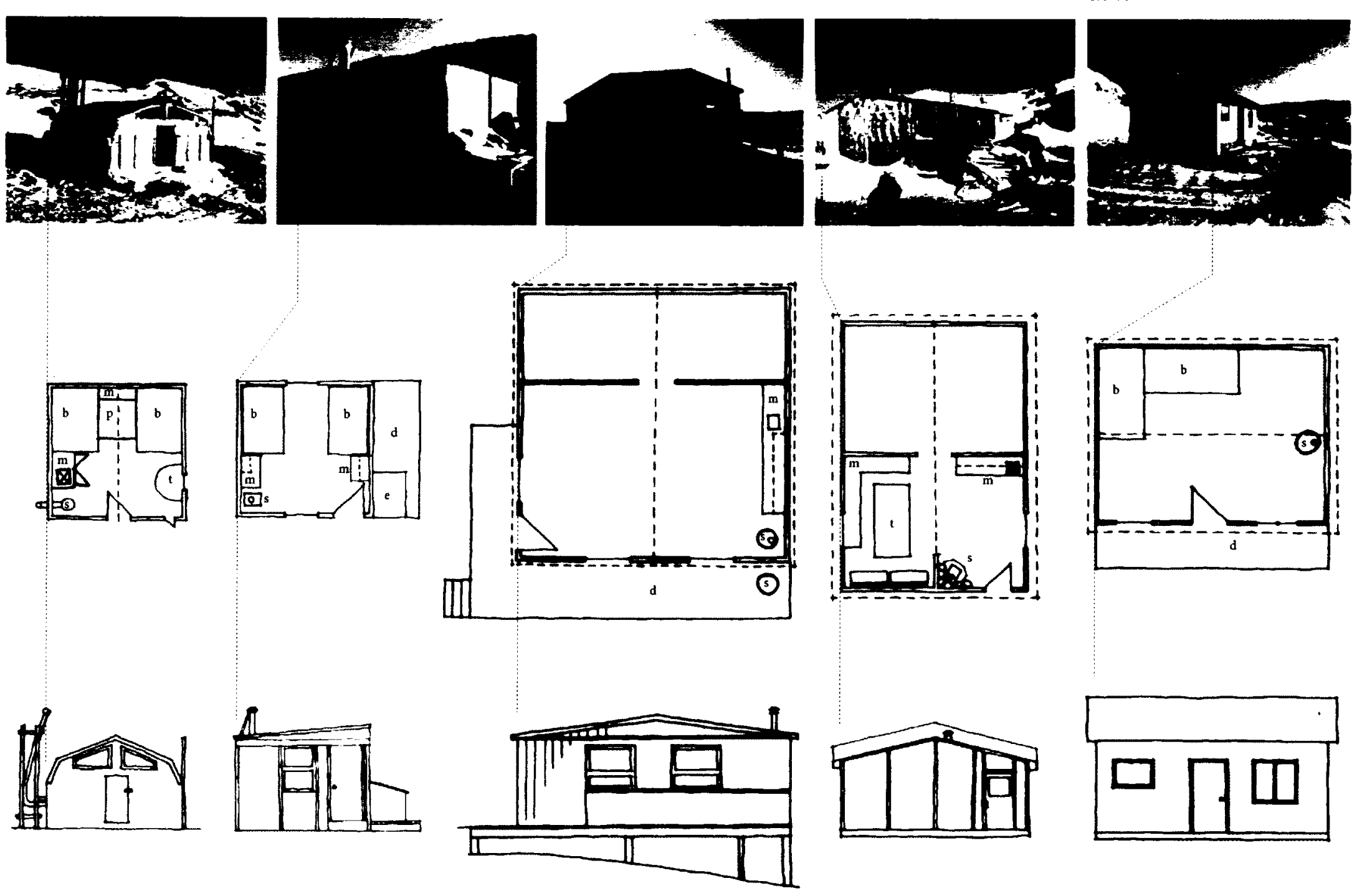

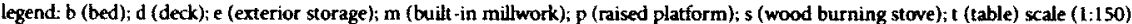


Tom Critelli "Personal Interview"

Jan 2012.

open-door policy Stemming from the use of cabins for emergency purposes even private buildings are recommended to remain unlocked by the Hunters and Trappers Association. All but one cabin visited was accessible. Further to this, the planning and visiting of cabins was met with enthusiam with owners whose only concern was that the doo was closed securely upon departure.
However, of particular concern to the notions of hybrid reversal and 'the second promise' are those cabins that have been 'sited' by individuals rather than organizations. Many of the cabins are self-designed and built by the owners in collaboration with friends and family, though there are instances of the purchase of cabins from other builders in Iqaluit which were transported and erected on site (Dinos Tikivik's cabin for example), as well as the buying and selling of cabins (Elijah Pudloo recently sold his for five thousand dollars). Indeed, ownership is hazy in many cases as usage permissions are often shared amongst numerous parties to encourage activity, as in the case of Tom Critelli's cabin, while the general open-door policy of cabins renders access universal, regardless. ${ }^{9}$

Nonetheless, cabin development has progressed from an early state of isolated buildings to nodal clustering or grouping of up to six cabins in close adjacency. This emergent pattern is significant in the sense that small communities that have a permanent intent are forming in places outside of the city. Are these tiny self-determined micro-sub-divisions? Certainly this is a 'planner motivated' reading, but it is worth consideration if we project development rates; Iqaluit's population has doubled in the last ten years while cabin construction rates have only just begun to manifest themselves (from nothing) over the same time period. This potential growth and its effect on both the landscape and the wildlife is of immediate concern to many Inuit, hunters, cabin users, and authorities who are struggling to define how and where building should occur. The Municipality on one hand is battling with cabin building in designated Open Area zones as highlighted in their ongoing public meetings, while Salamonie Shoo has noted that QIA is deliberating over a restriction to building beyond Tassirujuaq as a measure to allay concerns from land users. Perhaps these considerations will provide a more grounded sense of the extents of a city that is embedded within a network of informal use. 

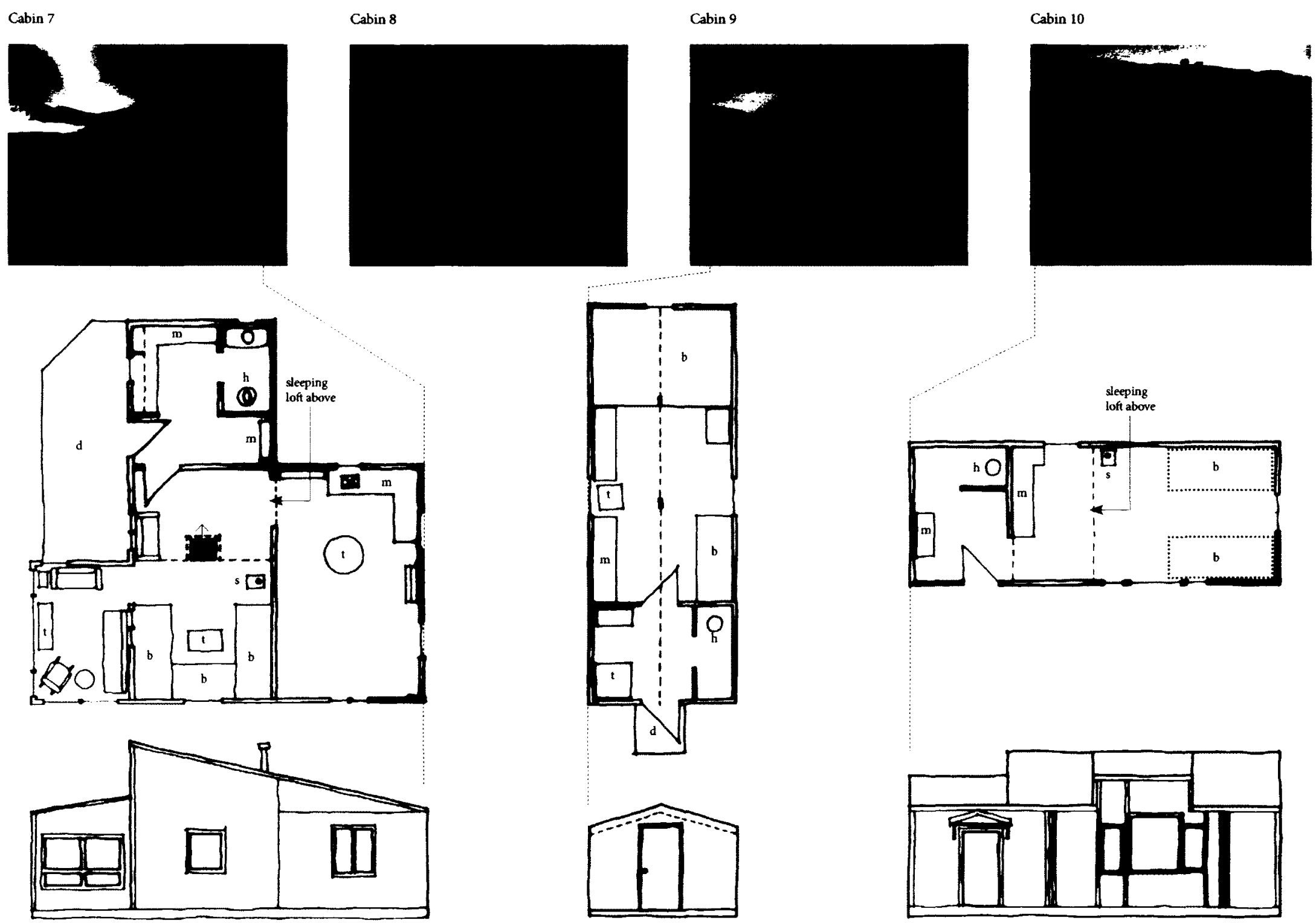

legend: b (bed); d (deck); e (exterior storage); h (honeybucket): $m$ (built in millwork); p (raised platform); $\mathbf{s}$ (wood burning stove); $t$ (table) . scale (1:150) plate 5-6. Cabins at Peterhead Inlet 
But what can we as urbanites, planners, and architects make of these clusters? And what do the buildings themselves tell us about this 'second city' that might be? Can we learn from those who are designing structures, spaces, and communities for themselves? Are they doing it properly? Is this authentic?

Rhetoric aside, this is a relatively unstudied trend in the North that could provide insight to the ways in which architecture and place making might be more reflective of a unique regional population. If we consider the architect's role, such a study represents an opportunity to provide visibility to these activities and by doing so help to legitimize both the act of building and design of buildings that are removed from rationally deterministic guidance structures. Indeed, it is difficult, given the general acceptance of paternalistic governance models in the North, to consider, as the nationally recognized Ilisasiviq Society of Clyde River, Nunavut has, that "people themselves know best." Illisaqsiviq's Nunatsiaq News "Tides Canada puts Ilisaqsivik on its Top 10 list: Nunavut centre among Canada's "most innovative and forward thinking projects" 07 Dec 2011. <http:// www.nunatsiaqonline.ca/stories/ article/65674tides_canada_puts ilisaqsivik_on_its_top_10_lisU/> mission is one of integrated wellness and community development within an isolated yet contemporary Inuit settlement that is dealing with familiar issues of displacement and disenfranchisement; developing agency is implied at all levels of their programming. ${ }^{10}$ Perhaps in 'making things visible', as this cabin study aims to do, we will uncover an agency that individuals have developed for themselves. Less an operation of uncovering hidden power structures and their influence which is, to quote Till and Schneider "a key aim of spatial agency", what is presented is an operation of accepting and investigating their absence. ${ }^{11}$

With this in mind, a sample of cabins were visited and explored through drawing to provide a range of self-building activities that are present outside of Iqaluit. This set, 

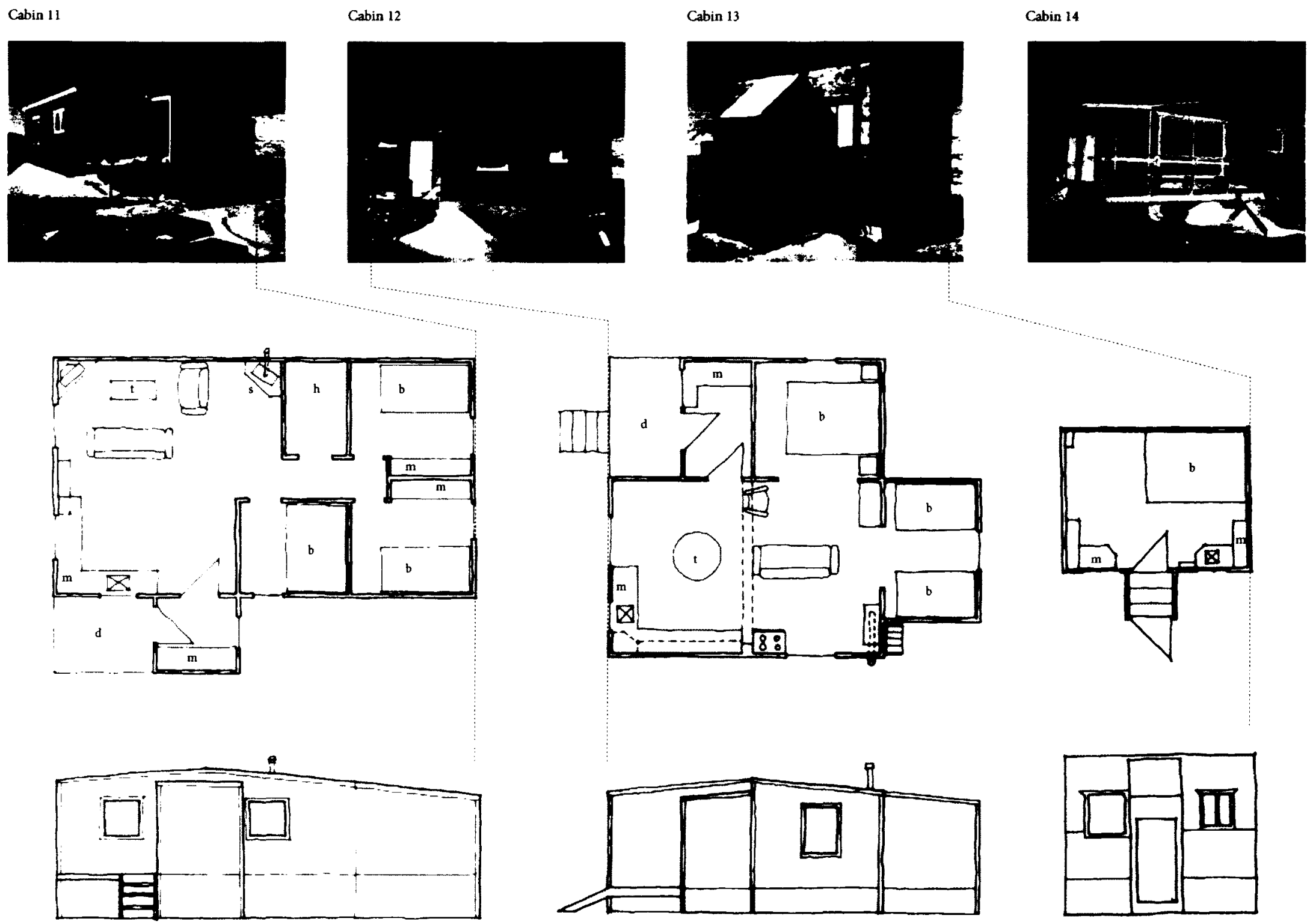

legend: b (bed); d (deck); e (exterior storage); h (honeybucket); $m$ (built-in millwork); p (raised platform); s (wood burning stove); t (table) . scale (1:150) 
Never Lose Sight National Film Board of Canada abou the building of a cabin on the land using recylced materials focused on the lack of infrastructure and programs to deal with waste in the city. The environmental agenda discussed illus. trated the difficulty from a social level of integrating larger scale organized intiatives. Composting for example was explored as a private program that is lacking in resources and public acceptance to become widespread. bookended by a 'traditional' model and a projective model, focuses on three clusters with varying proximities to the formal city. Yielding a large range of differentiation and individualization due to the heterogeneity of the builders, as is illustrated, this project did yield a few consistent general themes that are worth brief mention.

Firstly, site selection is fundamental and is factored by numerous common criteria interpreted individually. Among these are included, beauty of the place, views (to the water in most cases), flat ground for construction (beaches and gravel flats are prominent choices), proximity to town (cost to travel, remoteness, cell phone range), seasonal transportation capacity (boat docking, pack-ice navigability, ATV accessibility, walk ability), proximity to other cabins (social connections, family connections, no connections), proximity to key harvesting grounds (whales, ptarmigan, geese, caribou, fish, clams), climactic sheltering (sun, wind, storm winds, snow), access to fresh running water (streams, tivers), proximity to trails (ease of access versus privacy), and safety of family (from topographical and animal danger). Choice of site is the most important and valued aspect of cabin development.

Secondly, and significantly, most if not all cabins visited employ the reuse of salvaged materials to some degree. From the wholesale recycling project of Cabin 15, which was the subject of an environmental awareness video for the National Film Board of Canada called Never Lose Sight, to the purchase of defective construction materials at very minimal costs, these cabins incorporate construction waste generated by the city. Dinos Tikivik's cabin is constructed almost wholly from insulated garage doors! They are also the retirement homes for furniture and household goods. Use of

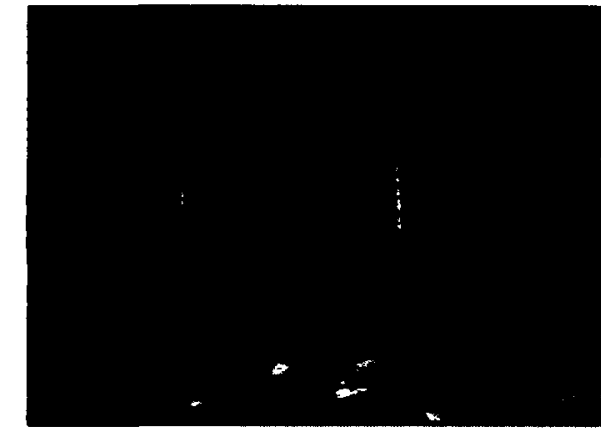

figure XX: Dinos Tikivik garage door cabin 

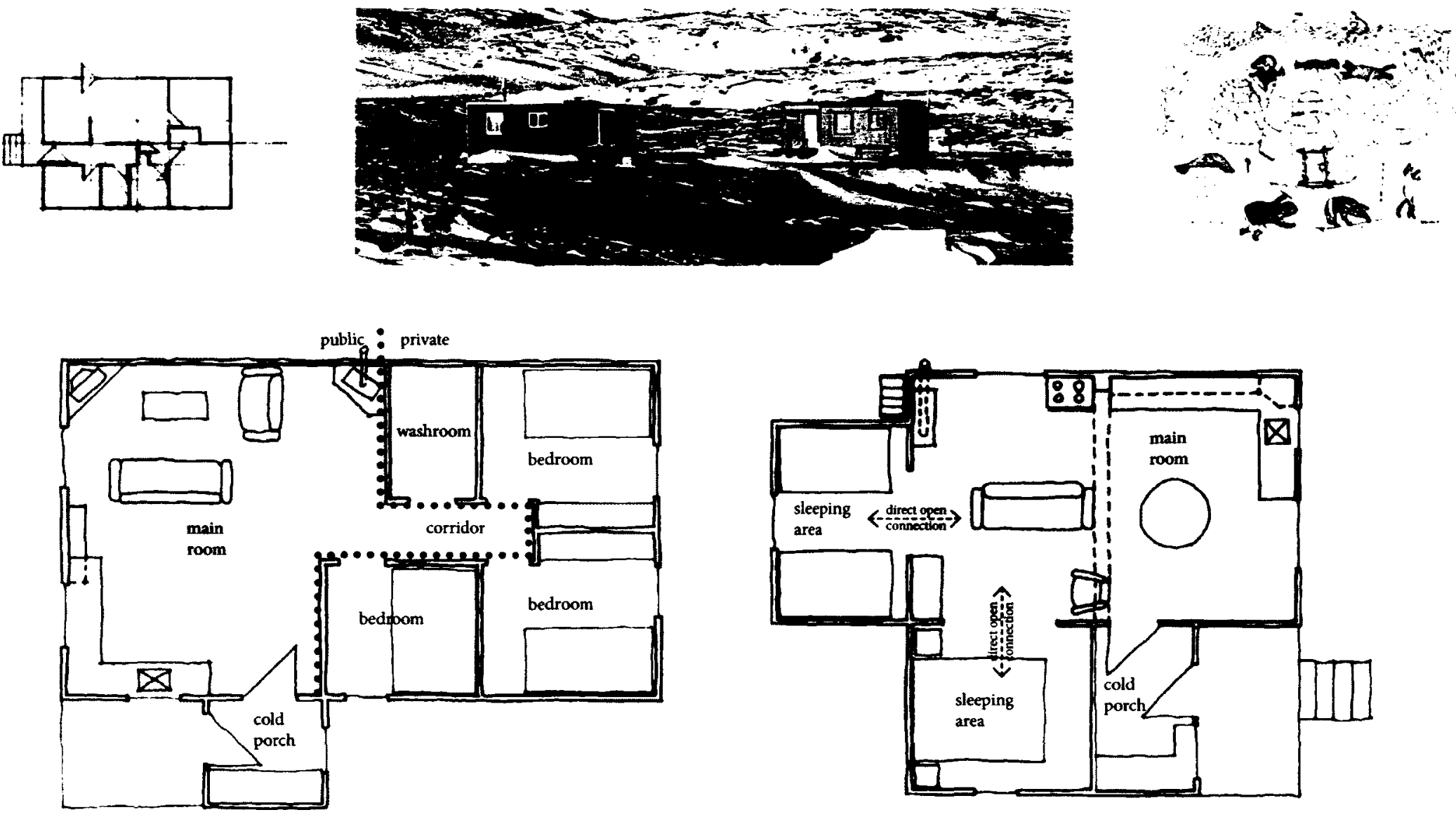

Reading Hybridity and Ideology in Cabin Design

Of the study selection, the Cabins 11 and 12 in Pichiit are perhaps the most easliy read as eliciting the difference of hybrid design in terms of ideology. Sited beside each other and built at the same time by the same builders, these cabins have much in common in terms of materiality, orientation, scale, and craftsmanship. However, the owners' contrasting backgrounds and ideological references can be clearly read in plan. Cabin 11 is owned by a northerner of English descent, who is also a boat builder, while Cabin 12 is owned by an Inuit elder and is the former's father-in-law. Whereas the plan design of Cabin 11 clearly references Western concepts of design that are evident in government house design, such as separation of public and private spaces and division of space to the individual, Cabin 12 references something different. Here, sleeping areas have a very direct and open relationship with the main space in a configuration that can be clearly drawn from igloo and qammaq planning to promote inclusivity and connectivity between the occupants. This change is significant spatially, while smaller in size it feels larger and has more daylit space, but seems 'cozier'. 
immediately local materials, those from the natural environment by contrast, is relatively unseen, barring use of rocks in foundations and exterior work.

They are also works in progress. Few, if any of the cabins appear to be completed, and

Critelli, Ungalaq, Hyndman "Personal

Interviews" moreover many have clearly been constructed as a series of additions. Interviews with various owners elicited an overarching sense that the building and refinement of these structures is part of their purpose. ${ }^{12}$

In addition, many of the builders are experimenting. Though there are examples where carpenters were the builders such as Cabins 11 and 14, many are constructed by amateurs and designed to suit. Standardized design principles such as door size and head height need not apply. Homemade trusses, built-up beams, modular panels, and various other custom built components were noted, as were countless variations in wall paneling and integrated finishing elements. Drywall was notably absent in all cabins. Individualization was highly evident.

And lastly, they are economical. Many are small and low, one would assume to save materials and but also to conserve heat. Likewise, many of the plans are open. Standardized material properties, such as the 4'x8' sheet of plywood, often seemed to influence design significantly. Transportation to remote sites and handling by few builders contributed to lightness in material, construction, and footprint.

Critically, of the five above themes only the last, economy, would be read as a common priority theme among the formal buildings that might be understood commonly as 'architecture' in Iqaluit. While there are notable examples that would invalidate this 

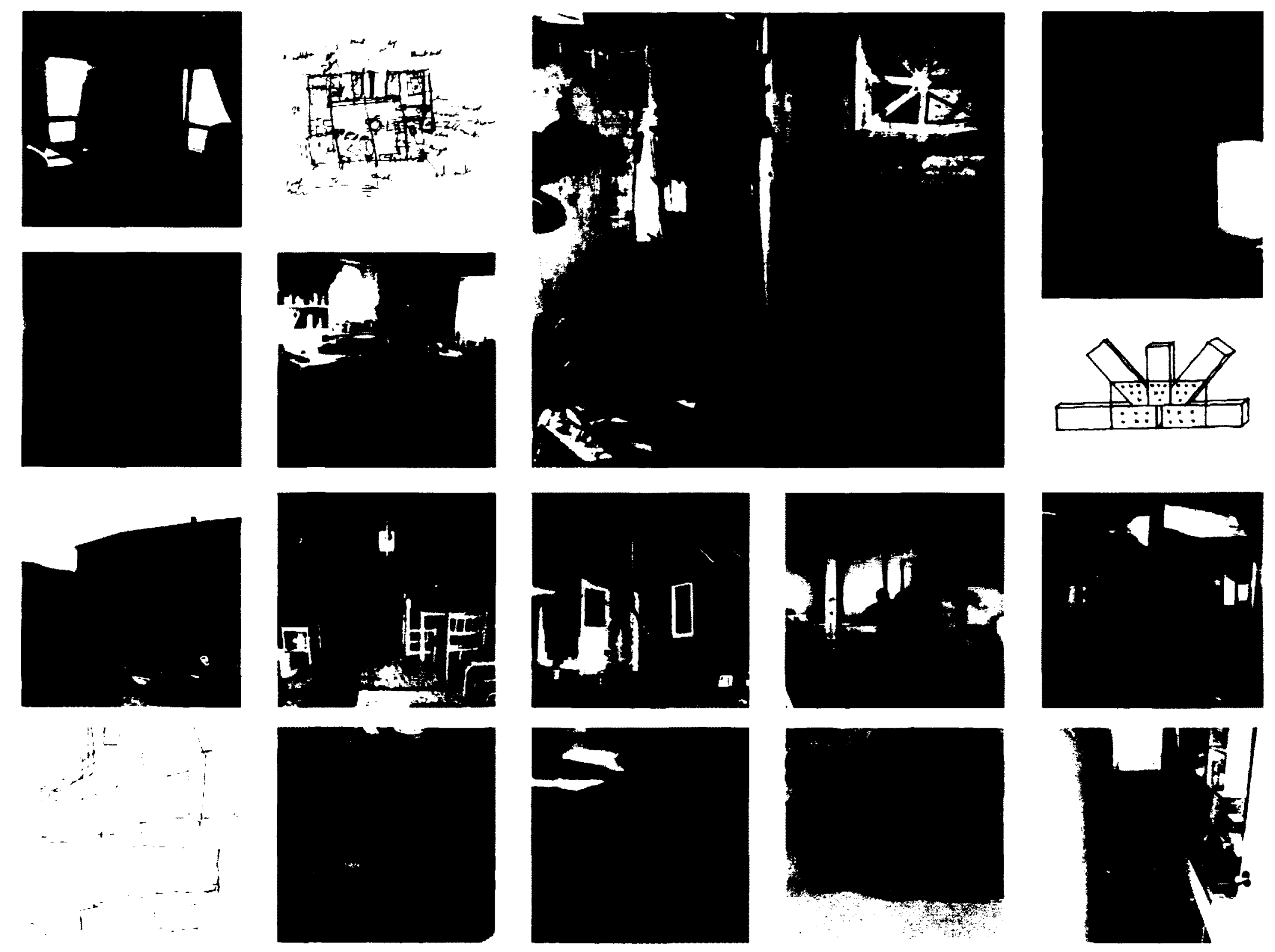
statement on account of its generality, it is worth considering. Think of a house. Or a school. Site selection is highly limited, defined, and regulated by planning regulations and space. It is almost always prohibitively expensive to build where you want. Contractors, and for the most part clients, want nothing to do with waste materials that are more time dependant to work with and not 'quality assured'. Long term relationships with contractors and funding sources are difficult to manage and thus costly, 'time is money' so it is always easier and more cost effective to build all at once; building later is also disrupting. Experimentation is different, different is risky, risky is costly for everyone and doesn't always like the code!

Ironically, cost doesn't seem to be a major issue for cabin owners, and yet everything that they do intuitively is too expensive to do in the city proper. Perhaps this is because they do it for themselves. Can their ideas be applied to building in the city? 


\section{CHAPTER 6}

On occasion, when mid-trip, it is worth exploring the forks in the road, smelling the flowers and all that. Odysseys are built on such circumstantial navigations and the coincidental events that come of them. Such is the oeuvre of happenstance that encapsulates our sojourn in the woods. In the woods one expects a different kind of wild; a different kind of shackland; a different kind of North. It is no mistake that we are here however; our circumbendibus was prompted by a man who built a cabin at the Bend of Sylvia Grinnell River on the land outside of Iqaluit. This man is Tom Critelli and he is building again, much more this time. Can we be of assistance?

Souchern tastes

To illustrate this connection between Ottawa and Nunavut it is worth considering that Ottawa's Inuit population is the largest in Canada outside of the territory, somewhere between 1,600 and 2,000 , enough to generate the creation of a specia Inuktitut word, Ottawamiut, to refer to the city's Inuit residents. <http://www.canada.com/ ottawacitizen/news/city/story html?id=9b43dcf9-3591-4a87-9a86-

5 breeedfe49a>

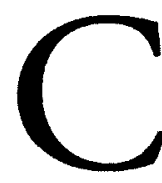

abin 5 is not unlike many of the others on the land outside of Iqaluit. It was built from spare parts; it was built incrementally; it was built in social tandem but by its original owner; it was built with little guidance or requirement by the authorities; it was built less than ten years ago. Today, its ownership has shifted hands, always in accumulation and never severing ties, to include at least five different owners, though most exist in honorarium at this point. Such shifting alludes to Iqaluit's nature as a transient place, a public sector work place for many, but not a place to retire for those who have deeper roots elsewhere or other woodland dreams. So people move on, but they take the North with them. Ottawa, with its twice-a-day direct air service, has become Iqaluit's gateway to the world and also a haven for Nunavummiut with more urban and southern tastes. This is where Tom Critelli, the original builder of Cabin XX, resides, in the city, while he builds a house in the Lanark Highlands of the forests beyond. His house is to be no ordinary house. It is to be but one part of a 'project' in which everything has been 

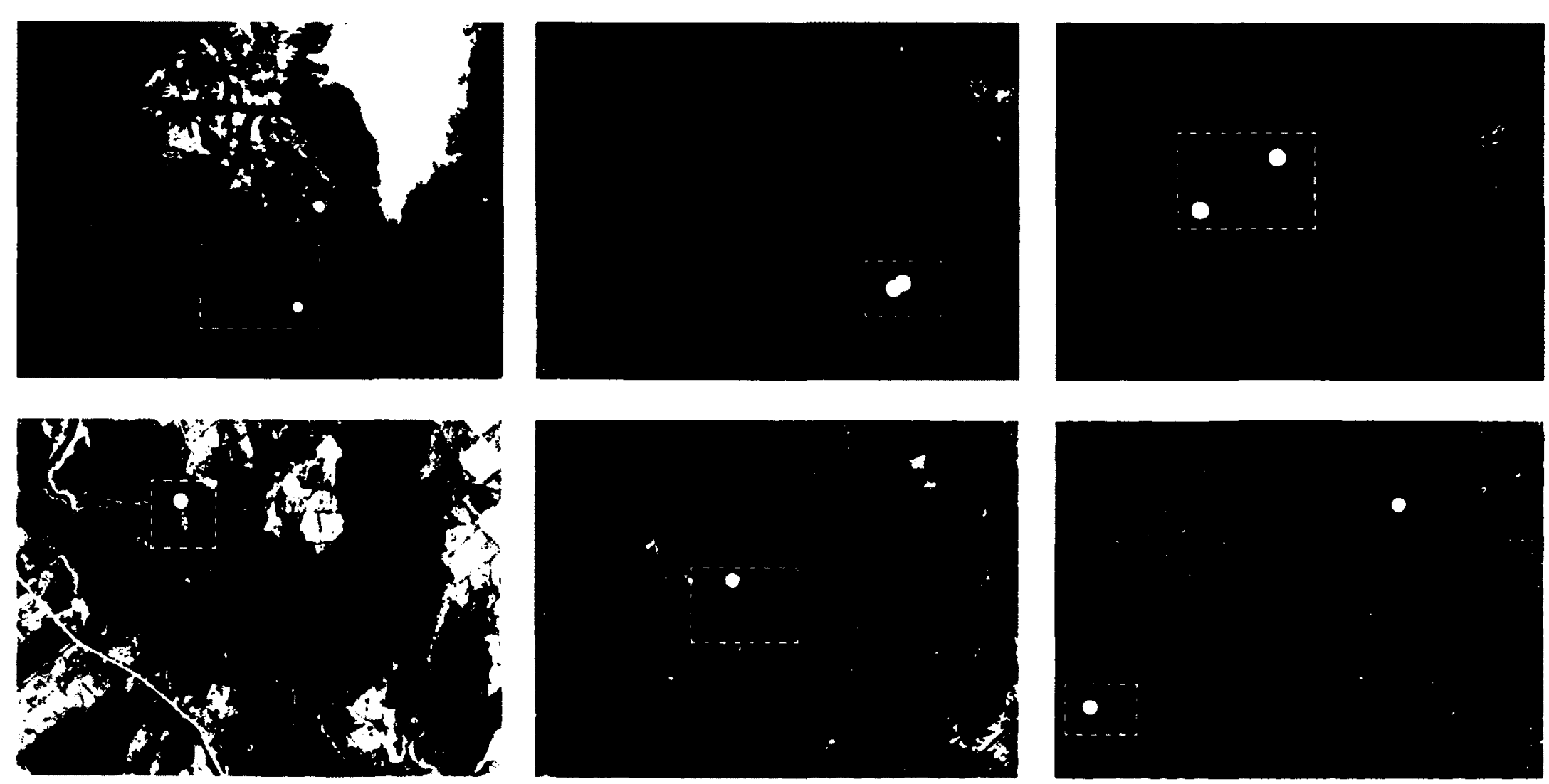
developed by his hand in an integrated process of living on a piece of land. His process is an extension of something learned and cultured with the building of his cabin in Nunavut; that the act of building is in and of itself liberating and of great value.

While much of our journey has focused on the idea of hybrid reversal from the vantage of the Hunter, the colonized, this is an opportunity to consider the Farmer who has in some senses 'gone native.' Indeed, if we look at our Farmer, we find an individual who spent his youth in Ontario, with a family cottage at Algonquin Park, and much of his adulthood in the communities and cities across the north working for various government agencies. Does this make him a northerner? As much as any other, though he is not in any way Inuit, nor he does not overtly posit the ascription to a Hunter ideology, but in living in the negotiation zones that are the contemporary settled north, an inherent appreciation of self-determination and informality, an unquantifiable 'northernness', has been nurtured. Can we read this 'northernness' in his project of land use and development? Perhaps this is best explored through a brief overview of the project as I was introduced to it.

Life in the Woods, Redux

Tom Critelli's project began with the purchase of a piece of land, fifty acres bordering the southern bank of the Clyde River, outside of Lanark, Ontario. His property is predominantly composed of deciduous forest with various species of hard and soft wood, sections of forested muskeg, and a number of wild grass covered clearings. Various animals including deer, beavers, ducks, geese, and cranes make this their home given its relative remoteness and natural state. To illustrate this notion, it is worth pointing out that the nearest neighbour on the south of the river is a hunting lodge over a kilometre away down 


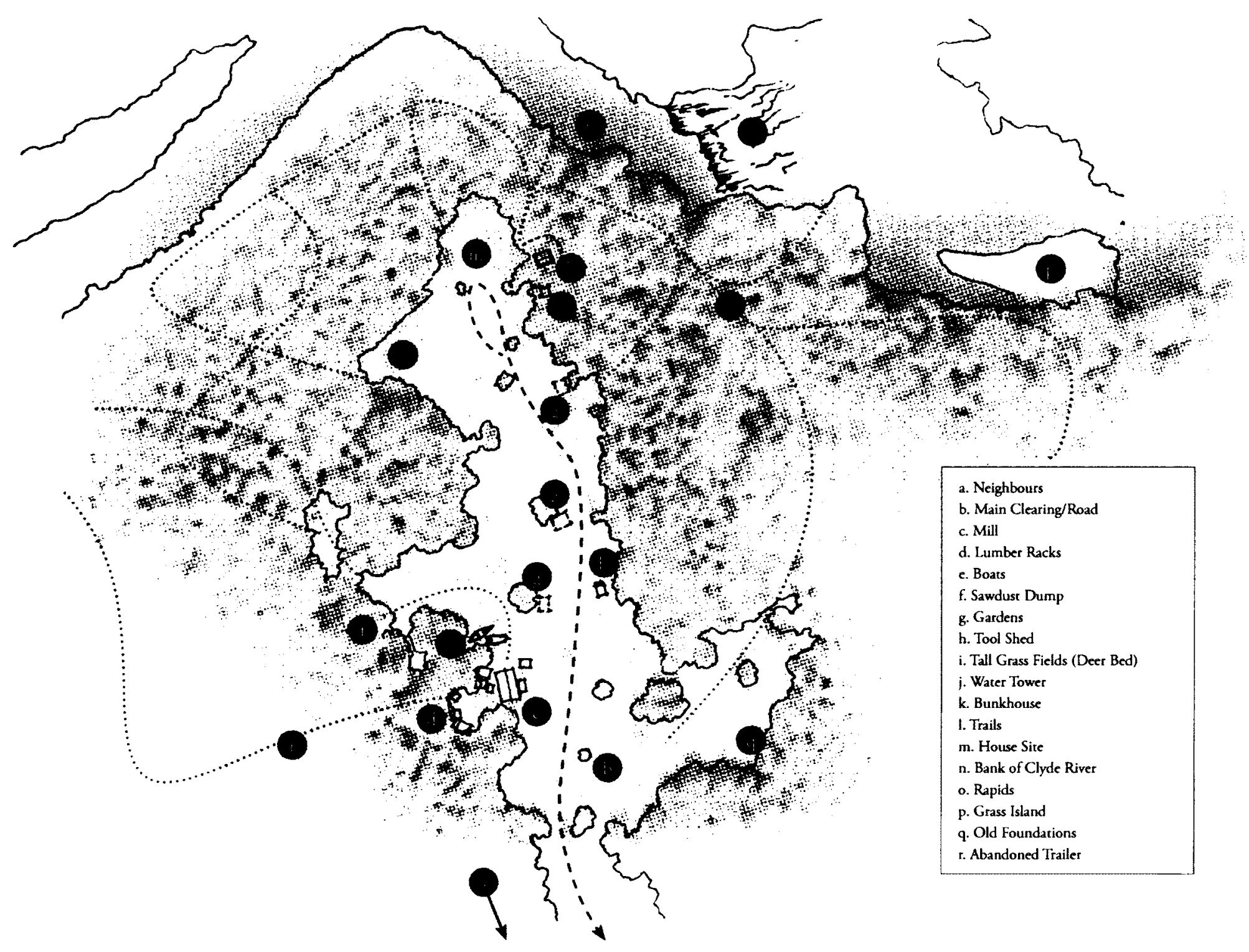

plate 6-2. Critelli's land site map 
the single 'established' forest road that serves as site access. The hunting camp and the neighbouring homestead closest to the main highway access share an air of rugged chaos that one might find on the beach in Iqaluit or perhaps the "hills of Kentucky", as one of Tom's well-travelled colleagues remarked. Despite the stereotypes that such outward appearances illicit, these neighbours have turned out to be capable and reasonable folk as well as a considerable resource of local knowledge. This local knowledge is irreplaceable if one's goal is to build his own house from the resources of the land; knowing who to talk to and where to get supplies are necessities that even the solitary figure of Henry Thoreau could not avoid at Walden. These are comparable projects, the Lanark and the Walden, though split by over a century and a half, as both ask critical questions of how we might live freely outside of convention. One must not mistake Mr. Critelli for the transcendental libertarian that Thoreau was at Walden; he is less concerned with the contemplation of moral truth that might be found in nature's orders, and more with simply living closer Henry David Walden Walden or, Life in the Woods (US: Knopf Publishing Comp. 2006) 187.

to the land.' But both projects were experiments in living 'outside' the norm, and both began with a building.

Little more than a bunk and table, Tom's first shack was a primal experiment of living in the woods. A literal transplantation of the ideas and techniques used in Cabin 5, this was a building of great economy and simplicity, sited on the eastern fringe of the road accessible Main Clearing. Incidentally, siting the building in this location was a poor choice as morning sun and exposure, in addition to a lack of adequate ventilation, made summer morning sleeping unbearable. Eventually, this first shack was supplanted by a second, the Bunkhouse, and was converted to a Tool Outbuilding that services other activities on the site, particularly the Mill. 

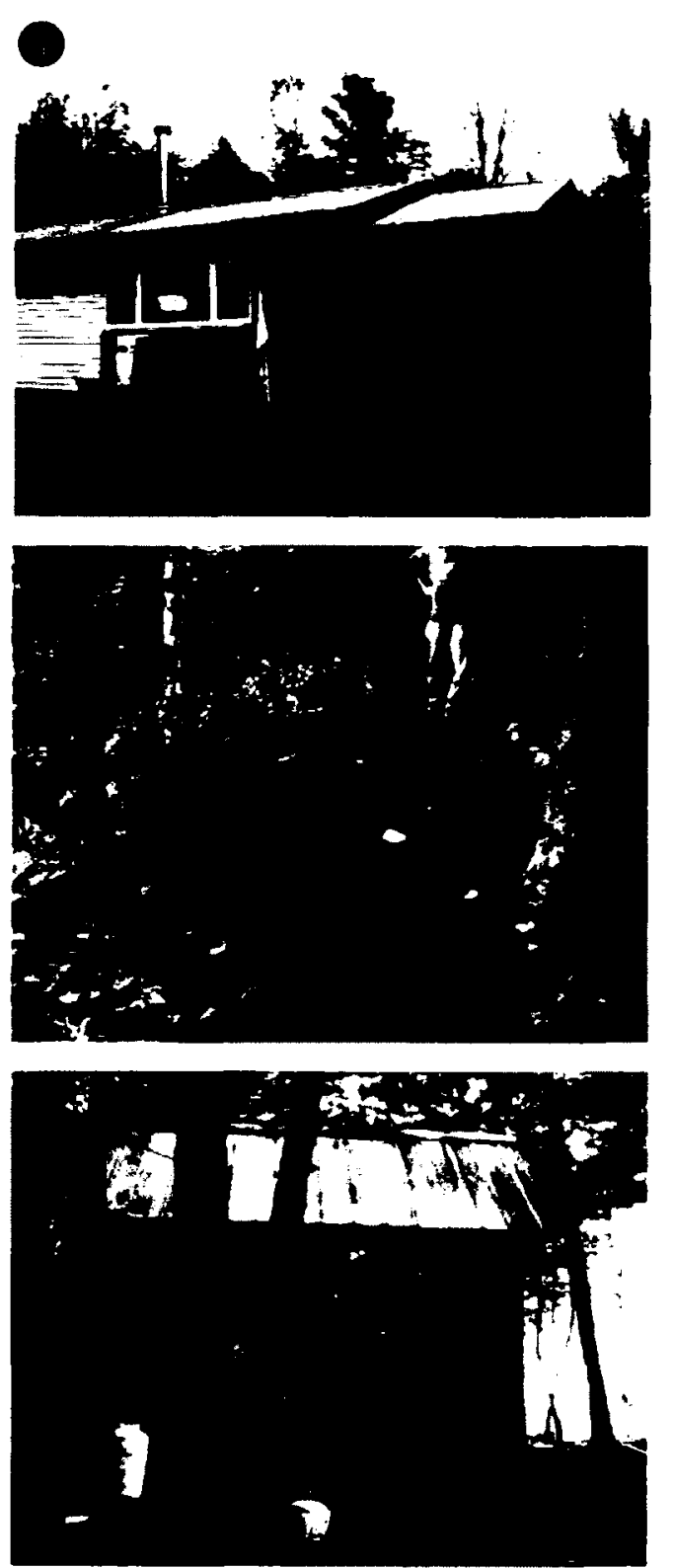
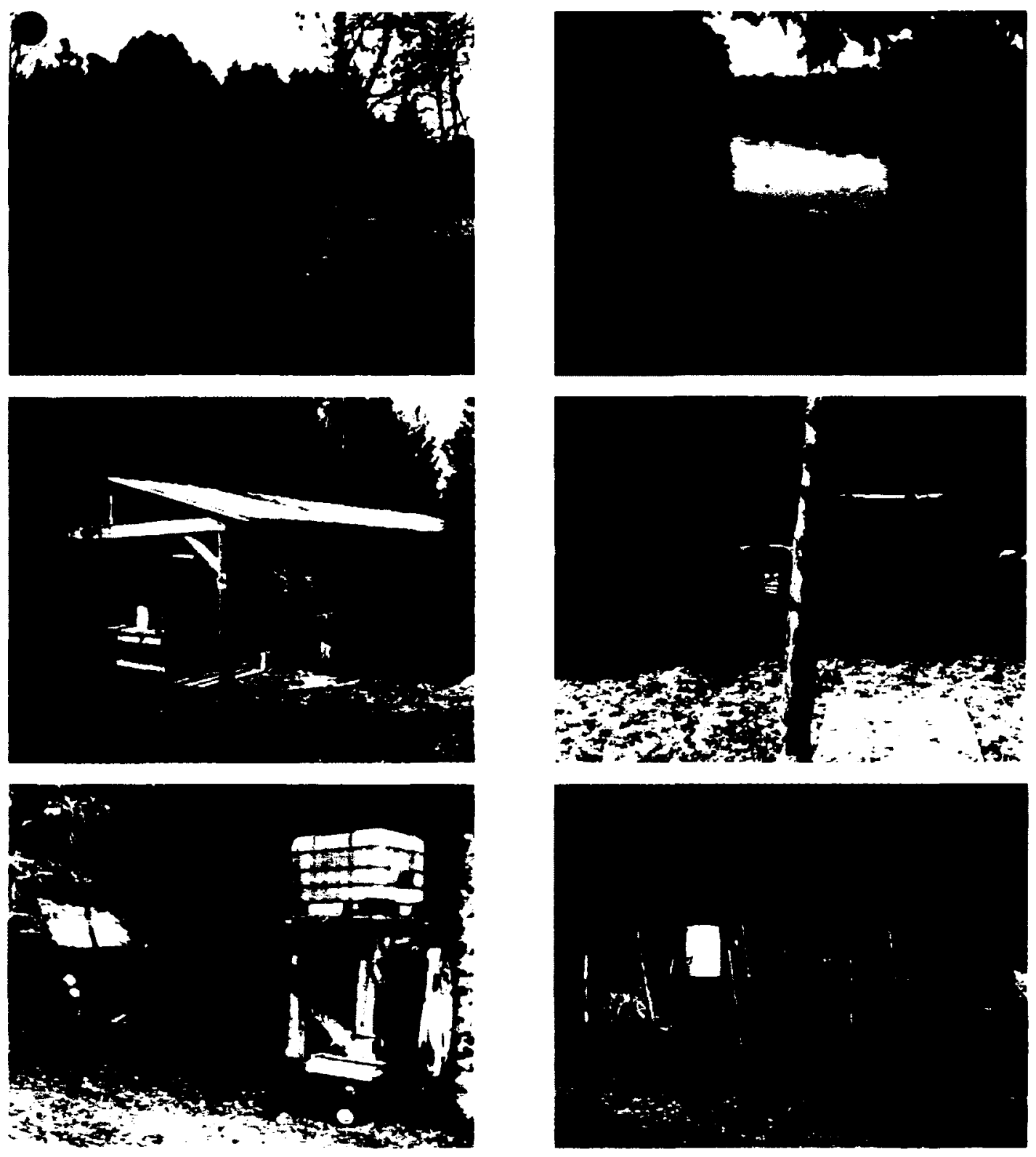

plate 6-3. Photo narrative of land use project 
By converting the bulk of the property to a Managed Forest, Tom received considerable tax reductions while opening up the potential for capitalization of lumber resources. In return this land must be developed through the planning, maintenance, and use of Trails for logging, recreation, and to establish ownership. Conceived as Nordic ski paths in the winter, many of those now in use are ATV accessible to facilitate the removal of logs from the forest. This accessibility is highly determinant on the size and type of wood that can be used for building. With the equipment at his disposal, a four-wheeler and a modified trailer, Tom considers 12 foot logs to be his ceiling.

The second building on site, amongst the trees west of the Tool Outbuilding, was the Mill. No more than a rough-sawn roof on log posts to shelter an industrial lumber milling machine, this structure required permitting and knee-braces by the authorities. Aside from the challenge of building so heavy a structure practically on his own, learning to assemble, use, and maintain this device was perhaps the most strenuous activity that has taken place; all of its 674 bolts were lovingly hand tightened. The steepest learning curve for this project, however, must be dedicated to tall-tree falling, particularly when YouTube is the professor. With this framework in hand, copious milling and testing cycles have been completed and hundreds of feet of lumber are air drying.

In anticipation of eventually building a house on the site, Tom constructed a third building, his small Bunkhouse, as a material testing mock-up of sorts. Sited under the trees at the north end of the main clearing near the edge of a steep slope down to the river, the Bunkhouse incorporates lessons learned with exterior detailing tests for cedar shingling, board and batten, and galvanized steel roofing. This building will serve first as sleeping quarters and then as a guest outbuilding as house construction progresses. 


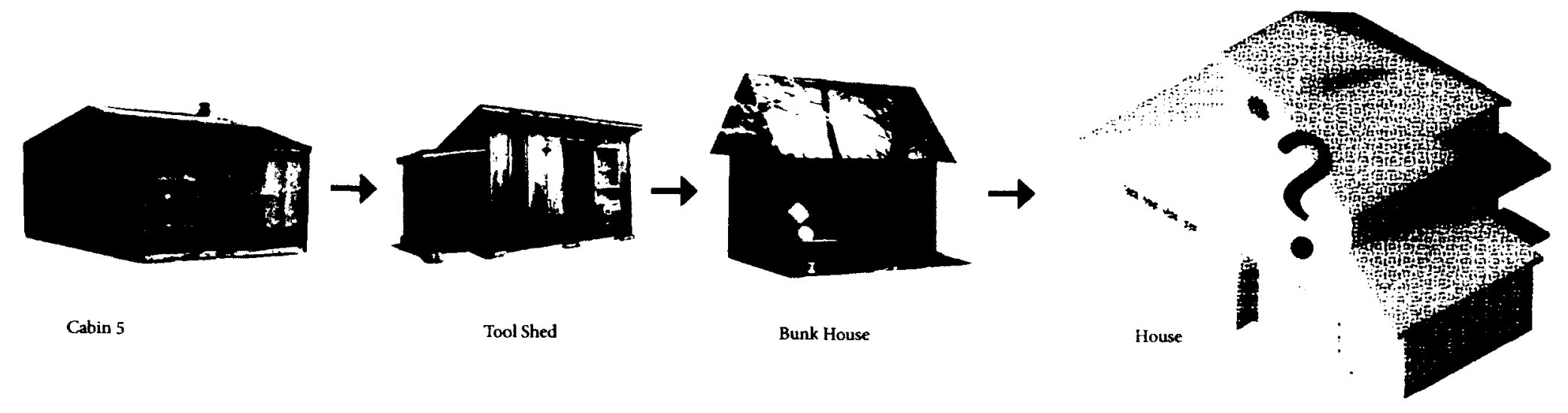

plate 6-4. A series of trasnlations 
Directly adjacent to this was built a small Water Tower. Supplied by a motorized pump with connection to the river, a cistern holds grey-water for cleaning and control of branch burning activities.

A number of small Fenced Gardens have been built in the Main Clearing, either side of the main Truck Path that leads from the Tool Outbuilding to the House site that sits on a rocky outcrop adjacent west of the Bunkhouse. This area was in the process of being cleared when I first met Tom at the beginning of last summer, marking his fifth year into his project. Before proceeding on to the House and my role in this story, we might take an opportunity to reflect upon the notion of hybridity as it relates to Tom's project.

denies the possibility of completion As a steward of his Managed maintain and develop it and its trails. It is a continuous process just as his movement of structures and programs on the site are.

Less a matter of tactics than on the beach, this project might be more relevantly interpreted as a translation of the cabins on the land, but how so? If we return to the general themes presented by the cabins on the land, there are obvious parallels; siting of his buildings is based on his biased and personal understanding of the place and his itinerant travel through it; experimentation is occurring at various scales - the whole project is an experiment; his is the process of learning to live in and build from the wild in an ongoing way, which inherently denies the possibility of completion; the notion of economy is linked between building and the land through integration and minimization of impact rather than by the commoditisation for profit. The idea of translation however, implies a fundamental change or re-creation, if we use the term as Bhabha has developed it, and it is in the use of materials that this is most clearly read. ${ }^{2}$ While the Tool Shed is almost a transplant of the small cabin typology found in the north, in its material treatment, roofline, and even its exposed site location, the Bunkhouse is of similar intent and program but is rendered and sited in a new way. This speaks more than anything to 


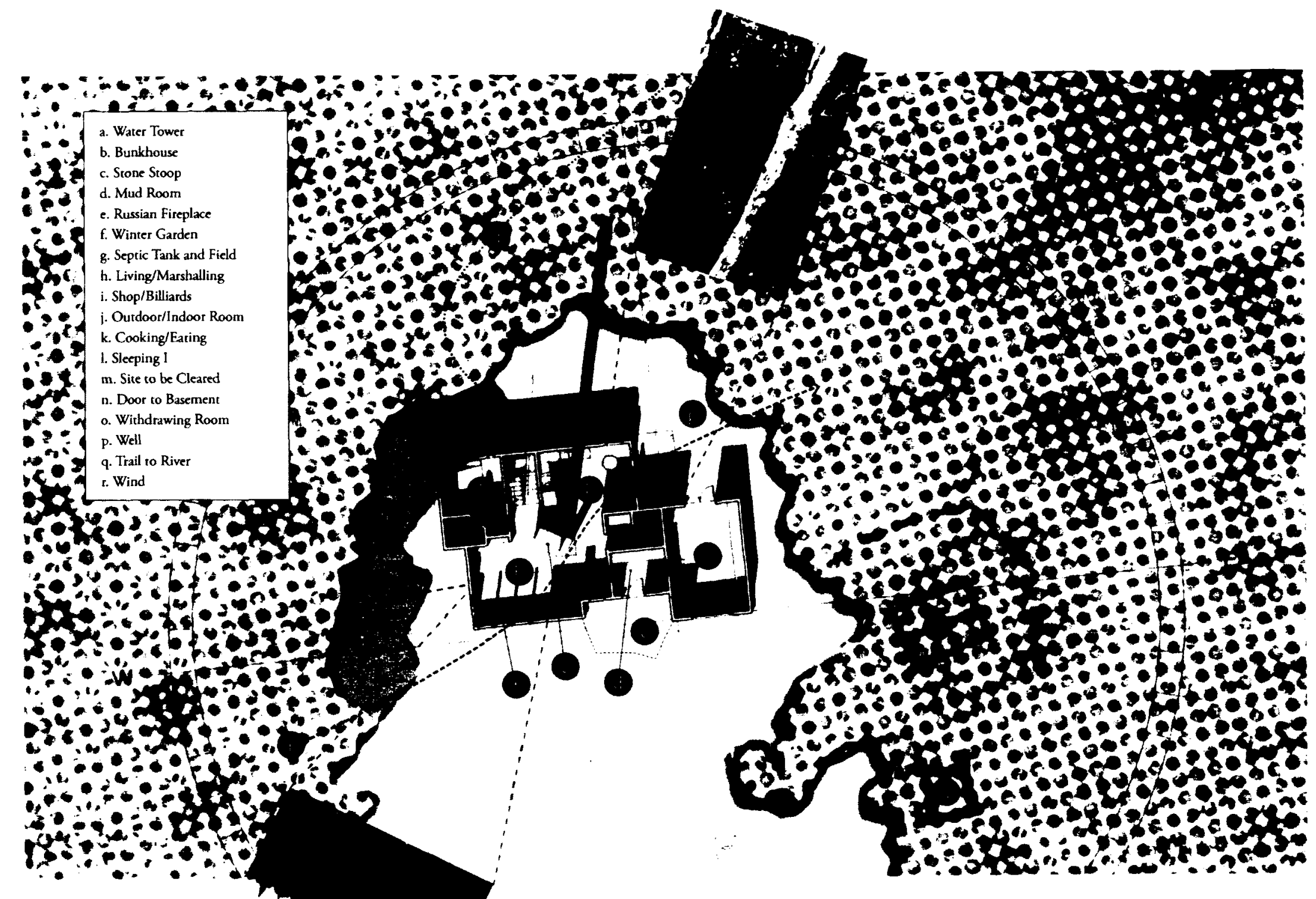


easily processed

While rock, sand, gravel, sand sod, ice, and tundra are all accessible materials in Iqaluit, none of these

has been successfully integrated into buildings in a mainstream way outside of landscaping and foundation

work. Further to this, there are no

skilled tradespersons to work with these malerials in a way that has been integrated into the contemporary construction industry.

Since Tom does much of his building and milling on his own he has developed a sense of what he can manipulate and maneuver; a typical $8^{\prime}$ by $12^{\prime}$ stick frame wall is his upper limit.

when we met I was first contacted by Tom previous to the undertaking of the thesis and our initial meeting was one of gauging parallel interests. Although we left positively it was unclear how things would proceed. the fundamental availability of raw materials and their processing. In the woods, and with the skills and equipment he has acquired, Tom is able to obtain vast amounts of 'free' renewable construction material if he is willing to put in the labour required to process it. In Iqaluit, there are no raw natural materials that can be easily processed and incorporated into modern construction for cabins, so the recycling and reuse of construction waste has taken its place. To further reinforce the notion that this is not simply a matter of material substitution, we must consider that Iqaluit has no formal means of recycling such waste; it is part of the environment and it's free in relatively large quantities. It is in this sense that Tom's maxim, "I'm not driven by a time schedule; I'm driven by what I want to build and what I can use from the land" is best appreciated.

What Tom is driven to build ultimately is a House on his land. It seems a natural progression given the story thus far, but to accomplish this next build critical thresholds must be traversed or at least negotiated. One such limit is a formal one, past it there are myriad codes and inspections that were not previously applicable. Scale presents another barrier for a single individual. A third threshold relates to permanence and the intent towards it. It is clear to Tom that the house in his mind requires help from professionals, contractors and engineers, but he wants to lead, to be involved at every turn, to mill, and to build. It is also clear to Tom that he needs an architect, though it was not so when we met. Indeed, it was not so clear to me either how such a partnership might turn out, as his involvement was such that I felt aggrieved to design so personal a project and sign on to something that might take a lifetime. This journey however, presented a collaborative opportunity to us both, to figure it out together working towards 'incompletion'. 

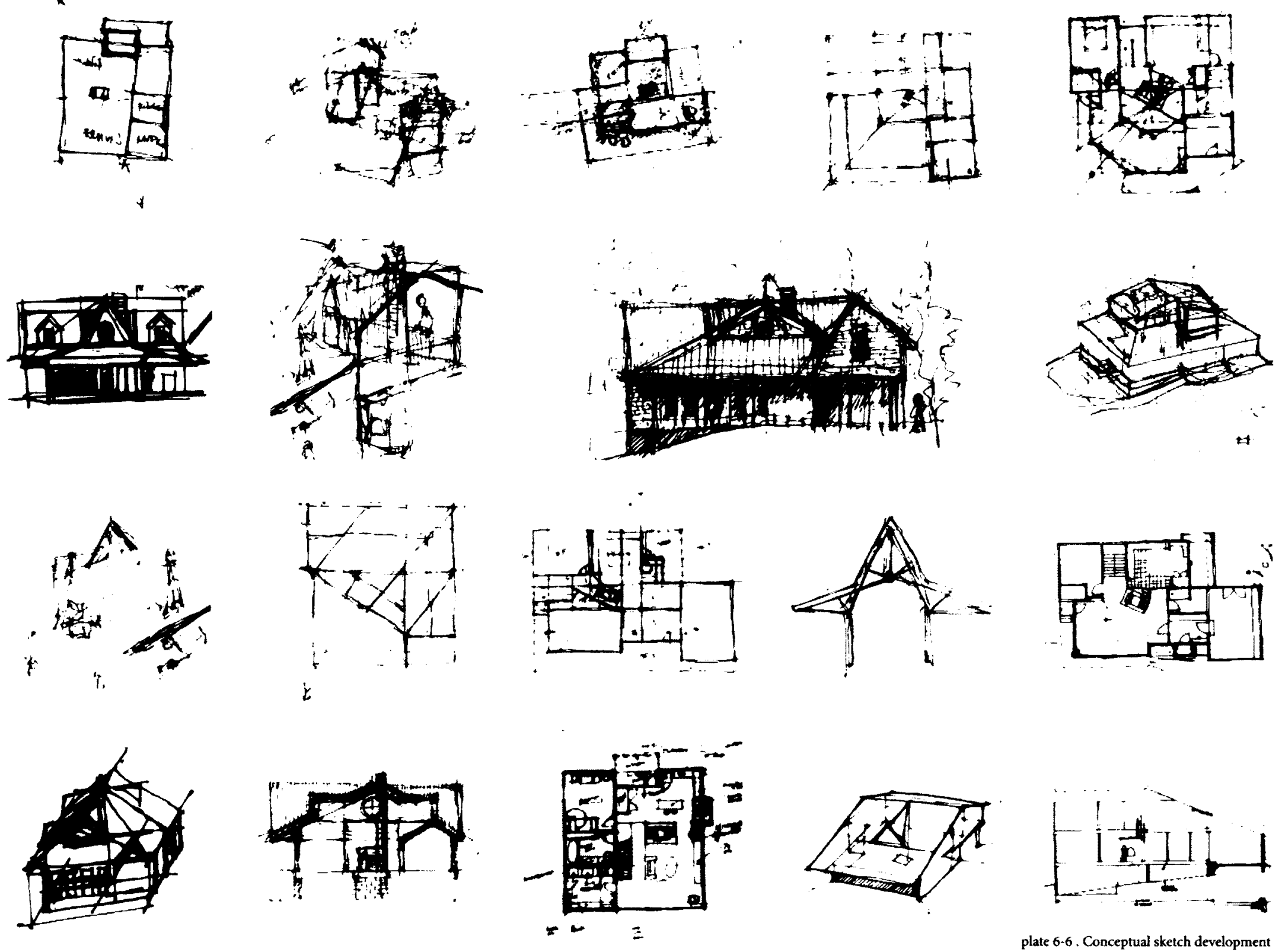
The Corporation of The Township of Lanark Highlands "Single Detached Dwelling Guide"
For many places in Ontario (and across Canada), by-laws governing construction are developed to prohibit occupancy prior to "finishing" a building through the provision of milestone inspections that speak to industry standards and best practices. If we look at the residential house typology in the Lanark Highlands outside of Ottawa, for example, there are seven municipal inspections that precede the final inspection which permits occupancy. ${ }^{3}$ While this framework facilitates the authority having jurisdiction through a measure of quality control and risk aversion it severely limits the ability of a house to be constructed over an extended period of time. In essence it assumes that the building process is finite and separate from the process of living on a site. This can be attributed in some ways to the idea that building is an industry that is part of a large and interconnected web of economic forces and not a way-of-life outside of capitalist endeavour. Can we reverse the emphasis of this idea, to consider building as a way-of-life that is supported by industry?

Intrinsic to such a concept is that building is a process that does not end; it is unfinished and is intended as such. Such a change, while seemingly subtle, is catastrophic for formal frameworks that are embedded in industrial relations to time. Likewise, if we consider Benjamin Franklin's capitalist maxim of "time is money", self-building as a way-of-life is an idea that is not concerned with the accumulation of wealth, but rather the expenditure of it. This switch signals a move away from the building as an object of embedded financial capital and towards a process of living for an individual based on the development of cultural and intellectual capital. The capacity of the individual to determine this process is critical. However, as the process of designing and planning this house has exposed, one cannot very easily turn ones back on the commercial-industrial systems of the status quo as Thoreau had done at Walden. Indeed, the concept and intended rendering of 


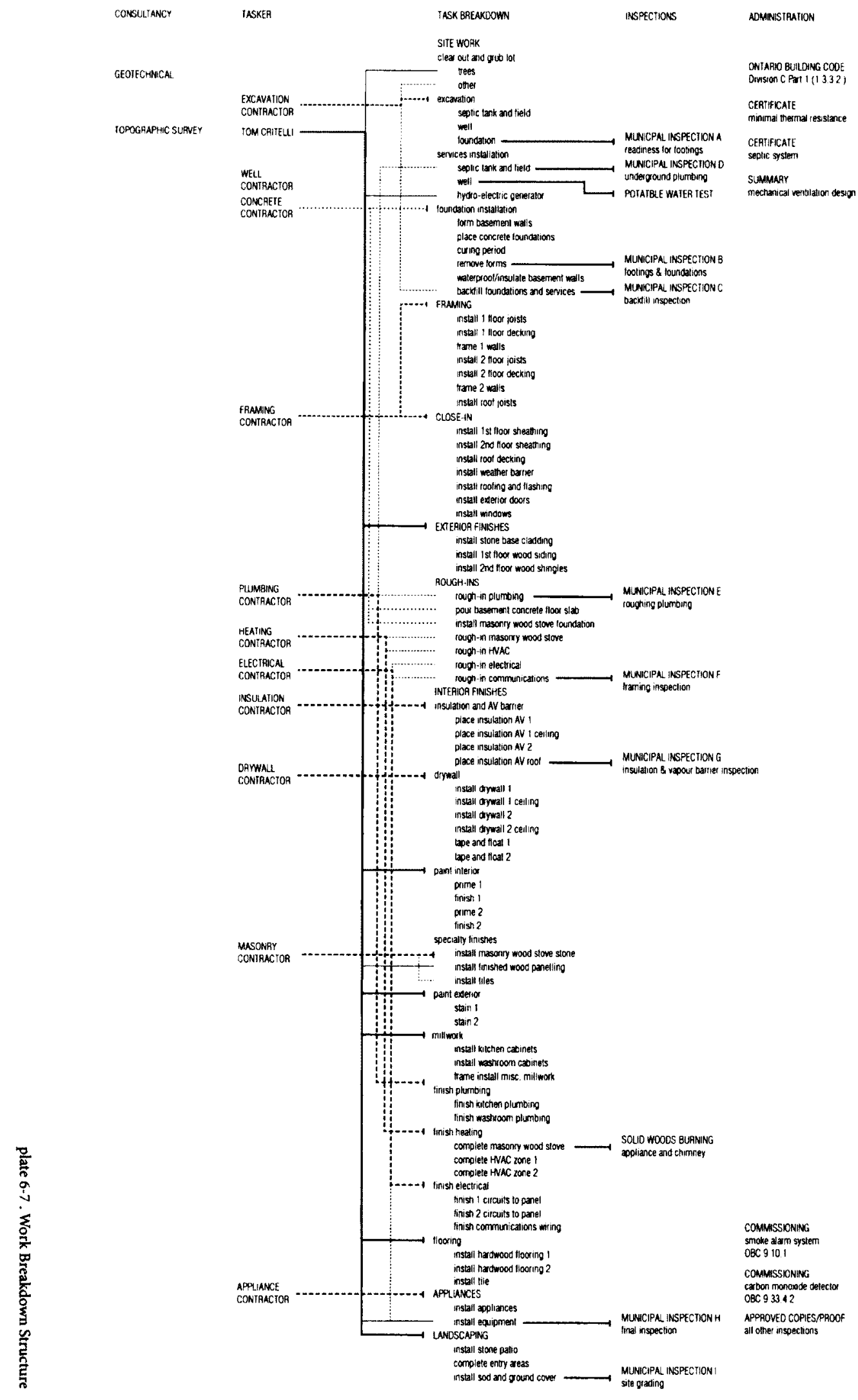


this house constitutes a divergence from the norm (as will be explored below) to the extent that financing it economically is the most significant issue. Numerous variations of mortgaging have been tested and have been found inapplicable while construction loans are too restrictive with regards to completion scheduling. It seems as though there is complicity in the enforcement of completion from all sides.

From the perspective of a lender, the concept of the House presents numerous issues due to its 'wildness'; it is remote, it is off-grid, has very limited access, will use non-nominal lumber, will include a concrete basement on a bedrock foundation, and is in a sensitive natural environment that is to have a minimal construction footprint. Tom's original idea for the House was to build it completely on his own beginning with one 24 ' by 16 ' room, and adding rooms and spaces over time as one would with a cabin or cottage. But this represents a project that might be too much for a man his age to undertake alone, so he accepted the basic model that a house represents for all of the large portions of the work such as foundation work, framing, roughing in, even roofing. This outlay provided me with a simple framework with which to approach our collaboration based around three questions; How do we translate the essence of his original idea into this model?, How can I help Tom be integral to the process at all times?, and What can I learn from this collaboration?

work breakdown structure This excercise placed Tom in the context of a series of tasks. contractors, inspections, codes, and consultants in a preliminary relational sequence. Through this we were able to fine-tune the parts of work that he wanted to do in relation to needs from outside and in turn where my focus would lie.
Our partnership began in earnest with the development of a modified work breakdown structure, which I believed could be the focus of an ongoing methodology of communication, and out of it we determined that his involvement would be focused on management, materials manufacturing, finishing, and site work. With respect to his contribution of building the House itself our question became, "How do we design a 'finished' house in the eyes of the policies while maintaining the potential for long-term building?" 


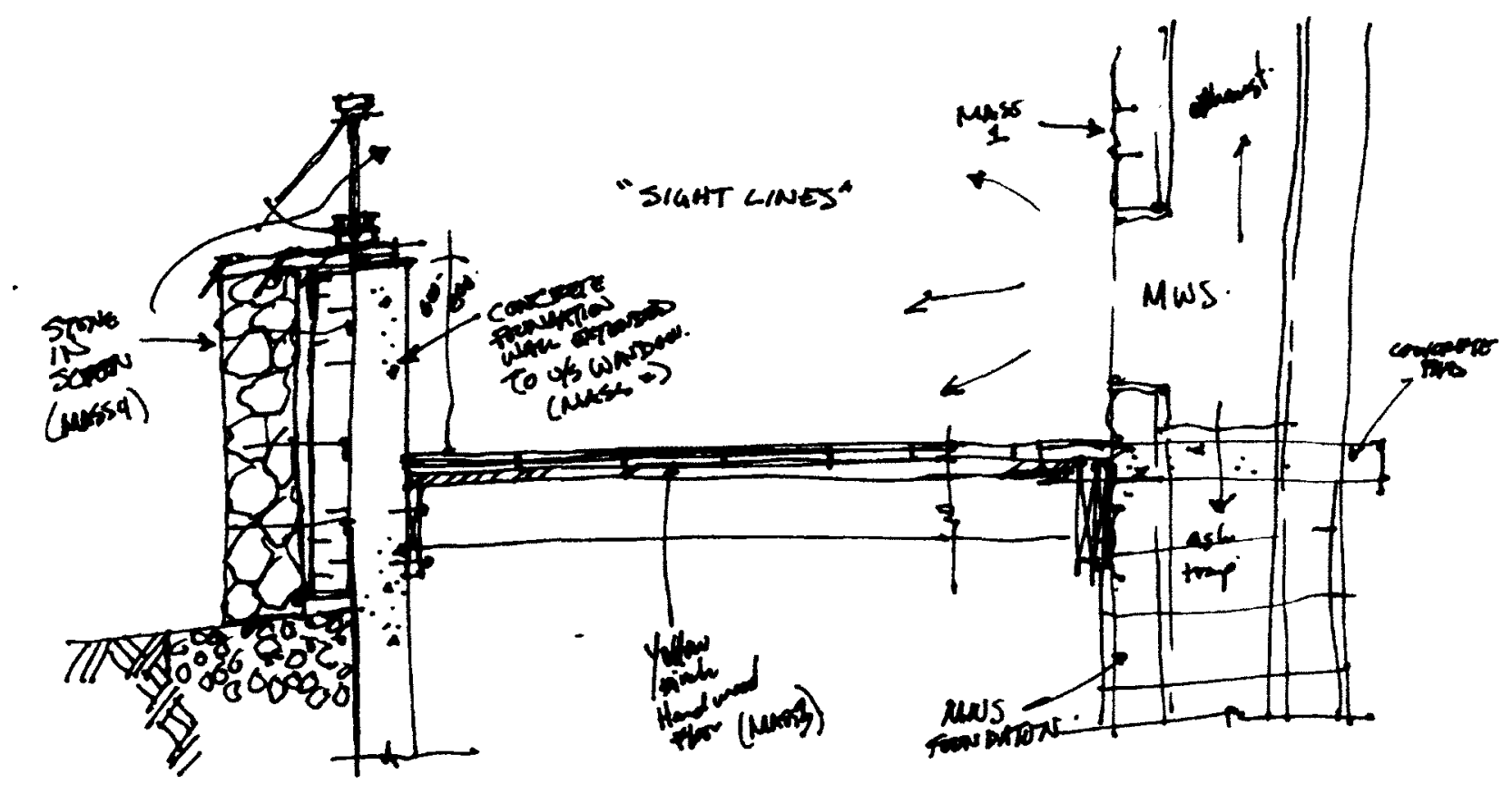


The house itself had been meticulously considered in terms of program, site orientation, internal and external adjacencies, circulation, and image before I had become involved; materials had been chosen and were in production while key products had been sourced. One such product, a masonry wood heater or 'Russian fireplace', became the critical conceptual and organizing element around which the design of the house evolved. It established the long-term commitment to a ritual of 'feeding' that implicates the interior to the exterior and other programs on the site in addition to internal multi-programmatic functions and technical requirements. Where the work breakdown structure ultimately became a tool for Tom, the plan became the tool through which we were best able to collaborate and communicate ideas. So lucid was the program and information provided by Tom, that within two iterations a parti was established, despite my own continual efforts to fine-tune and disprove its solution. Elevational, sectional, and volumetric representations did not centre discussions; the House, with its growing program and complexity was not something that was accessible for him in its totality, as Tom's viewpoint lay at the level of detail and use. Here it became clear that the architect's capacity for synthetic visualization was to establish a key role in the design process. Being able to interpret Tom's imagination within the context of my own codified language, which has been developed in the north
I'm thinking of a house that looks and feels like a cottage. Check Wood frame construction over two floors and a concrete basement. Check (fantastic, no permafrost, I finally get to do a basement). Russian fire place for the main heat source, they are fantastic, radiant heat. Check (what is a Russian fireplace?), no wait, are you sure about that you'll probably want some backup, or maybe that could be the backup. It's the most important part. Let me have a look at it (can't believe he's got a make and model number pulled out). Probably just one big room on the main floor as the fireplace requires and some bed rooms upstairs. Check. But we will definitely need a mud room. Better make it a big one, and let's program it (now we're talking). Here is a picture of a house that I like, I'm thinking about a roofline like this. Uh, alright (wow, Harry Potter aesthetics. especially the roofline), you know, with a compact house like this we will probably want to look at getting some light into the deep interior, let me work with that roofline to get some light penetrating. Okay, also this is going to offgrid, with propane appliances, cold cellar, well, septic field. and micro-hydro if I can get it past the authorities. Check (damn, none of these are used in the North. I'm out of my comfort zone). I'm going to clear the lot and make a road myself. Check (he's quite industrious). Oh yeah, and I'm going to cut and mill the all lumber myself and build of much of this as I can. About that, you know I had this discussion with our mutual friend last year, it makes no financial sense for you to build yourself, the contractor has economies going for him, it'll take you forever; you may never get it finished. That's the plan. At least conside subbing out the framing and use engineered lumber for the long spans (risk aversion plan step one). That sounds rational, I was planning on using contractors for some of this, how much do you charge? I'll have to get back to you on that one, but I'm interested (I will never be able to make money on this)

Initial Interpretation of Tom's Program (based on a pre-thesis meeting) 

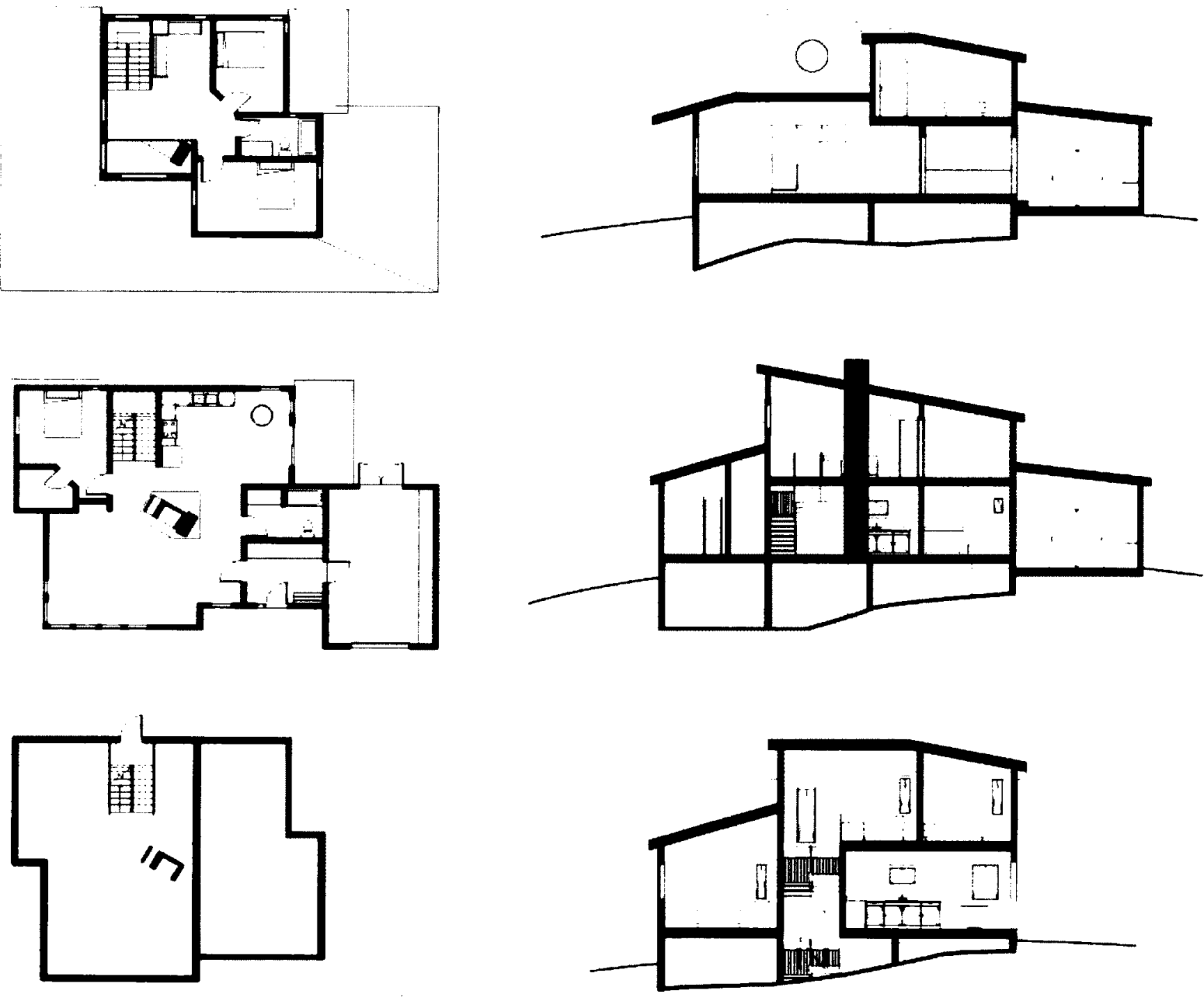

plate 6-9. Plans and sections 
and with a decidedly 'neo-modern' aesthetic, was a challenge for us both. My desire to make this 'Tom's house' led to a tempering of my own design instincts though he, it seems, was quite content to let me express myself. To date this issue of authorship is, for me, still unresolved and ongoing.

To mediate the step from informal building to house while maintaining a capacity for incompletion, the building as a design object was replaced by the building as design strategy. Tactically this was rendered in a number of ways that are necessarily subtle; provision of substructure for future growth, faux-finishing of surfaces to allow for on-going 'minor' revisions over a long period of time, flexible programming that anticipated both ongoing construction and the migration of building throughout the house and on the site, and phasing of small projects to both precede and follow the minimum requirement of obtaining occupancy.

making time

A final reflection on this sojourn speaks to this tangential aspect of hybridity in building from the standpoint of agency. A house is not a cabin, but at its heart Tom's House wants to be one. It is a zone of negotiation in this sense between formal requirements and informal intentions of self-building. Money is not the driving force. To operate
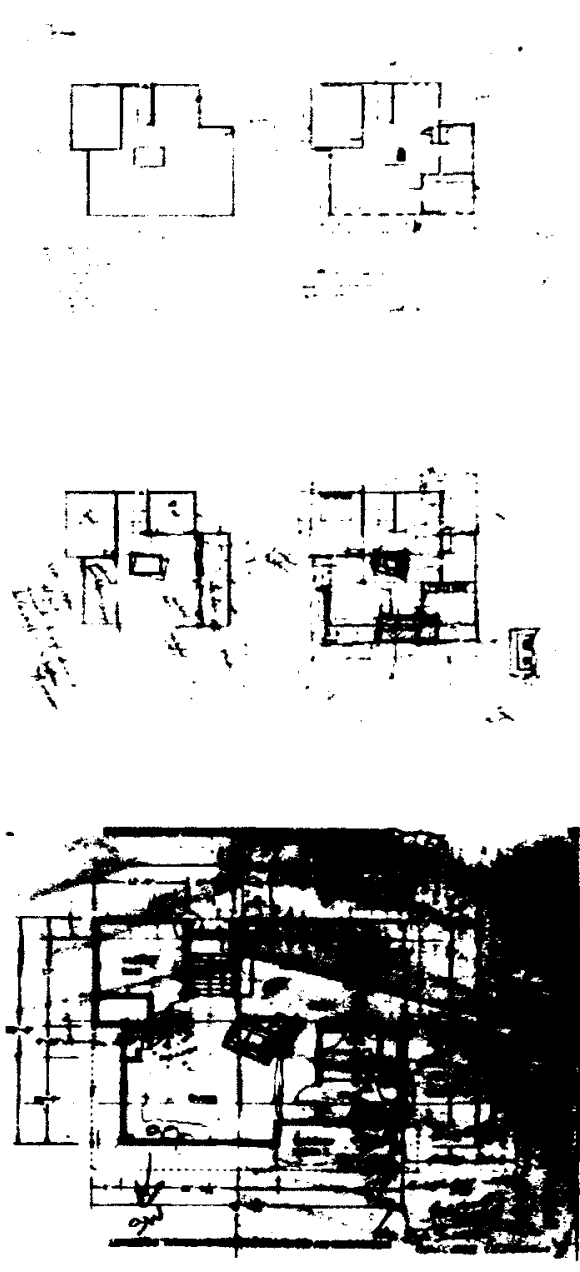

figure XX: Plan-based communication 


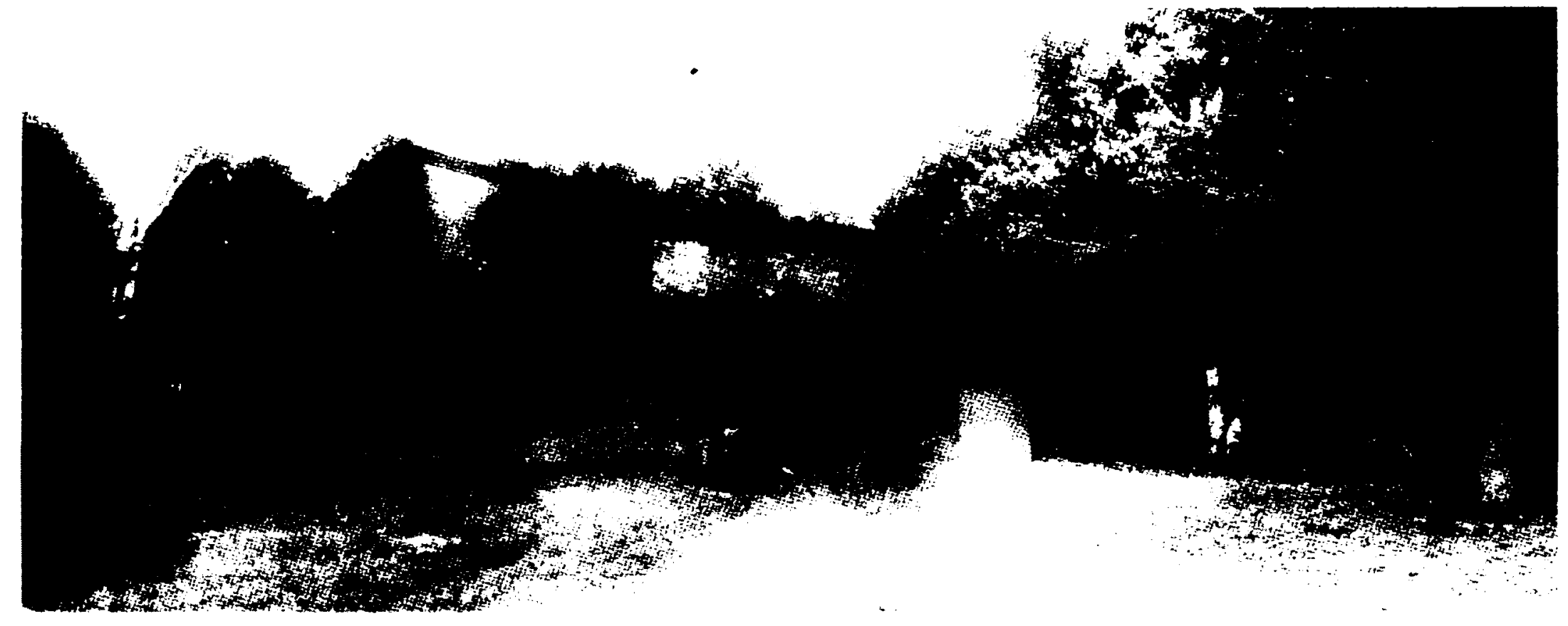


outside of, but in parallel with, a model in which money is the driving force requires the buy-in of collaborators rather than simply the employment of others to achieve its agency.

In Spatial Agency authors Schneider and Till remark that "the most valuable commodity of all in such contexts [as communal planning networks] is the giving of time, the making of time, and not giving up." My own trepidation with initially engaging this Schneider et al. 72 project outside of the thesis was related to the giving of time in relation to money, as I realized immediately that a cash-for-services approach was inappropriate and would not be profitable. Tom's informal network has grown to include a surveyor who called me to confirm technical information, but more so to make it clear that he took the job on minimal non-profit fees because Tom was "a man's man" and he "believed in the project." His work was thus minimal, his impact light, and it is in this way that the project is progressing. Though he himself is not 'driven by a time schedule', Tom must manage, negotiate, and advocate for it.

With this notion our time in the woods is done for now as we once again look to the North. We are leaving just as Thoreau did, to seek out more, but not without a final thought that we architects and builders alike might hold dear; "If you have built castles in the air, your work need not be lost; that is where they should be. Now put the foundations Thoreau 286 under them." 


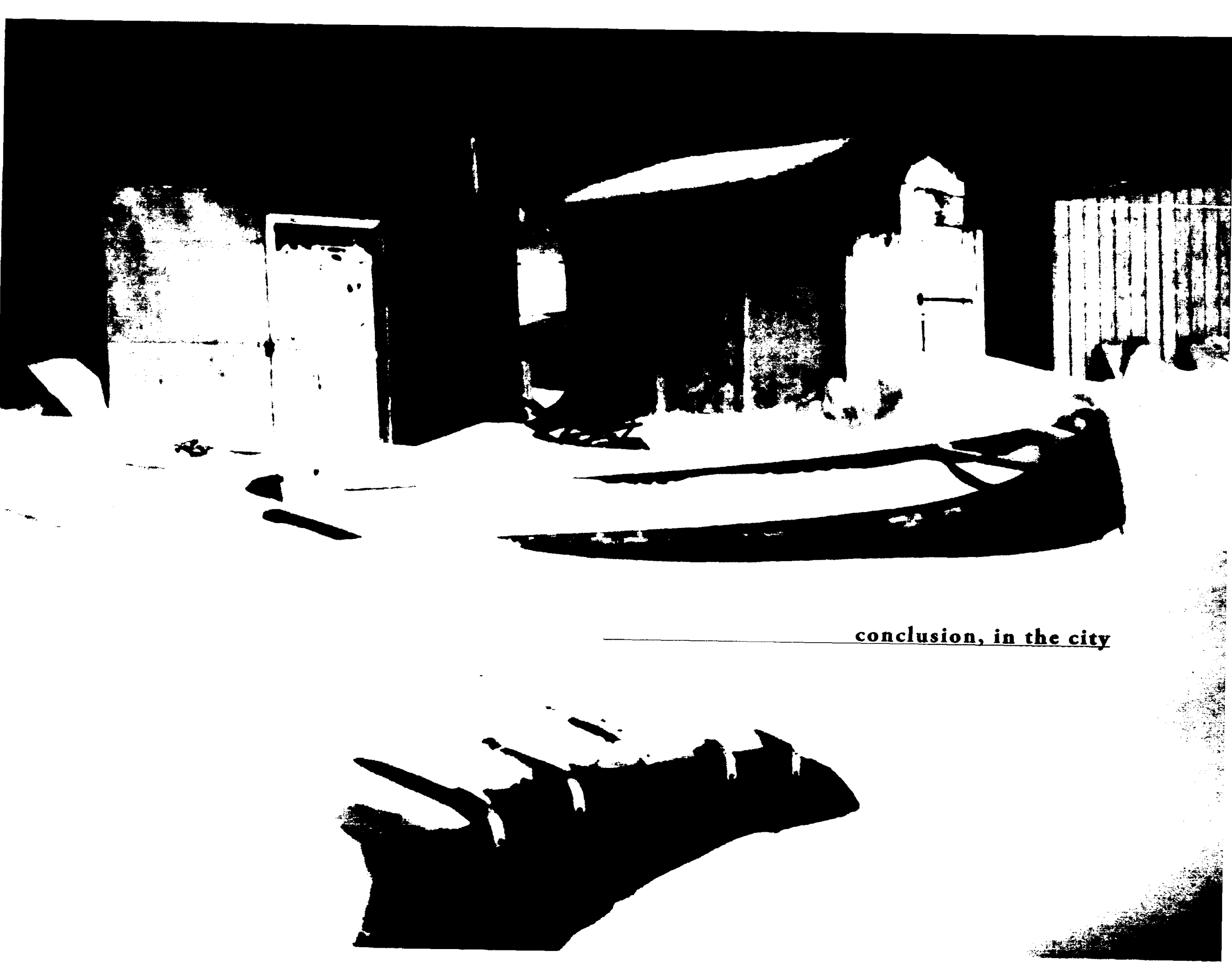


CHAPTER 7

Is this the destination, or just another stop for tea? It is busy, business is booming, and everyone seems to be looking forward to something. Oh yes, spring is coming. The animals are returning and the sun is getting higher. They will be building soon. Perhaps we should stay awhile and make something of our trip so far. What is there for an architect to do?

The architect's role is under scrutiny, again.

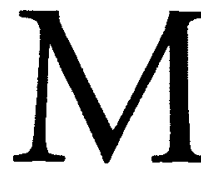

any miles ago, we embarked with the premise that the Shacklands were of a domain outside of the realm of the professional architect because of the inability to become situated informally. This basis presented an opportunity to question why that is, what ideologies are relevant, and which constitute the status quo. We also surmised that we might draw upon the notion of hybridity as a means of critically approaching these investigations from the perspective of an unfulfilled second promise.

How might we assess the notion of 'agency' as it has been invoked; what have we learned thus far?

To begin again here, it might be useful to reconsider our working definition of agency as it relates to the architect. Drawing from Kossack et al., we noted that agency is the acknowledgement that unless a critical stance and responsibility to act on behalf of others are prioritized, the actions of the architect inherently support the ideologies of the status 
quo because architecture, as a field, is complicit with them. The idea of the second promise, that there is a space for Nunavummiut related to a culture outside of the bureaucracy dependent dominant stream (that we have determined is in a process of de-colonization), finds accord with Stewart Brand's ideas about 'low-road buildings' and the inherent freedoms of building for one's self. Both the second promise and the 'low-road' are critical of the status quo and thus of the architect. Throughout the study of the Shacklands, which are spaces built of these two ideas, we have attempted to become situated and in this way to test our own agency.

Recalling our first stop, on the beach, we endeavored to make sense of what is now seen as a 'messy situation', both literally and in its political interest, by considering how it evolved as a hybrid urban space. This study proposed the consideration of a series of formative tactics, employed by both authorities and users, which have impacted this evolution and provide a backdrop for further considerations of development and management. It is clear from the perspective of the City that change must occur, and through this study we argued (by attempting to establish value) for a balanced and inclusive approach, at least with respect to the Inuit Owned Land areas. At one level we could claim that we are acting as agents on behalf of this space, 'making sense' by exposing and linking networks of influence,

formative tactics $(p 63,65)$ Tactics of Authority disengagement vague definition minimal enforcement individual based intervention deferral of responsibility

\section{Tactics of Subversion} action through building squatting

avoidance of visibility ignorance of poicilies complaint resistance however without the input of all beach shack owners and stakeholders, we cannot claim to have been completely accurate. How might our views have changed through extended public consultation? Such a long-term relationship is beyond our scope but remains a critical deficiency. We must also question what we have done that a hired architect would not, and in this case we must claim that our key contribution was to take an interest. This should not read as an understatement; for numerous stakeholders (both authority and public) the voicing of opinions, views, concerns and hopes to an aware and implicated 
building operations ( $p 83,85)$ freedom in site selection and response to environment

use of salvaged materials and re-use of old materials

flexibility in design to facilitate continuation of building process for the long-term

experimentation in technique, program, and form

high regards for economy in scale. efficiency, impact, and cost

ohn Maurice and Rhoda Ungala "Personal Interview" Feb 2012

resourcing the environment $(p 99,101)$ This speaks more than anything to the fundamental availability of raw materials and their processing. In the woods, and with the skills and equipment he has acquired, Tom is able to obtain vast amounts of 'free' renewable construction material if he is willing to put in the labour required to process it. In Iqaluit, there are no raw natural materials that can be easily processed and incorporated into modern construction for cabins so the recycling and reuse of construction waste has taken its place. To furthe reinforce the notion that this is not simply a matter of material substitution, we must consider that Iqaluit has

no formal means of recycling such waste; it is part of the environmen and it's free in relatively large quantities. mediator, is an opening up to inclusivity and, at its best, a cathartic reconciliation. Who else is there in Iqaluit to ask such basic questions of building, space, and value?

Nowhere was this more obvious than on the land. Indeed, in our attempts to 'make visible' the new trend of building and land use practices that are elicited by cabins, it became keenly apparent that built into these structures were "hopes and dreams" to quote cabin owner John Maurice.' This study of an emergent typology yielded a set of general building operations that came out of an absence of authoritarian determinacy. Clearly, our reading of these structures was premised upon a background of architectural codification, and it is in this translation that we as architects might take a further role, as agents for the consideration of including such practices in the city proper, and within the systems of the status quo. However, this study requires further analysis and interpretation, and would greatly benefit from visits to the clusters at the American and Bishop Islands which are known hunting bases for Inuit families. Further, additional documentation of cabins with owners/builders would add considerable depth to this survey of hybrid land use.

Our retreat in the woods might read as a departure to some extent but it offered an opportunity to examine the proposition that hybridity is a concept that must be considered not only through the lens of the North, but rather in relation to the individual's translation of a 'Northern way' or ideology. Through the documentation and interpretation of a land use and building project by a northerner in Ottawa, a practical framework of resourcing the environment was considered in relation to Iqaluit. In addition, this sojourn provided an opportunity to both test the application of said framework and the notion of agency through the collaborative design of a house. Through this collaboration, the contradictory ideologies of the northerner as a self-builder and the structures of the status quo were 
exposed to elicit a re-situating of both the role of the architect and the client. By 'making time' and becoming a collaborator, rather than simply a distanced consultant or designer, the architect as agent was forced to focus less on the architectural object and more on the process of integrating the self-builder into the structures that govern formal construction. In this sense the architect operated in the capacity of mediator-translator between his language and that of the codified industry. However, it must be noted that the resulting design and role of the architect became increasingly aligned with a 'conventional model' as the process proceeded towards the resolution of an object-idea as presented herein. Finally, this exists as an unfinished project and an unfinished collaboration, both intentionally and not; the self-builder is still assessing funding and using the current design to develop a network of contractor estimates and contacts while detailed design progresses.

Can these studies inform a new vision for the Shacklands and its place in the City?

\section{A new vision for architects?}

Turning to the beach, we must accept both that there are significant problems and tremendous values in its evolution and current manifestation but also that it is critical to Iqaluit's spatial identity. As the ciry continues in its densification of core areas through de-colonization and development, the contesting of this zone will be further amplified and, given the recent negative attention that it has garnered, further marginalized. As the Mayor recently intimated with regards to the lack of authoritarian 'nous' in the planning and management of such Shacklands, "we need to change our attitudes."2 
Such a call represents an opportunity to advocate for a change in the way that the city, as an assemblage of people, political bodies, and structures, both physical and social relates to the beach, but also for a change in how an archirect might take part in a more invested way. This 'attitude shift' requires architects to step out of the formal bounds of practice to include "others, amateurs, in the processes" and to reject "the building as the sole source and representation of expertise" as Till and Schneider have remarked in Spatial Agency. ${ }^{3}$ If we move instead towards the leveraging of architect's abilities to visualize, communicate, take responsibility, and moreover, to navigate networks that link with the profession, might we take on a different role that better responds to the socio-cultural inclusivity that the 'second promise' references?

A point of departure for the conception of such a role might be drawn from a brief consideration of Project Nunavut and how change can occur through the leveraging of 'situation.' Founded by William Hyndman (co-owner/builder of Cabin 14 in Sojourn 2), Project Nunavut is a social enterprise that focuses on implementing "About" Project Nunavut <http:// www.projectnunavut.com/about/ the 'traditional economy' in Iqaluit. ${ }^{4}$ The most significant of these projects to date is the Country Food Market that brings together hunters who have accrued surplus harvest and buyers who are looking for country food. Hyndman notes that this project is premised on the simple fact that "you can't put a seal [or a fish] into a gas tank

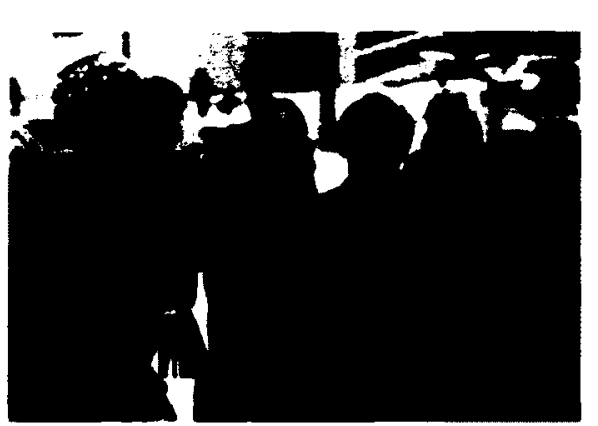

Hyndman (left) at the Country Food Market

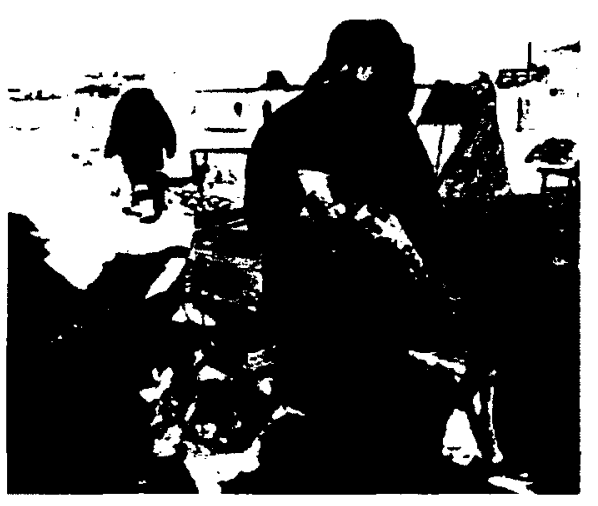

A hunter displaying his ware

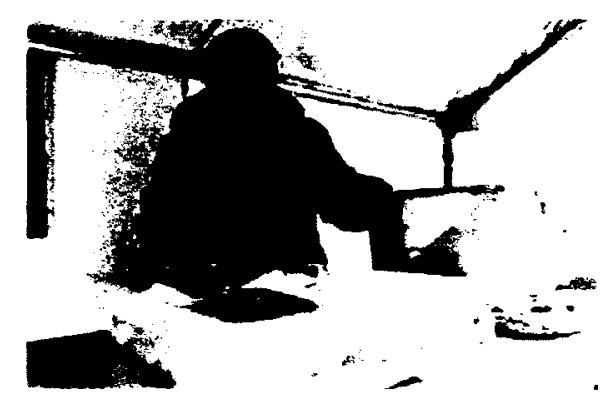

Tents and tables fulfill the program needs of the marke 
[and go anywhere]," and that hunting, as discussed in Sojourn 1, is expensive and almost always requires second employment in the wage earning society. ${ }^{5}$ Operationally, once a month, Hyndman notifies hunters and the public through various media of a coming market and sets 5 Hyndman “Personal Interview” up a number of canvas tents as stalls. This temporary spatial action has a low operating cost and high gain for its participants while making use of a highly visible, expensively constructed, and, according to the Mayor, absolutely unused space in the city; Iqaluit Square. For our purposes however, the significance of this project lies in Hyndman's acknowledgement that a top-down model was inappropriate and that his response was to take action. Hyndman, in his previous role as an Economic Development Officer for the GN oversaw a number of case files that attempted to turn hunting practices into an economic commodity driven model based on and for a southern market. Inherently these programs were expensive and mired in bureaucratic fatigue, while ultimately they were unsustainable and unfeasible. Seizing upon his situated knowledge, experience, and connections, Hyndman lobbied for, and received the opportunity to transform the budget allocated for a feasibility study (of country food markets) into an operating market that is not government run. It is not government regulated either, not in the sense of the southern market (consider the regulations required for the beef industry for example), due to the application of a clause in the Nunavut Land Claims Agreement that allows Inuit hunters to sell their harvest directly, such heavy structures have been avoided. ${ }^{6}$

Project Nunavut serves as a clear example of leveraging the notion of 'situation'. By understanding the models and processes that were influential to the traditional economy in its relation to the hunter's needs and opportunities, Hyndman was able to place himself centrally as an agent. With a long-term vision for the project as self-organized and operated through the community of participants, he is trying to change attitudes by supplementing existing sociocultural structures rather than changing their underlying relationships. 
Perhaps this model might serve us analogously for a project of architecture that further reconsiders how we might leverage the 'situation' of the architect through agency. Drawing from earlier studies we might establish a manifesto for such a project;

Self-building is an existing practice among Inuit and northerners in Iqaluit that has inherent virtues;

these virtues include the freedom to contribute directly to the shaping of one's own environment, the freedom to represent oneself physically in the city, the freedom to practice one's culture without interference from authority, the freedom to occupy built space relationally, the freedom to experiment in building, the freedom to build without completion, the reduction of waste from the environment of the city, the economical use of space and resources;

the Shacklands, most notably on the beach and on the land, exhibit a nascent built language that can be read separately from the formal buildings of the city due to self-building;

the beach is a contested, culturally implicated zone that is, in general, undervalued by the city;

the cabins on the land are emergent hybrid developments that question the definition of the city;

the city is a hybrid zone with disparate ideological influences highlighted by the contradictions of territoriality and transience;

the formal buildings in the city have little historical basis from which to draw reference for translation into the built processes of de-colonization;

the architect occupies a central position in society with regards to matters of building and planning, between the individual, the public, the construction industry, the authorities, and academia;

the project should aim to affect a change in attitude towards built space in the city that promotes the aspirations of the 'second promise';

any changes must question how self-building practices might be positively utilized to develop hybrid languages of architecture that are reflective of existing and future structures at play in the city;

any changes must be inclusive;

any changes must be supplementary rather than imposing;

any changes must serve both the city and any community of stakeholders with long-term vision. 


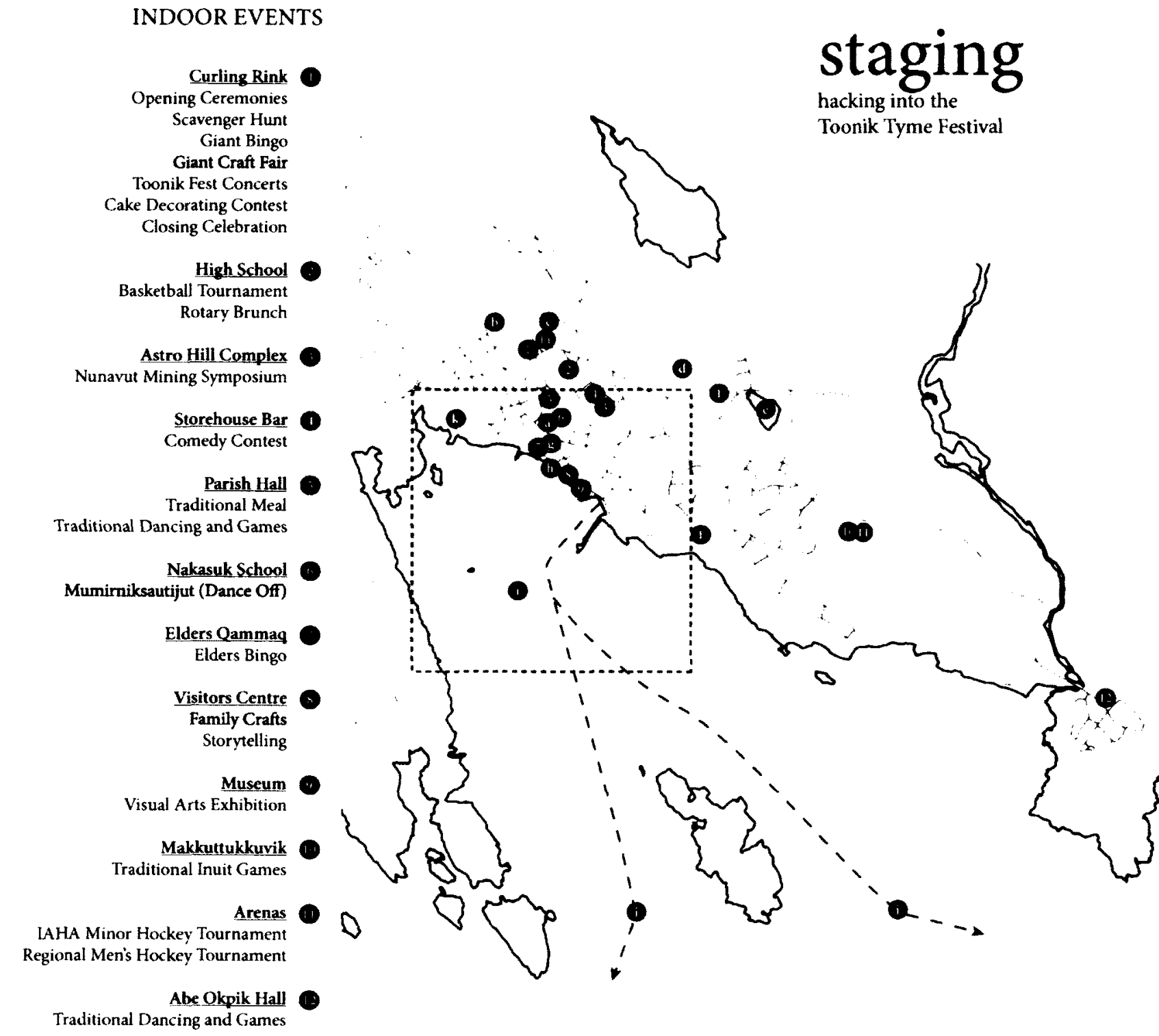

OUTDOOR EVENTS

(1) Nakasuk School Field

Outdoor Soccer

Traditional Outdoor Games

Seal Skinning Contest

Tea and Bannock Contest

Street Hockey Tournament

(1) RCMP

Ice Sculpting Contest

- Iustice Centre Hill

Igloo Building Competition

(a) Hospital Hill

Uphill Snowmobile Race

- Toonik Lake

Childrens Snowmobile Race

Ice Golfing

(1) Mountain Area/Nowhere Sliding Events

(5) Igaluit Square

Country Food Market

(b) On the Beach

Skijoring and Dog Dash Elders Outdoor Games

(1) On the lce

Kite Regatta

Snowmobile Drag Races

Snowmobile X Country Race

1. On the Land

Kimmirut Snowmobile Race

Ice Fishing Derby

Seal Hunting Derby

Traditional Dogsled Race

(1) Sealifi Are

"Shack" Building Competition: Community Shop

plate $7-1$. Toonik Tyme events 
What can we 'make' of such vision that builds upon 'the second promise?

Out of this relatively loose framework we can begin to imagine a host of scenarios but it is critical that we begin once again with the Shacklands and the lingering question that hangs over them; can they be places for 'everyone' in the city and still retain their essential and contested freedoms for Hunters that have appropriated them? Despite access restrictions to Inuit Owned Lands, as covered in some

sections of the NLCA, these already are for all intents and purposes, places in the city that anyone can travel through and use. What they are lacking however is a spatial language that promotes Tunnganarniq or "the fostering of good spirit by being open, accepting, and inclusive." Perhaps, in attempting to frame a response, it would be useful to think about use of these spaces in their dynamic temporality by reframing our question; 'when should' these be places for everyone in the city? This fundamental change in perspective opens up the opportunity to consider existing 'situated' socio-cultural structures in a supplementary way rather than attempting to overhaul major relationships. In this respect there are key moments in the life of Iqaluit that highlight the use of the beach in relation to both rest of the city and to the land outside of it, and one in particular stands out through its periodic animation of the City as a whole; the spring Toonik Tyme Festival.

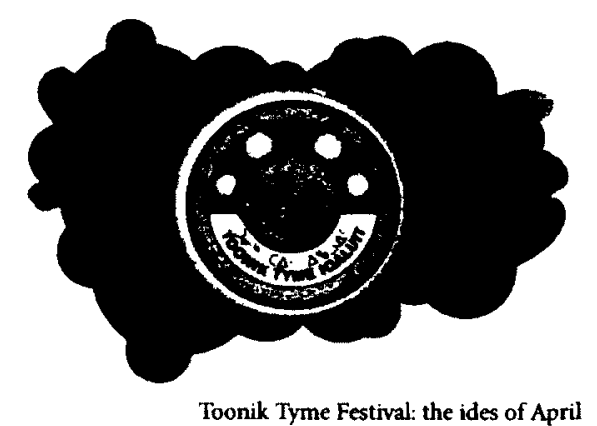

Toonik Tyme Festival: the ides of April 


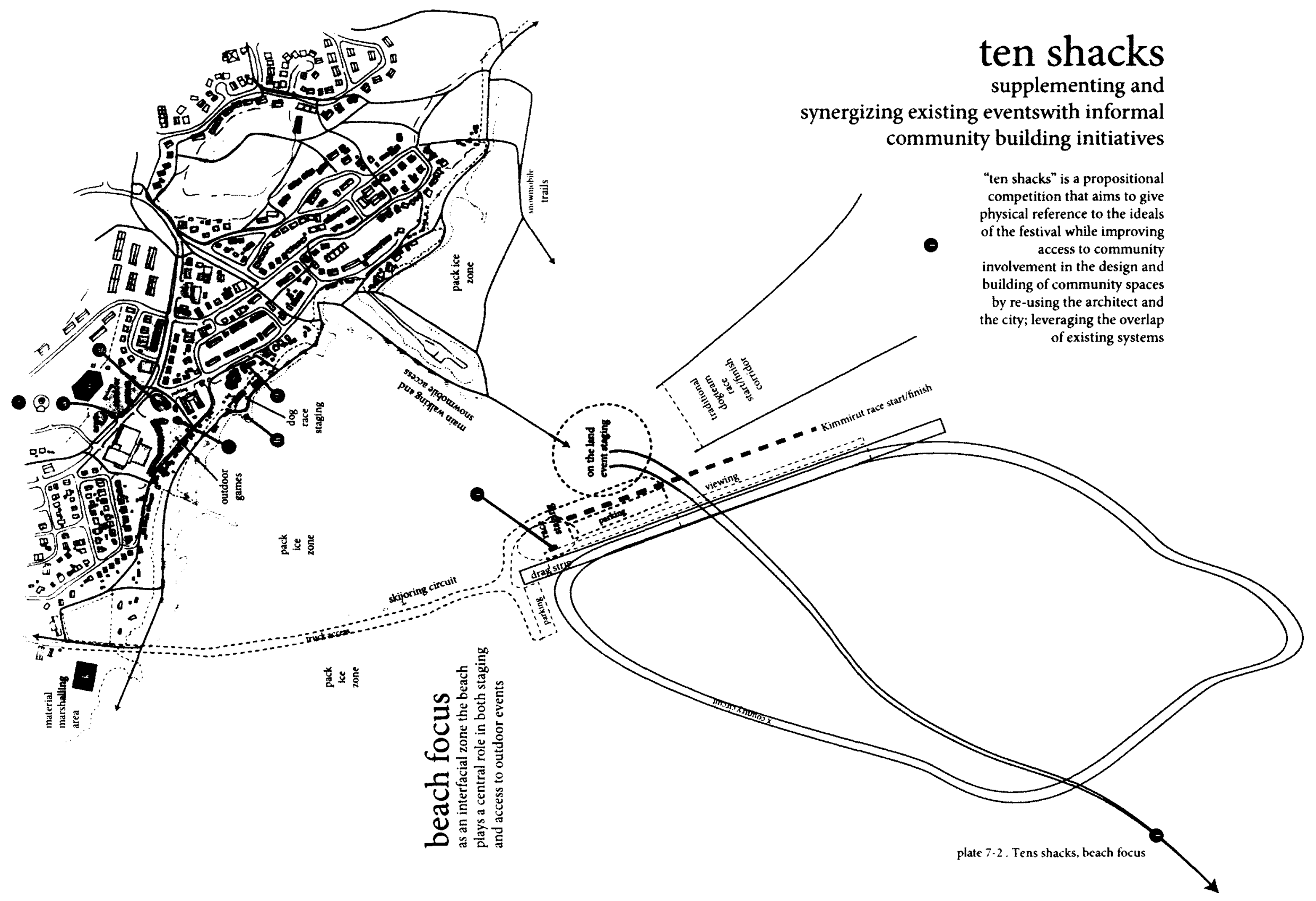


Toonik Tyme Board of Directors "About" Toonik Tyme Mar 2010 <http://tooniktyme.com/en/en about-2>
For arctic communities the onset of spring provides great motive for celebration; the dark barren cold of the winter has been survived once again. The Toonik Tyme Festival, which lasts for one week each April, began in 1965 on the auspices of "purting the settlement on the map" and providing "the community with an event that both revitalized traditional Inuit activities and promoted Iqaluit has a tourist destination" according to event organizers. The festival, in its current manifestation, is highly reflective of the hybrid population, boasting seal-hunting competition, traditional Inuit games, a major regional ice hockey tournament, races of all kinds, concerts, and of course ice-golfing. As a non-for-profit organization, the event is run by a committee and relies upon a multi-tiered sponsorship strategy for fundraising and significant community volunteering for operation. ${ }^{8}$ One implication of employing a grassroots oriented model such as this is that many of the events either borrow or rent time in existing facilities for indoor events or go without completely for outdoor events. Outdoor events, held in various established locations around the city, must often compete for attendance with weather and access to public facilities which are often located far from these sites. In addition, there is no identifiable built representation of this event with which the community can relate; the only spatial addition to the city in recent years has been a dark, cold, empty, unwelcoming industrial tent that sits in the field in front of Nakasuk School. This lack of a representative spatial language resonates with some of the conclusions drawn from previous sojourns, namely that the

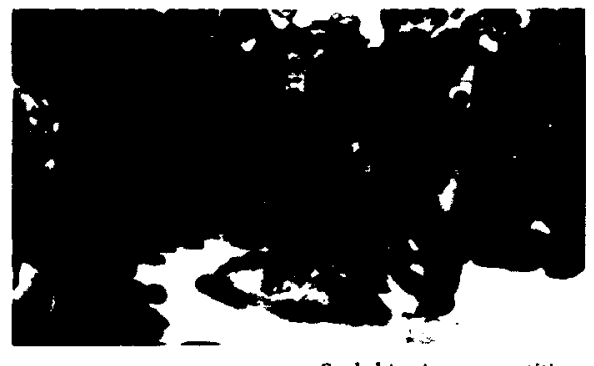

Seal skinning competition

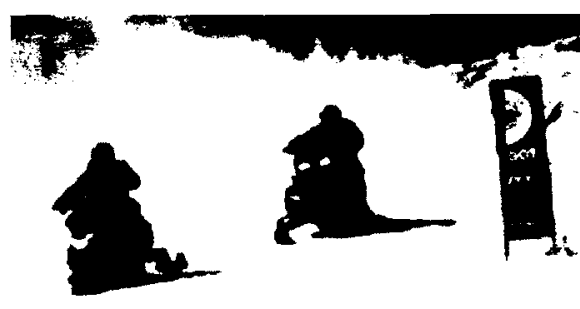

Snowmobile racing

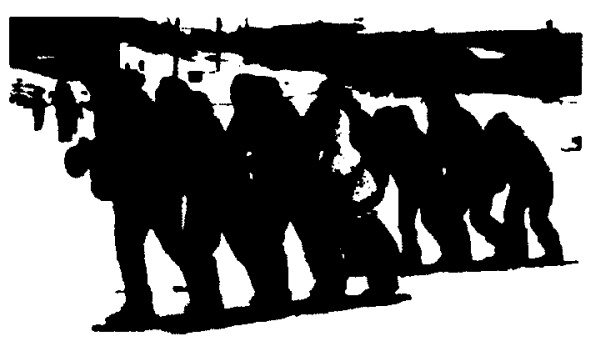

Community games

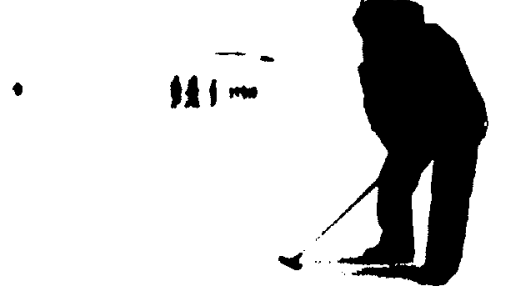

Ice golfing 
(b) on the beach

skijoring, viewing, identification

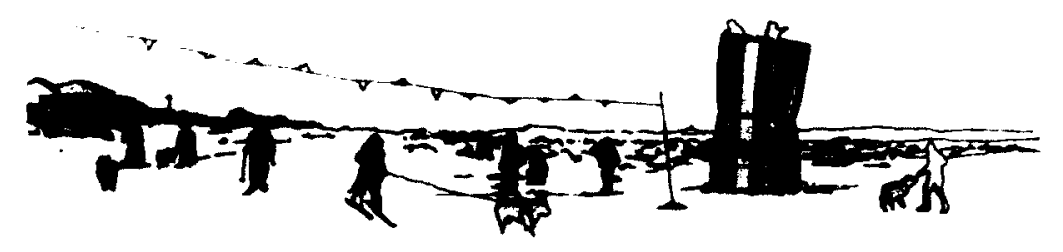

i on the ice

staging, races, services

i on the land

ice fishing derby, races
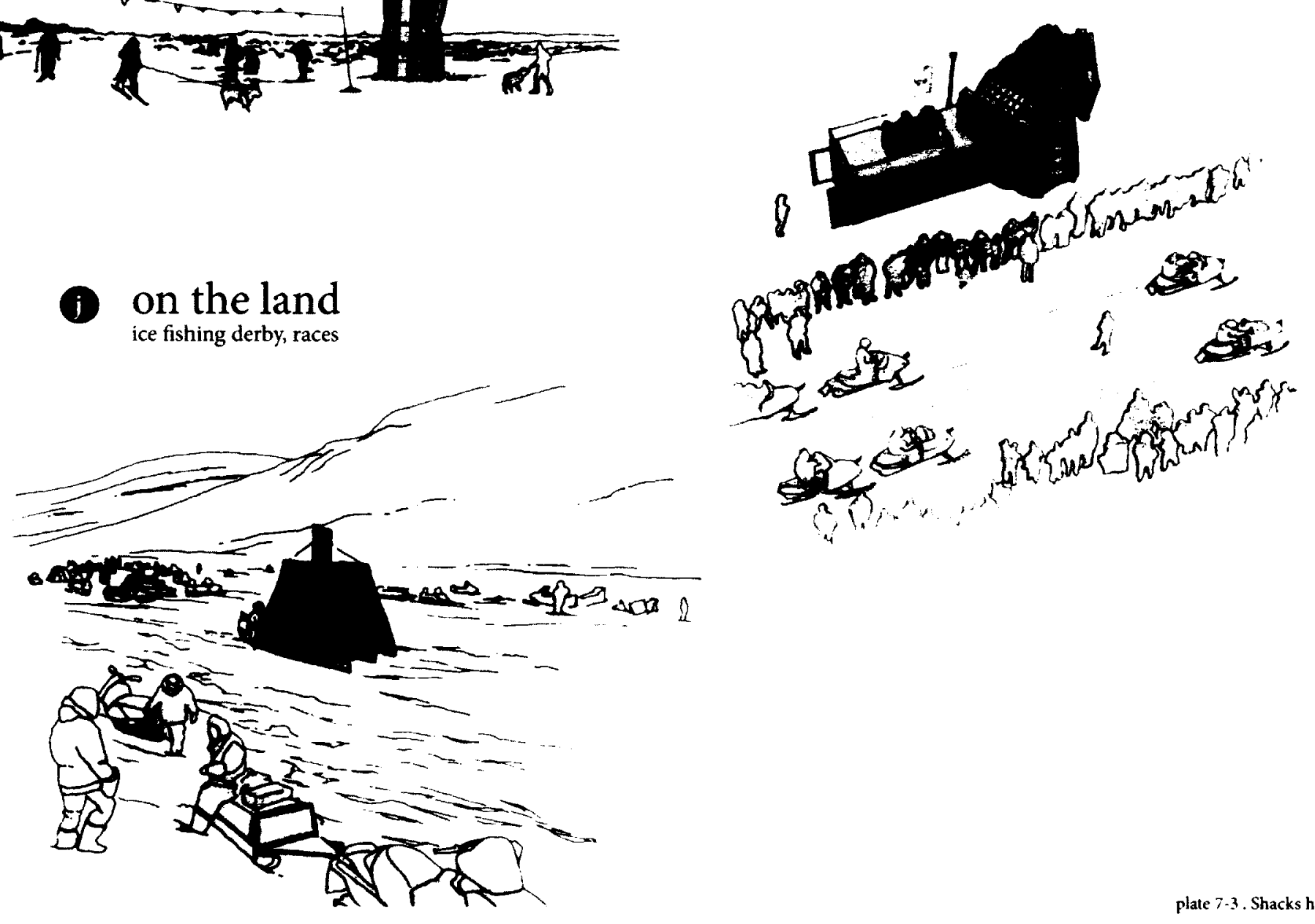

plate $7-3$. Shacks $h$, i. and 
community is less represented than the individual on the beach and the individual is less so represented in the city, even during such an inclusive event. Can we bring these two together, the individual and the community of the city, to imagine a built language that responds to the gap that the Toonik Tyme Festival presents to us?

Looking primarily at the outdoor events, we might offer that the addition of programmed buildings would benefit the events in numerous direct ways. By acknowledging that such buildings would inherently rely on community participation to resonate with both the fiscal realities of the Festival and with our manifesto, we might move forward by considering how the virtues of self-building might find application. Further, by structuring the designing/building process as an event in and of itself, thereby extending the inclusive programming of the Festival, numerous opportunities for synergy with outside influences arise. An architect clearly has roles to play at all levels of such a scenario, but the crux of this project lies in identifying and nurturing these synergies by 'making connections' berween the formal and the informal realms.

\section{Shacks are architecture. Architects are everywhere!}

By reaching out to communities that link with architecture and self-building in Iqaluit there are an inordinate number of potential interested participants including those members of the city who are directly implicated (Toonik Tyme volunteers and individuals interested in building and outreach), as well as those who might gain from the experience and exposure (school students, college students), and those who might be of insight (elders, architects, contractors, self-builders, engineers). Habitat for Humanity has built two houses recently, employing a similar strategy, 
St. Jude's Cathedral

This project serves as an ideal base for

reuse of constures an idenals through

cer

o loaluit By sampling the orignal design

and materiais (one that incorporated

cast-off small dimension lumber), new

arrangements will be determined and

possible translations will be imagined.

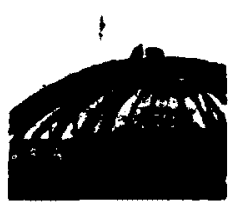

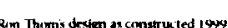

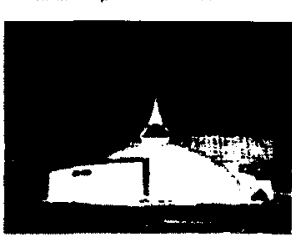

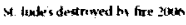

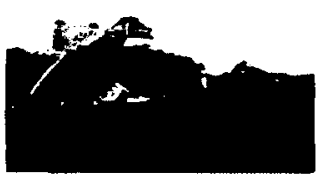

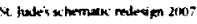
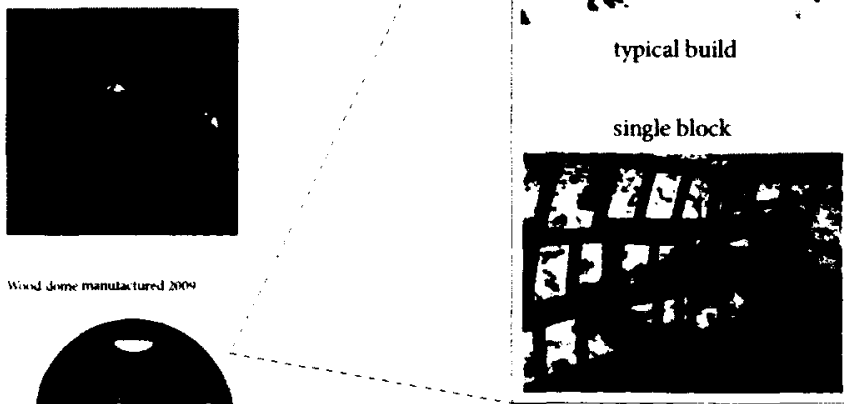

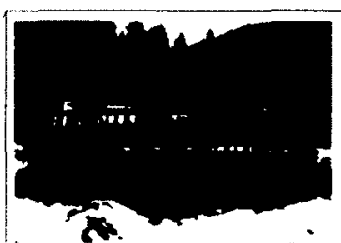

typical build

single block

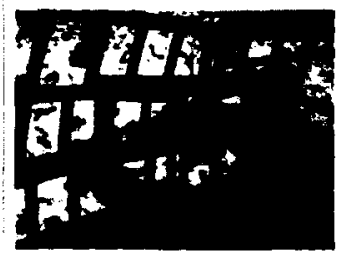

Existing Unbuilt Configuration

$30^{\prime}$ wide by $100^{\prime}$ tall dome with

occular and tangential openings

risky due to its scale material inventory

exsising wood bock domeldesign

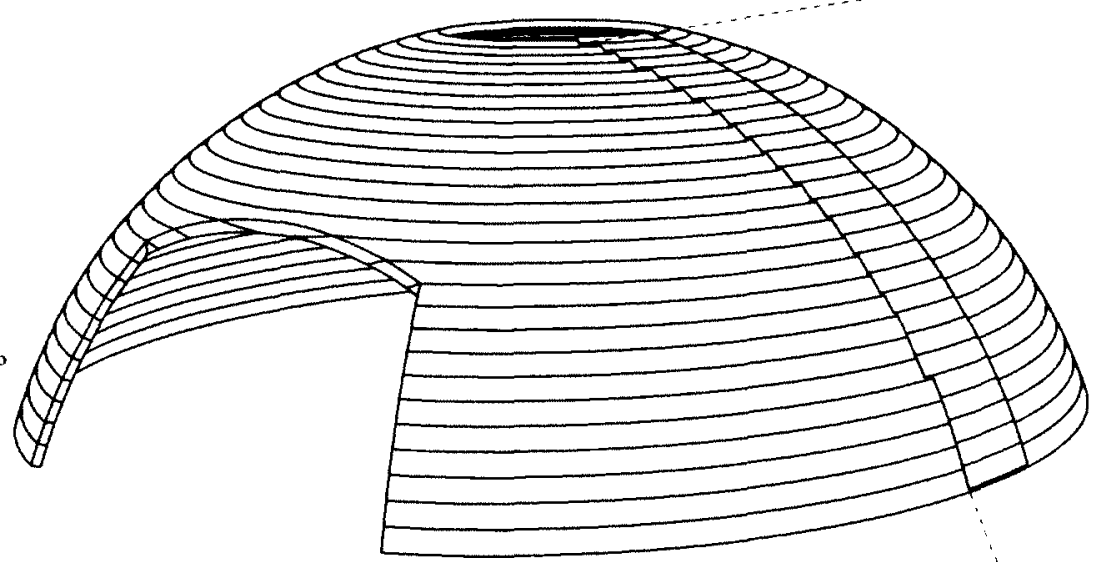

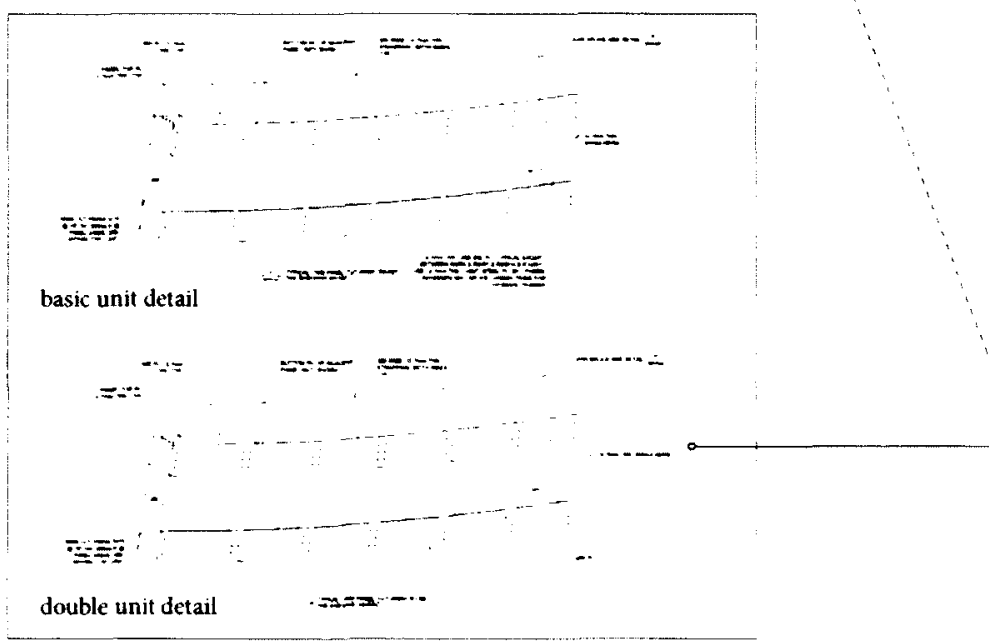

cross-sectional

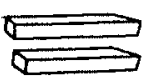

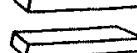

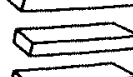

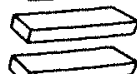

2

$\infty$

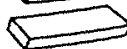

2

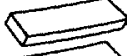

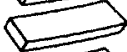

$\longrightarrow$

$\square$

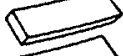

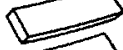

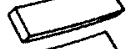

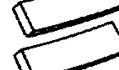

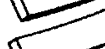

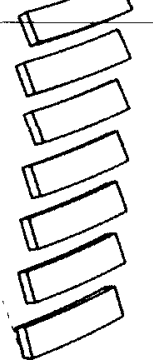


with good success in volunteerism. To fully capitalize on the inclusive nature of the event, to help fund it, and to promote interest in the project in terms of tourism and greater exposure (thereby contributing to the economy of the Festival and the ciry) the greater architecture community itself might be invited. What synergies could come out of a community-university project of 'shack' building for the North in the North? This scenario presents an opportunity to study and learn for both parties particularly if the intent is to experiment.

The word 'shack' is appropriate in some senses as it alludes to a how such buildings might be designed and built; as architectural sketches. Like the cabins on the land, these structures should be experimental and interrogate the tenets of the manifesto. They should neither be considered permanent nor complete; most of the outdoor sites are on rough terrain and they must be transported to these sites using means at the community's disposal (snowmobile, truck, ATV, by hand). These restrictions lend themselves to modular construction that can be site assembled in some manner befitting the climate. Given issues with 'formal' buildings that are larger than shacks, such as a house (see sojourn 3) scale and infrastructural needs should be minimal. In addition, with minimal funds to draw from, assuming some sponsorship or grant money can be found, these buildings should be built from materials attainable locally in the city: rocks, sand, sod, ice, snow, purchased or donated construction material, and most significantly, waste.

Waste accumulation in Iqaluit is a significant cause for concern. Unlike the cyclical relationship with waste that Inuit traditionally had through their integration in the environment, the contemporary situation is notably one directional; waste comes in on boats and planes and never leaves. Sea-containers are a good example of this, since it is much cheaper to leave an empty sea-can than it is to bring one back south; they almost 


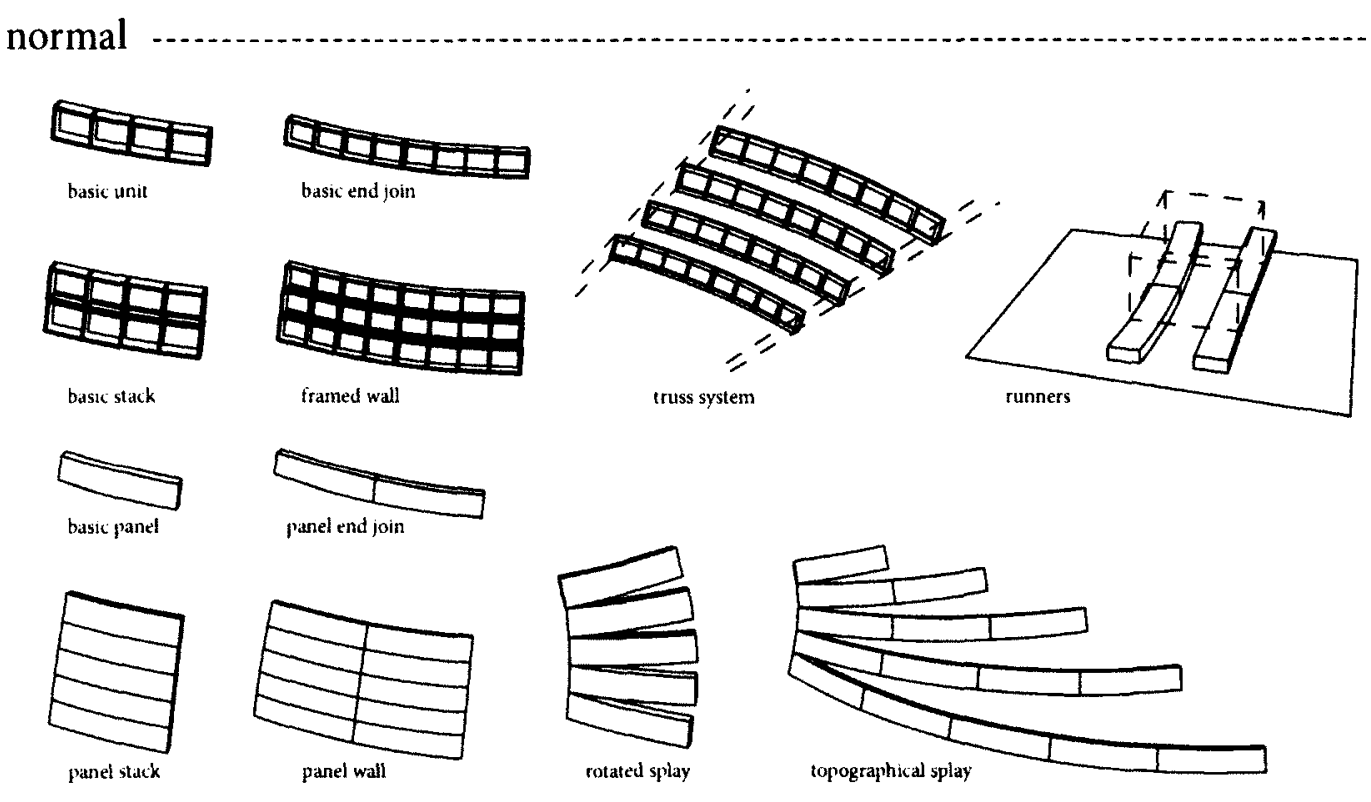

on edge

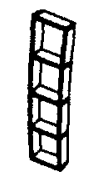

basic anit

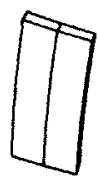

basic join

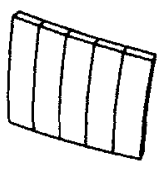

edge wall

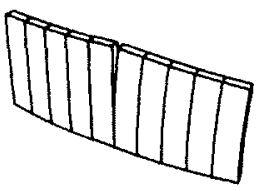

double wall

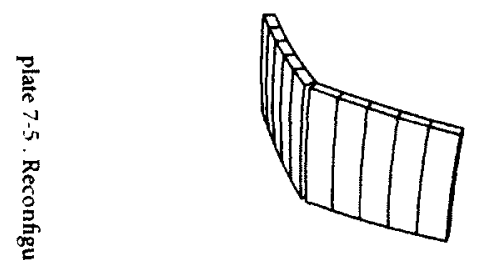

single wall fold

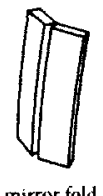

mirror fold

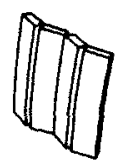

double fold

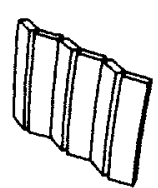

fold wall

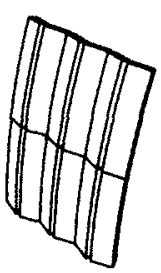

fold wall stack
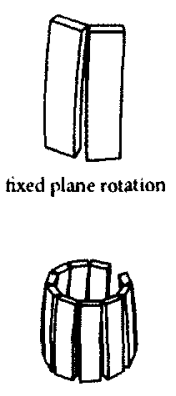

mirrored ring

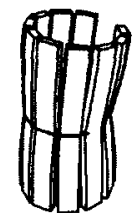

mirrored mirror ring

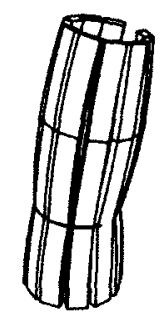

fixed plane rotation
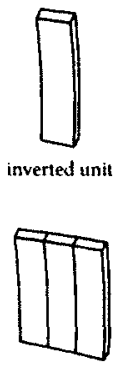

inverted wall

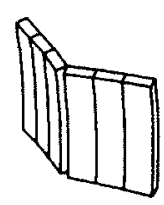

shell fold

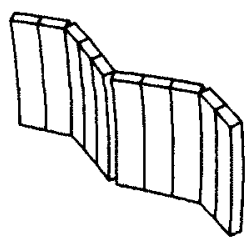

shell wall 
always remain in the city. Likewise recyclable materials are abundant. With a booming construction industry, Iqaluit produces a significant amount of construction waste that ends up at the dump as pointedly noted in Never Lose Sight. There is a clear need to find a way to make use of recyclable waste, and perhaps this is a project that can begin to question how that can happen. At a higher level though, we might make use of our position in the field of architecture to consider the reuse of buildings and components, to project and anticipate potential materials from major projects that are nearing the end of their lifecycles, and to re-source projects and components that failed for one reason or another. One such project of the latter category is the new St.Jude's Cathedral, an igloo shaped church that is built using a metal space-frame system; it was supposed to be constructed out of a custom manufactured wood block system that was eventually deemed an engineering liability, but only after all of the materials were manufactured and shipped to Iqaluit. One of the issues with the failed design stems from the large scale of the cathedral, since this was a system originally designed for use in the housing industry. Perhaps instead of one failed large building this material could provide a unifying framework for a series of small buildings, our shacks. Incidentally, this is a system of construction that is based on the use of small lumber (under 2' in length) and strips of oriented strand board, materials that are commonly found in construction waste in Iqaluit. How might the testing of this system affect the creation of similar cast-off systems related to Iqaluit's waste stream?

This second synergy is significant for another reason as well; in specifying and appropriating the dome system (which would probably need to be a gift) the architect is making connections but also taking on authorship in the larger sense of creating an identifiable umbrella under which the project takes place. 
B community shop

experimenting, building, waste diversion

mobile plant

collaborating with Nunavut Construction

Corporation, an innovative mobile plant for

use in wall panel construction in the high

arctic will be tested

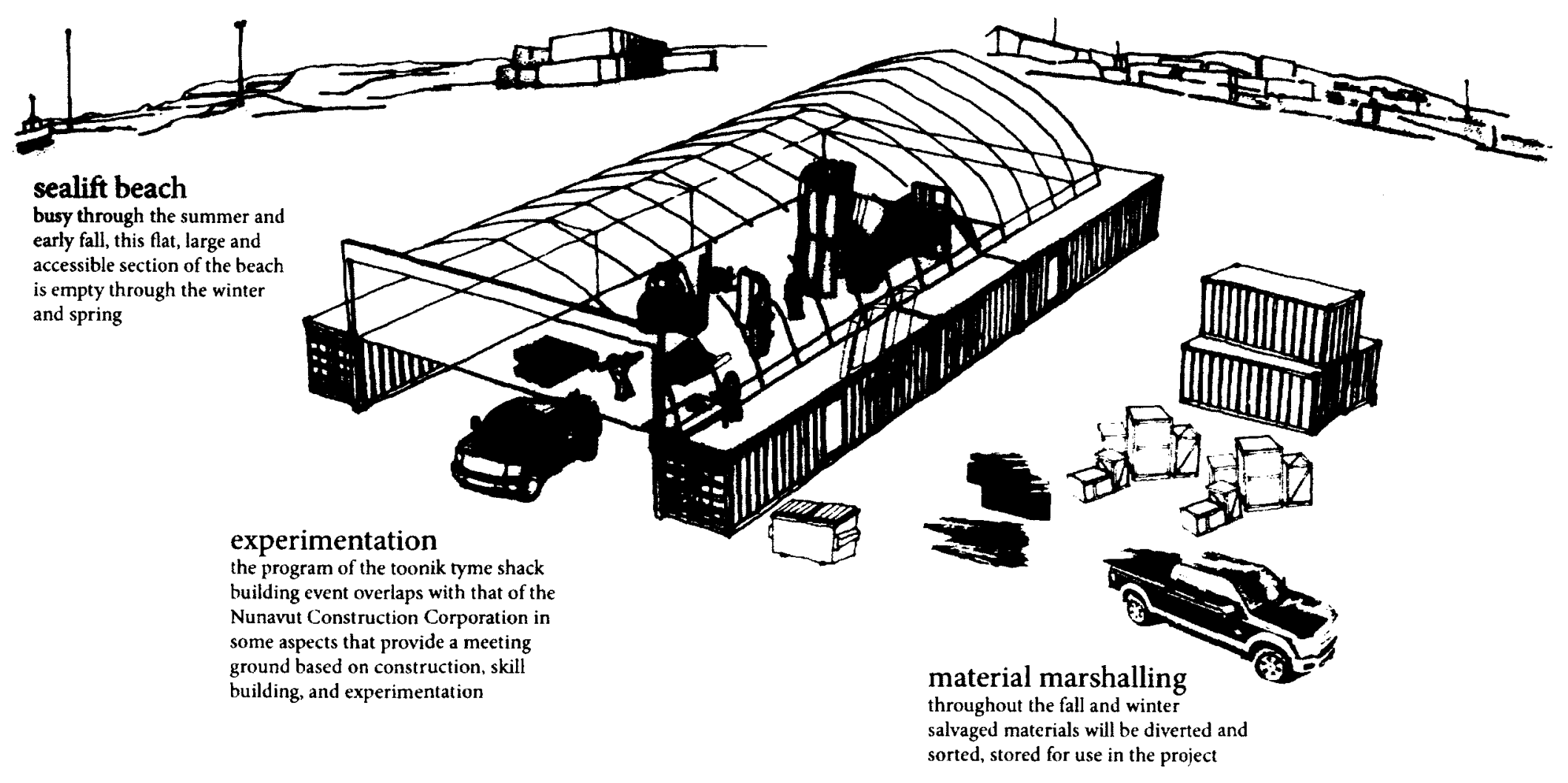


Architects are not alone in imagining new ways of approaching more inclusive ways of design and building in the Nunavut. The Nunavut Construction Corporation (NCC), a semi-private construction company with Inuit Organization stakeholders, has and continues to look for new ways to integrate the Inuit into the construction industry. It is a difficult task however, according to vice president Brent Crooks, due to culture but more so to sporadic opportunities for Inuit to work in their own communities; to be a tradesman in Nunavut one
Brent Crooks "Personal Interview" Feb 2012

Brent Crooks "Panel

Manufacturing in the North Draft for Review - Construction Manufacturing Roundtable NCC 21 Feb 2012. must follow the work. ' In an effort to develop other models, Crooks has recently been leading the discussion regarding the viability of a mobile plant that would facilitate local contractors in the production of wall panels for houses. Made from recycled shipping containers and a lightweight long-span roof, the plant would be shipped from community to community as required to meet seasonal needs. ${ }^{10}$ Though NCC is in the design and costing stage this idea serves our project in its potential; as an experimental model, both our project and NCC's stand to gain from testing and experimenting in the relatively (in Nunavut terms) well serviced city of Iqaluit with the construction of buildings that represent low risk in terms of investment (ie. shacks). Additionally, Brent Crooks' goal is to develop better wall panel systems while looking for ways to incorporate community waste; perhaps the shack project will open other avenues that are worth pursuing. A further spin-off from this synergy is the opportunity to test the interests in and requirements for a community shop that would be of great benefit to hunters and other self-builders.

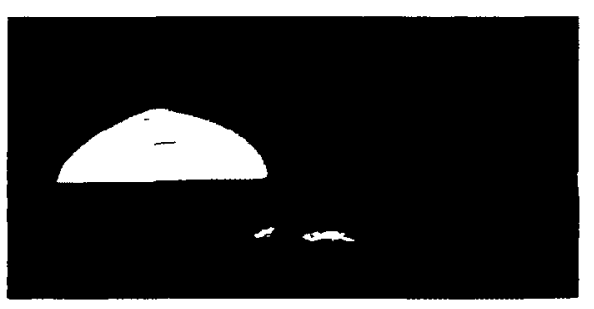

Mobile plant constructed from sea-cans and light-weight long-span long demountable roof

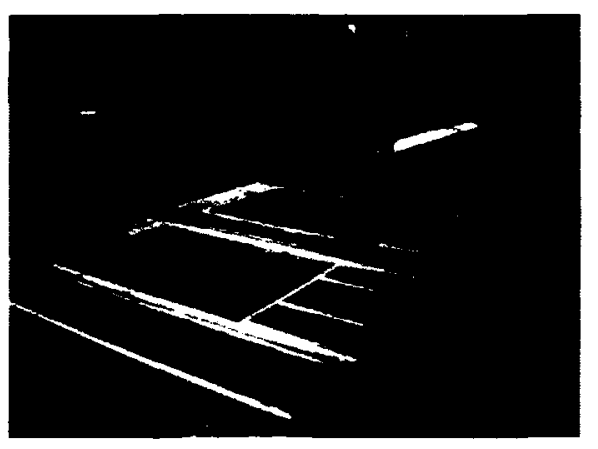

Wall panel manufacturing

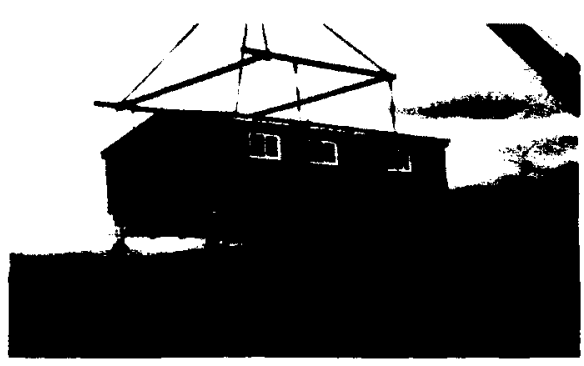

House manufacturing? 

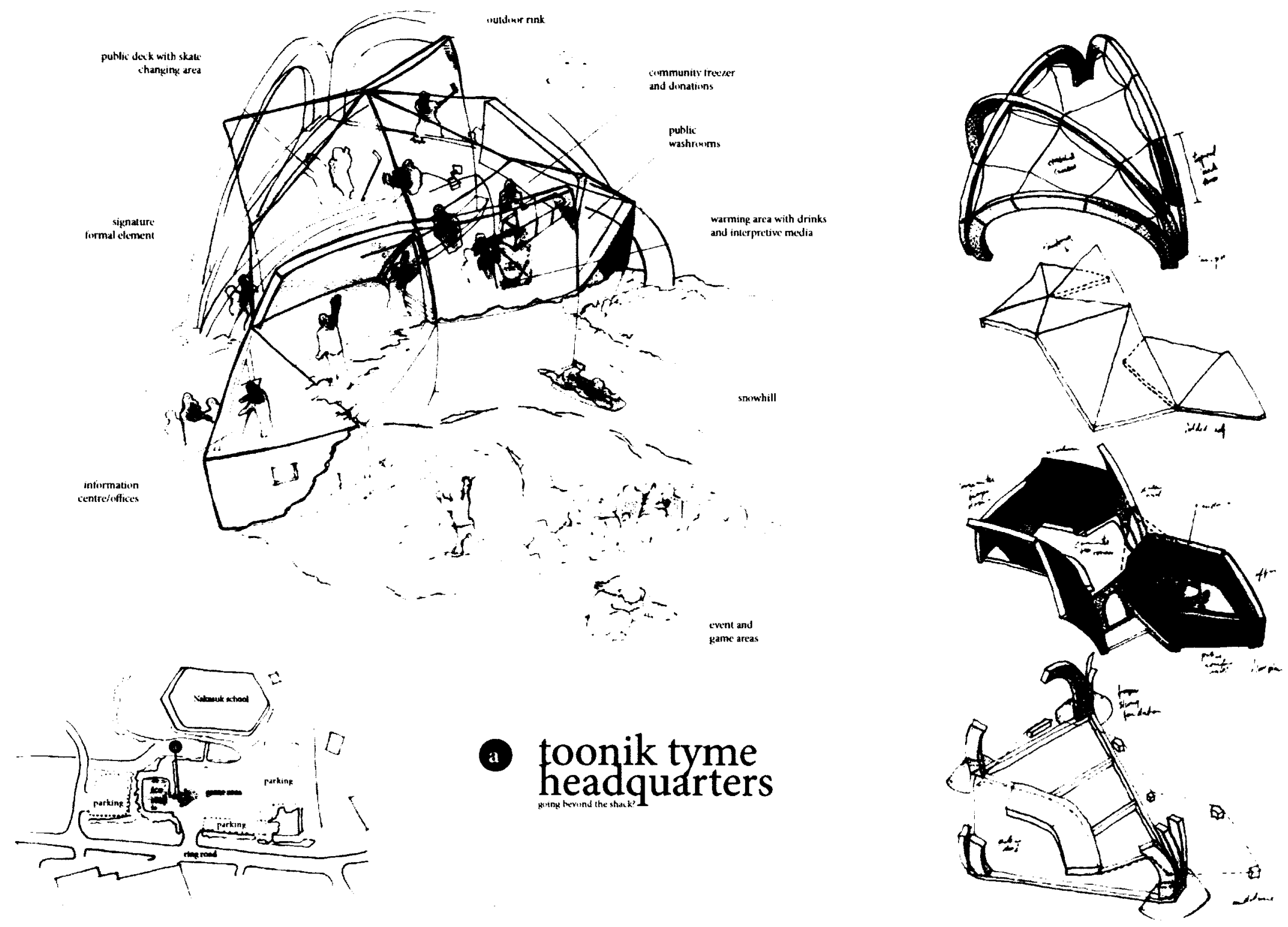

plate 7-7, Shack a 
This final note is critical as it lays a foundation for the potential that such events might happen again, to think ahead to other Toonik Tyme's and other collaborations, to imagine what might be fashioned from the carcasses of modernism, from the schools and towers. How might we re-use twenty foot tall fiberglass panels? What could be made from two hundred old windows? These will be riddles for the community to solve, and if they are given the opportunity and support, they will. We might change attitudes, by building shacks.

\section{What happens next?}

The project for the Toonik Tyme Festival is idealistic and a touch utopian, fraught with unseen limitations and disappointing results no doubc. It is not a project for the Hunter or the Farmer; it is a project for the Iqaluimmiut, the city dweller. Iqaluit is a place with many social problems that can be directly linked to the colonial relationship, a relationship of division. It is a city that has been so busy trying to keep up with change, growth and de-colonization, that it has only just now realized that there is something happening that needs attention. It's on the beach. It's on the land. It's in the past. It's in the future. Iqaluit is a hybrid place with hybrid people who have hybrid dreams about building hybrid buildings. We have much to learn from the low-road.

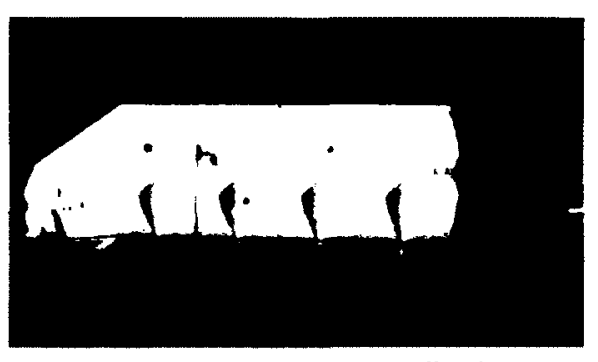

Custom fibreglass panels

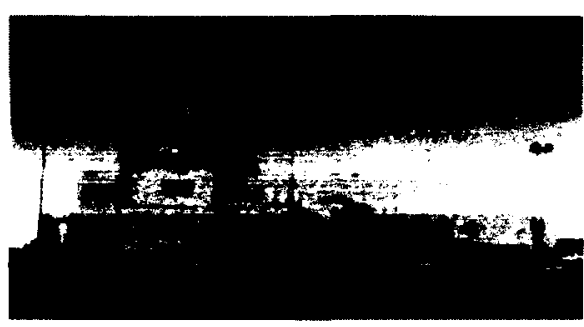

Bolt fixed modular panel systems

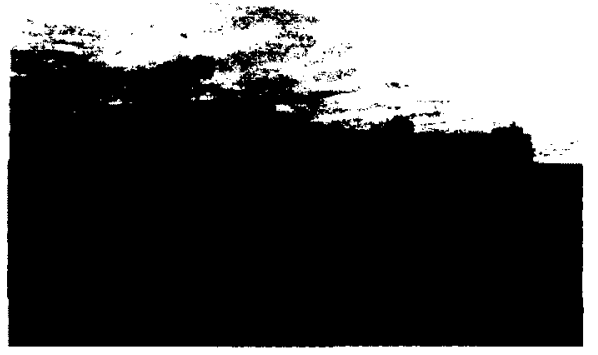

Hundreds of inefficent windows 


\section{regards to the beach}

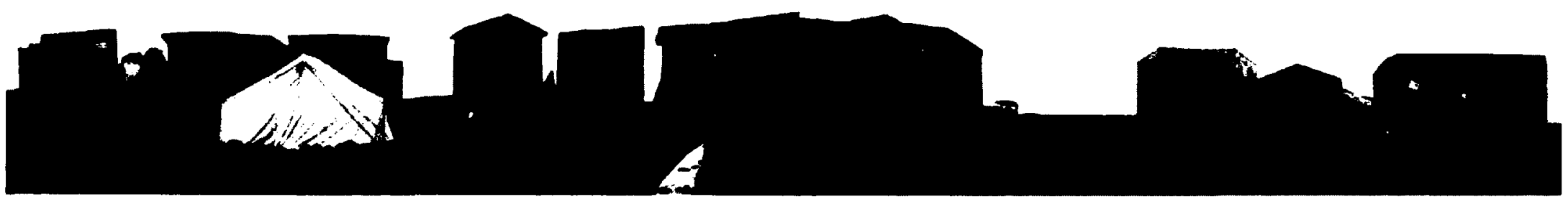

existing condition: freespace

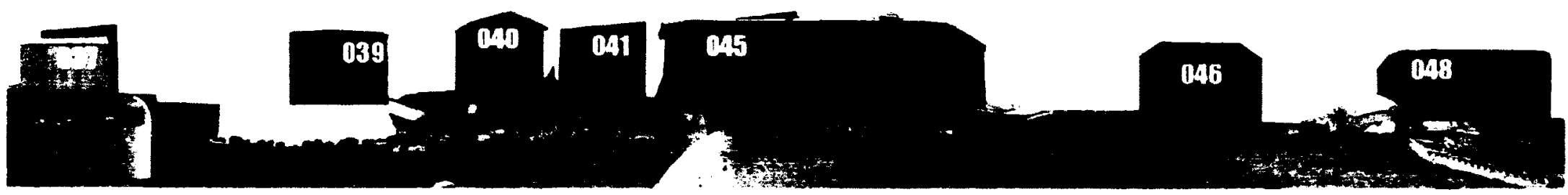

formal management plan phase 1: clean, paint, register

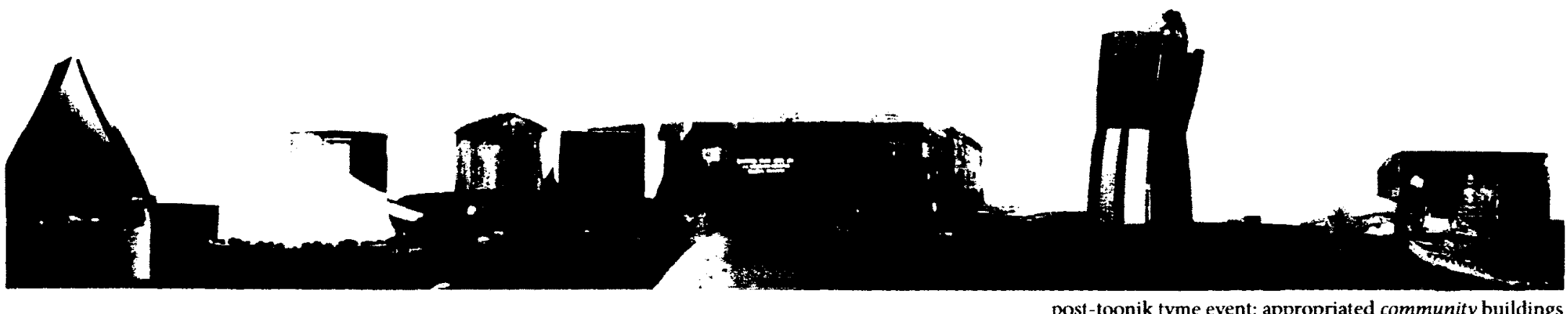


Our journey exists as a thought experiment that attempts to consider what an architect could do rather than considering what an architect does; to explore the ether. 'Making connections' as Willie Hyndman did, and as we imagined doing, will not make us money, not yet anyways, but it proves our capacity for agency. These 'shacks' for Toonik Tyme are for 'everyone in the city', but when the festivities come to a close what will happen to them? And the beach? Should the shacks remain where they stand, as testimonials to the 'great building event of 2015', or should they take leave to some empty lot until a hunter brings one back to the beach for his uses? Perhaps this is the way, to give them up to appropriation, to spread this new language amongst the old ones and the thin ones. After abundant iteration there might be enough for an exhibition of some kind. Or maybe we could call it 'a museum of hybridity.' Wait. Isn't that what the beach is already? 


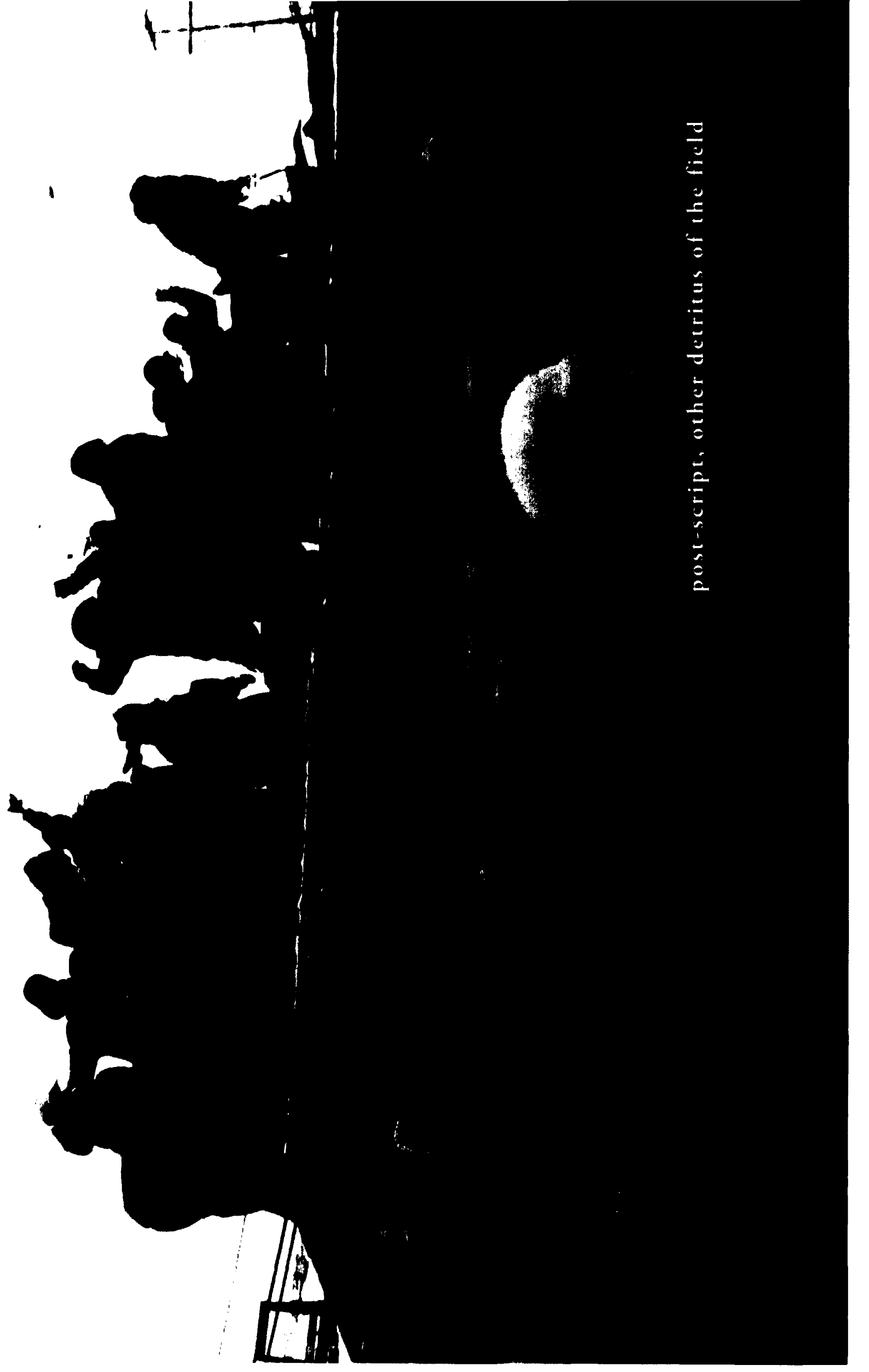




\section{CHAPTER 8}

We can learn alot from this picture. Every year in Iqaluit over the Christmas holidays, the Hunting community comes together to give acknowledgement to the young who have caught game or 'made something traditional' in a short evemt called the 'pudlapoo'. News of this event is spread by word of mouth with help from the local radio. Last year it was held in the shadow of the Nakasuk elementary school, a modernist behemoth, because, one must assume, there was accessible parking adjacent to an elevated platform, in this case three sea-cans. The children who are being acknowledged are brought up to the platform via handyman's ladder, where, surrounded by hundreds of kindred Inuit and northerners, their deeds are exclaimed; "Deion shot his first ptarmigan!'" Piuyuq sewed seal skin mittens!" "Joetanie caught his first char!" And then it begins; hundreds, maybe thousands of candies and trinkets are hurled into the air over the crowd. Apparently becoming a Hunter is not about receiving, rather it is about giving, about sharing what you have and more. As architects, how can we not be tempted to imagine a more fitting stage for such an event. Is it our place to do so?

$\mathrm{P}$ romises, promises. Thoughts of the future. Nunavut, it seems, is built of them. Though we have endeavored to make distinction between the promises of government and the promises of people acting for themselves, there is another even more basic promise that has been implied but not spelled out.

What is Nunavut? Quite literally it is "Our Land" in Inuktitut, a language that is built specifically upon an intrinsic knowledge of that particular territory. And while it is a language that makes difference between the land (Nuna) and the person (Inuk), it is a language that for millennia did not have a word for environment. Perhaps, it has been suggested by Hugh Brody, this is because Inuit traditionally saw themselves as part 
of the environment and not separate from it. From this perspective Nunavut might be seen as a promise to ensure the integral shared stewardship of the land, a claim to shared responsibility. This is a promise that is at odds with the 'Western way' at a most principle level if we look at the state of the natural landscape after a century of profuse global development.

As working architects today we cannot avoid considering sustainable design, but given the perspective of aboriginal peoples, are these not half-measures at best? Douglas Cardinal claims that such aboriginal worldviews are not resigned to the past, rather, that they are the future. And while the arctic has long been seen as the 'canary in the coal mine' of global warming and climate change, Nunavut in particular has the potential to do things a different way that is not only aboriginal but wholly projective.

When we look back at Iqaluit, a city in vast undeveloped space of Nunavut, we might see a paradox. To live in the present is, for most, to live where there is fixed infrastructure, where economies of scale can be managed, and where services can be efficiently delivered. But to live in a city, a fixed and ultimately growing confluence, is to give up on the primary tenets of aboriginal environmental awareness; if you do not relocate, the land that you inhabit cannot recuperate.

Must we give up Architecture to pursue such promises? Is a renunciation in order? Perhaps what is required is not so much a matter of giving up Architecture but rather giving back as architects. Like the hunter who is bound to sharing the toils of his labor, might we be generous with our work? This is the question that must be asked. Are we owners or are we stewards? Are we authors or are we collaborators? To affect change and 
embrace the potential of a wholly different future we must be willing to operate between the object and the system.

This thesis is not a closed argument. The beach remains a point of interest and hopefully the research herein will provide those concerned with fresh impetus for imagination. Tom's house will, with luck, begin construction this summer, though much collaborating yet undone. Toonik Tyme is done for this year, but who knows what one might find around town in the springs to follow. For now however, the cabins on the land, are of most pressing interest.

Architect-imaginer Cedric Price once spoke of cabins as "serious playthings", and to be sure that is what some of type outside of Iqaluit are, but this is too limited a view given our context in my estimation. If we look to the future of the North, of the Inuit, of the City, these cabins and the people who build them seem to be forging a new path of latent potential. We might continue our journey, talk to more builders, share more tea, and write another volume. Are cabins, in their translation, outpost camps after all, and if so are we looking at the birth of a new kind of urban north?

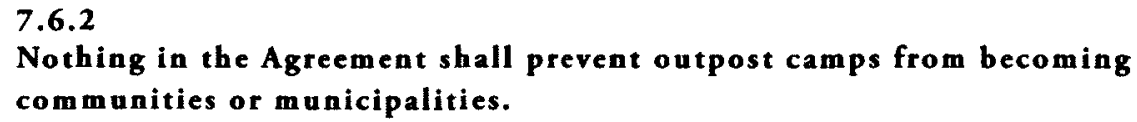




\section{BIBLIOGRAPHY}

Auge, Marc. Non-Places: An Introduction to Supermodernity. France: Verso, 2009. Print.

Alan, Colquhoun. "The Concept of Regionalism." Postcolonial space(s). New York: Princeton Architectural Press, 1997. 13-24. Print.

Aporta, Claudio. *The Trail as Home: Inuit and Their Pan-Arctic Network of Routes," Human Ecology. April 2009: Volume 37: 131-146.

“Archives.” Nunatsiaq News. N.p., n.d. Web. 1 Apr. 2012. <http://nunatsiaqnews.com>.

Awan, Nishat, Tatjana Schneider, and Jeremy Till. Spatial agency: other ways of doing architecture. Abingdon, Oxon [England: Routledge, 2011. Print.

Bennetr, John, and Susan Diana Mary Rowley. Uqaluraic: an oral history of Nunavut. Montreal: McGill-Queen's University Press, 2004. Print.

Bhabha, Homi K.. "Signs taken for wonders: Questions of ambivalence and authority under a tree outside Delhi, May 1817." The location of culture. London: Routledge, 1994. 102-122. Print.

Brody, Hugh. The other side of Eden: hunters, farmers, and the shaping of the world. New York: North Point Press, 2001. Print.

Canada. Agreement Between the Inuit of the Nunavut Settlement Area and Her Majesty the Queen in the Right of Canada.

Carter, Paul. Material thinking: the theory and practice of creative research. Carlton, Vic.: Melbourne University Press, 2004. Print.

Carter, Paul. Dark Writing: Geography, Performance, Design. US: University of Hawaii Press, 2009. Print.

Choi, Esther, and Marrikka Trotter. Architecture at the edge of everything else. Cambridge, Mass.: Work Books :, 2010. Print.

Findley, Lisa. Building change: architecture, politics and cultural agency. London: Rourledge, 2005. Print.
Gagnon, Mellanie, Alexina Kublu, and Anugaaq Arnaqquq. Inuit iqaumanirijangit unaliksajait iqalungniinniri lauqtanginni Inuit recollections on the military presence in Iqaluit / Anugaaq Arnaqquq ... [et al.] ; Inuktitut text translated and edited by Alexina Kublu.. Iqaluit: Nunavut Arctic College, Language and Culture Program, 2002. Print.

Greenwald, Barry. Experimental Eskimos. White Pine Pictures, 2009. Film.

Hernandez, Felipe. Bhabha for Architects. New York: Routledge, 2010. Print.

Himanen, Pekka. The hacker ethic: a radical approach to the philosophy of business. New York: Random House, 2001. Print.

"Iqaluit History." Qikiqtani Truth Commission. N.p., n.d. Web. 23 Jan. 2012. <www.qtcommission. com>.

Jacobs, Jane. Edge of Empire: Postcolonialism and the City New York: Routledge ,1996. Print.

Kossak, Florian. Agency: working with uncertain architectures. London: Routledge, 2010. Print.

McEwen, Indra Kagis. Vitruvius: writing the body of architecture. Cambridge, Mass.: MIT Press, 2003. Print.

Mellin, Robert. Tilting: house launching, slide hauling, potato trenching, and other tales from a Newfoundland fishing village. New York: Princeton Architectural Press, 2003. Print.

Moody, Leslie, and Isabel Cordua-von Specht. "Stones: Social Capital in Canadian Aboriginal Communities." A dynamic balance: social capital and sustainable community development. Vancouver: UBC Press, 2005. 134-155. Print.

Ponte, Allessandra. "Journey to the North of Quebec: Understanding Mcluhan's Media." Presented to Landscapes in Change Symposium. Tromso: January 2011.
Ralston Saul, John. A Fair Country: Telling Truths About Canada. Canada: Penguin Group, 2008. Print.

The 8th Fire. Crichton, Kelly . Canadian Broadcasting Corporation. CBC, Ottawa. 2012. Television.

"The Low Road." Brand, Stewart. How Buildings Learn. BBC. 1 July 1997. Television.

Thoreau, Henry David, and Verlyn Klinkenborg. Walden or Life in the woods. New York [etc.: Knopf A, 1992. Print.

Till, Jeremy. Architecture depends. Cambridge, Mass.: MIT Press, 2009. Print.

Widdowson, Frances, and Albert Howard. Disrobing the aboriginal industry: the deception behind indigenous cultural preservation. Montreal, Quebec: McGill-Queen's University Press, 2008. Print.

\section{Key Personal Interview Visits, and Discussiona}

Critelli, Tom. Various. May 2011 -Apr 2012.

Crooks, Brent. Nunavut Construction Corporation offices, Iqaluit. Feb 2012.

Hyndman, William. Residence of interviewee, Iqaluit. Feb 2012.

Maurice, John and Ungalaq, Rhoda. Residence of Interviewee. Feb 2012.

Monteith, David. Residence of Interviewee, Iqaluit. Aug 2011.

Redfern, Madeleine. Telephone, Mar 2012.

Sayani, Arif. Municipal Lands Offices, Iqaluit. Aug 2011.

Shoo, Salamonie. Qikiqtani Inuit Associayion Lands Office, Iqaluit. Feb 2012. 


\section{PLATES AND FIGURES}

\section{Plates}

i. "The Saddest Beach in the World" Ger source

1.0 "Blue Beach Shack"

2.0 "the Shacklands"

3.0 "Faces of Iqaluit Tiles" Ger source

4.0 "Beach Shacks"

4.1 "Map of Tassiujarjuaq"

4.2 "Places in Iqaluit"

4.3 "Waterfront Snowmobile Trails"

4.4 "Waterfront Shacklands"

4.5 "Parterns of development"

4.6 "Diagram Parterns"

4.7 "Authority View of Beach"

4.8 "Waterfront Place Map"

4.9 "Waterfront Photo Narrative"

4.10 "Activities on the Beach" Get source

4.11 "Shack Evaluation I"

4.12 "Shack Evaluation II"

4.13 "Textures"

5.0 "Qammaq at Ikaluradjuk"
5.1 "Common Land and Water Roures" Adapred from ISIUOP Carlecon University

5.2 "Cabins of Tasiujarjuaq"

5.3 "Study Clusters"

5.4 "Cabin Srudy 1"

5.5 "Cabin Study $\mathrm{II}^{\text {" }}$

$5.6^{\circ} \mathrm{Cabin}$ Study III"

$5.7^{\circ} \mathrm{Cabin}$ Study IV"

5.8 "Cabin Srudy V"

$5.9^{\circ}$ "Cabin Srudy VI"

6.0 "Tool Shed"

6.1 "Location Maps"

6.2 "Site Map"

6.3 "Site Photo Narrative"

6.4 "Translation Diagram"

6.5 "House Sireplan"

6.6 "House Section"

6.7 "Work Breakdown Structure"

6.8 "Development Sketches"
6.9 "Tactical Diagrams"

6.10 "Volumetric"

7.0 "Snow Covered Beach Scene"

7.1 "Making Connections Diagram"

8.0 "Pudlapoo!" Photo by Wendy Bens.

\section{Figures}

Unless nored all! photos, diagrams, and drawings by author, all figures nored by page from top: p.i "che saddest beach of the world" rahn_mard panaramio.com; p.v renders by aurhor for FSC Archirects and Engineers; $p .3$ base image
courtesy of Google Earth; p.14 aerial images http://www.flickr.com/photos/bn/5928945755/; p.16 (botrom) courresy of Rick Armstrong; p.19,21 composite images based on hatp://celebratecanada.files.wordpress.com/2010/01/ courtesy of Google Earth; p.14 aerial images http://www.ficks.com/photos//bn/5928945755/; p. 16 (botrom) courtesy of Rick Armstrong; p.19.21 composite images based on hatp://celebratecanada.files.wordpress.com/2010/01/ attachmos (bor index.php?title= Darei:Q(a) recollections on the military presence in lqaluit / Anugaaq Arnaqquq ... Let a..], Inuktitut text translated and edited by Alexina Kublu.. Iqaluit: Nunavut Arctic College. Language and Culcure Program, $2002 ;$ p.57 (top) hrtp:// ronwassink.blogspor.com/; p.71 (top) http://www.sfu.ca/archaeology-old/museum/danielle_longhouse/keepers/housing.hernl, (center) based on logo from http://www.piqqusilirivvik.ca, (bortom) hetp://qucommission.com/ actions/GerPage.php?pageld=112communiryld=4,; p.73 http://isa2585.files.wordpress.com/2011/10/p1020800.jpg; p.75 (top) http://1.bp.6logspot.com/-xiWuiOLCQQM/TFGWY_Kg)CI/AAAAAAAAAXU/80Qxs885zXk s1600/4_sylvia\%20river\%20rents_fpo_DSC0915.jpg, (center) http://i33.tinypic.com/51pr95.jpg; p.111 courtesy of Janer Armstrong; p.117 (top) hrtp://ronwassink.blogspor.com/, (center/bottom) hrtp://titizaqti.fles. wordpress.com/2011/03/country_food_8_640.jpg?w=640: p.121 hrrp://www.ropeventscanada.com/images/nunavut/toonik-tyme-festival.jpg; p. 123 (rop/bortom) hrip://ronwassink. blogspor.ca/2011/04/seal-skinning-in-iqal uittoonik-tyme.html, (center rop) http://www.nunatsiaqonline.ca/archives/2009/904/90424/news/features/90424_Pgl6-17_uphill\%20climb.jpg, (center/bottom) http://3.bp.blogspot.com/_CW/js_WZ74PU/SAkxlLPHM41/ AAAAAAAAAOA/9CFWDijOJ3U/s320/P4180418cropa.jpg; p.131 (top/bottom) Brent Crooks, Panel Manufacturing in Remote Communities Draft Discussion Paper, Nunavut Construction Corporation, February 2012. (center) hetp://www.builderschoice.us.com/wall-panels; p.133 (top) http://upload.wikimedia.org/wikipedia/de/e/ef/Nakasuk_School_lqaluir_2000.jpg, (center) http:/11.bp.blogspot.com/-PSCxXF--EOs/T/_g_gf)U31/ AAAAAAAABWg/oUY273VoUUY/s1600/3.JPG, (bottom) http://images.travelpod.com/users/brookeandehris/1.1313440170.frobisher-inn-6-storey-and-8-storey.jpg http://images.travelpod.com/users/brookeandchris/. Unless noted all photos, diagrams, and drawings by author. 